Universidade de São Paulo

Instituto de Psicologia

Carine Savalli Redigolo

FUNCTIONALLY REFERENTIAL AND INTENTIONAL COMMUNICATION IN DOGS (Canis familiaris)

\title{
COMUNICAÇÃO FUNCIONALMENTE REFERENCIAL E INTENCIONAL NOS CÃES (Canis familiaris)
}

São Paulo

2013 


\author{
Universidade de São Paulo \\ Instituto de Psicologia \\ Departamento de Psicologia Experimental
}

Carine Savalli Redigolo

\title{
FUNCTIONALLY REFERENTIAL AND INTENTIONAL COMMUNICATION IN DOGS (Canis familiaris)
}

\section{COMUNICAÇÃO FUNCIONALMENTE REFERENCIAL E INTENCIONAL NOS CÃES (Canis familiaris)}

Tese apresentada ao Instituto de Psicologia da Universidade de São Paulo como parte dos requisitos para obtenção do título de Doutor em Psicologia.

Área de concentração: Psicologia Experimental Orientadores: Prof. Dr. César Ades (in memoriam)

Profa. Dra. Briseida Dôgo de Resende Co-orientador: Profa. Dra. Florence Gaunet

São Paulo 
AUTORIZO A REPRODUÇÃO E DIVULGAÇÃO TOTAL OU PARCIAL DESTE TRABALHO, POR QUALQUER MEIO CONVENCIONAL OU ELETRÔNICO, PARA FINS DE ESTUDO E PESQUISA, DESDE QUE CITADA A FONTE.

Catalogação na publicação

Biblioteca Dante Moreira Leite

Instituto de Psicologia da Universidade de São Paulo

Redigolo, Carine Savalli.

Functionally referential and intentional communication in dogs (Canis familiaris)/ Carine Savalli Redigolo; orientador César Ades (in memoriam); orientadora Briseida Dôgo de Resende; co-orientadora Florence Gaunet . -- São Paulo, 2013.

$142 \mathrm{f}$.

Tese (Doutorado - Programa de Pós-Graduação em Psicologia. Área de Concentração: Psicologia Experimental) - Instituto de Psicologia da Universidade de São Paulo.

1. Dogs 2.Communication 3. Animal ethology 4. Social cognition I. Título.

QL795.D6 
Carine Savalli Redigolo

\section{FUNCTIONALLY REFERENTIAL AND INTENTIONAL COMMUNICATION IN DOGS (Canis familiaris)}

\section{COMUNICAÇÃO FUNCIONALMENTE REFERENCIAL E INTENCIONAL NOS CÃES (Canis familiaris)}

Tese apresentada ao Instituto de Psicologia da Universidade de São Paulo como parte dos requisitos para obtenção do título de Doutor em Psicologia. Área de concentração: Psicologia Experimental

Aprovado em:

Banca examinadora

Prof.

Instituição: Assinatura:

Prof.

Instituição: Assinatura:

Prof.

Instituição: Assinatura:

Prof.

Instituição: Assinatura:

Prof.

Instituição: Assinatura: 


\section{To César}

"I've heard it said

That people come into our lives for a reason Bringing something we must learn And we are led To those who help us most to grow If we let them And we help them in return Well, I don't know if I believe that's true But I know I'm who I am today Because I knew you..."

"Wicked-Broadway" 


\section{César}

Who does a second mastering and a second doctorate? Besides having a special interest in animals, one of the greatest motivations to face this challenge (apparent madness) was to interact and work with César...

A brilliant, open and provoking mind. An enthusiastic professor, all students became contagious from that. An ethical, meticulous researcher, and at the same time creative and challenging. He proposed studies that some people would consider excessivelly adventurous, like spider's memory studies and a dog using a keyboard to communicate, among others.

As a supervisor he was always there for his students. Of all the process of supervising a student, what he liked the most was to discuss ideas; he usually said "we need a great idea". The most interesting quality of this outstanding professor was his multidisciplinarity. $\mathrm{He}$ supervised students from different areas, like psychology, biology, veterinary, zootechnic among others. However, I am used to say that he reached the peak of the multidisciplinarity with me! After all, I came from a really distant area, the Statistics!

In 2004, when I sent him an email saying that I was finishing my first doctorate in Statistics and I would like to start studying animal behavior with him, I did not expected such a quickly and welcoming response. I was aware of the audacity of my request. César answered me that very same day, and from that moment on, we realized that we would share many scientific interests. I found my own route thanks to him.

This last year was not easy to continue without him. Every single day I remembered him and tried to picture how he would be fascinated with the results.

This thesis is dedicated to César Ades. I was his last PhD student, and I hope that I will be able to carry a little of his enthusiasm by the animal behavior for my own students. 


\section{César}

Quem faz um segundo mestrado e um segundo doutorado? Além de ter um interesse incomum e especial pelos animais, uma das minhas maiores motivações para encarar esse desafio (aparente loucura) era interagir e trabalhar com o César...

Uma mente brilhante, aberta, instigante. Um professor entusiasmado, contagiava todos os alunos. Um pesquisador ético, meticuloso, e ao mesmo tempo criativo, ousado. Ele propôs pesquisas que muitos considerariam excessivamente aventureiras, como memória em aranhas, um cão usando um teclado, entre outras.

Como orientador estava sempre presente para seus alunos. De todo o processo de orientar um aluno o que ele mais gostava era discutir ideias, sempre dizia "Precisamos de uma boa ideia". A mais interessante qualidade desse notável professor era a sua multidisciplinaridade. Ele orientou alunos de diversas áreas, psicologia, biologia, veterinária, zootecnia entre outras. Mas eu costumo dizer que ele atingiu o auge da multidisciplinaridade comigo. Afinal, eu vim de uma área muito diferente, a Estatística!

Em 2004, quando lhe enviei um e-mail dizendo que estava terminando meu doutorado em Estatística e queria começar a estudar comportamento animal com ele, eu não esperava uma resposta tão rápida e receptiva. Eu tinha consciência da audácia do meu pedido. César me respondeu no mesmo dia, e a partir daquele momento percebemos que teríamos muitos interesses científicos em comum. Encontrei o meu caminho graças à ele.

Esse último ano não foi fácil continuar sem ele. Todos os dias me lembrava dele e tentava imaginar como ele ficaria fascinado com os resultados.

Essa tese é dedicada ao César Ades. Sou sua última aluna de doutorado, e espero ser capaz de levar um pouco do seu entusiasmo pelo comportamento animal para meus próprios alunos. 


\section{Acknowledgment}

To Fernando, it is required a lot of love, patience and tolerance to accept a wife doing a second doctorate. I should thank him also for the English revision and technical support.

To Florence, I learned with her to be very careful and to think about all the details. I thank her for the dedication; she was always available, on a daily basis, during these 4 years.

To Briseida, who accepted the role of supervisor in a very difficult and atypical situation. I hope that this partnership could continue on and we could develop new researches together.

To the DOGS and their owners that came to the laboratory Saturdays and Sundays specially to participate in this research.

To Psychology Institute of USP-University of São Paulo, for having allocated the laboratory of dogs for this research being conducted.

To professors Patrícia Izar and Angélica da Silva Vasconcellos for the important remarks done during the qualification exam.

To my family, besides the fact that they frequently asked me to stop studying (!), they know that this is important to me. To my mom, dad and brother, thanks.

To my beloved cats, Meggie Lee and Whisky, always by my side, sleeping of course! Specially thanks to my persistent Meggie Lee, 19 years with me. This last year was not easy for none of them, so many health problems... part of this thesis was written in waiting rooms of veterinary clinics and hospitals.

To the beautiful Vitória, who fulfilled an important role: the role of being MY DOG! I should also thanks, Ernesto, Camila and Heloísa for helping me to take care of her.

To Fernanda, who was essential for this research, she played the role of helper in the first experiment, was the second judge in the behavior analysis, helped me to recruit the dogs and 
their owners, and, the most important, she was there all weekends for the data collection with a lot of enthusiasm.

To Natália, she always supports me and makes me believe that I am especial.

To Luciana, a good friend, who helped me with English.

To Rosana, always taking care of me. She was essential during the whole process and especially in this last difficult year.

To Anderson that in this last year encouraged me; an example of strength and persistence.

To all my colleagues of the group of dogs, that contributed in some way for this research, Daniela, Angélica, Maria, Gisele, Denise, Alice, Patrícia and Amanda.

To Angélica Sabadini from the library for the valuable help with the references.

To my statistician friends, who were always available to discuss statistics with me! Frederico, Lilian, André, Liliam, Angela and Rejane and to professor Julio Singer.

To UNIFESP-Federal University of São Paulo and colleagues that supported me. Thanks to my students that comprehended the difficult moment that I had to be absent to finish this thesis. 


\section{Agradecimentos}

Ao Fernando, precisa de muito amor, paciência e tolerância para aceitar uma esposa fazendo um segundo doutorado. Eu devo também agradecê-lo pela revisão do inglês e suporte técnico. À Florence, aprendi com ela a ser cuidadosa e pensar em todos os detalhes. Agradeço a dedicação, sempre receptiva e diariamente presente nesses 4 anos.

À Briseida, que aceitou o papel de orientador em uma situação muito difícil e atípica. Espero que essa parceria possa continuar e que possamos desenvolver novas pesquisas juntas.

Aos CÃES e seus tutores que em pleno sábado ou domingo vieram até a universidade especialmente para participar dessa pesquisa.

Ao Instituto de Psicologia da USP - Universidade de São Paulo por ceder o espaço do laboratório de cães para essa pesquisa.

Às professoras Patrícia Izar e Angélica da Silva Vasconcellos pelas importantes sugestões feitas no exame de qualificação.

A minha família, que apesar de com frequência pedirem que eu parasse de estudar, sabem o quanto essa conquista é importante para mim. À minha mãe, pai e irmão obrigada.

Aos meus gatinhos Meggie Lee e Whisky, sempre ao meu lado, dormindo claro! Em especial minha persistente Meggie Lee, 19 anos juntas. Esse último ano não foi fácil para os dois, tantos problemas de saúde... parte dessa tese foi escrita em salas de espera de consultórios e hospitais veterinários.

À linda Vitória, que preencheu um papel importante: o papel de ser o MEU CÃO! Também devo agradecer o Tito, Camila e Heloísa que me ajudam a cuidar da Vitória.

À Fernanda, que foi essencial para essa pesquisa, além de fazer o papel de auxiliar no primeiro experimento, de ser o segundo julgador nas análise dos vídeos, auxiliar no recrutamento de cães, o mais importante de tudo, ela estava lá todos os sábados e domingos, sempre com muito entusiasmo. 
À Natália, que sempre me apoia e me faz acreditar que eu sou especial.

À Luciana, grande amiga, que me ajudou com o inglês.

À Rosana, sempre cuidando de mim. Ela foi fundamental em todo esse processo e especialmente nesse último ano tão difícil.

Ao Anderson, que no último ano me incentivou. um exemplo de força e persistência.

A todas as colegas do grupo de estudo sobre cães, que contribuíram de alguma forma para essa pesquisa, Daniela, Angélica, Maria, Gisele, Denise, Alice, Patrícia e Amanda.

À Angélica Sabadini da biblioteca pela valiosa ajuda com as referencias.

Aos meus grandes amigos estatísticos, sempre dispostos à discutir estatística comigo! Frederico, Lilian, André, Liliam, Angela, Rejane e ao professor Júlio Singer.

A UNIFESP - Universidade Federal de São Paulo e aos meus colegas pelo apoio. Agradeço em especial aos meus alunos que compreenderam o momento delicado em que eu precisei me ausentar para terminar essa tese. 


\begin{abstract}
Redigolo, C. S. (2013). Functionally referential and intentional communication in dogs (Canis familiaris). Tese (Doutorado), Instituto de Psicologia, Universidade de São Paulo, São Paulo.
\end{abstract}

The exposure to the human's social environment provided a special niche for dogs to develop socio-communicative skills to cooperate with human. It has been exhaustive studied the ability of dogs to use human's communicative signals. The current study arises a question about the production of signals by dogs to communicate with humans: are dogs able to communicate by using directional signals toward some desirable entity in the environment and with "intention" to manipulate their owner's behavior in order to receive it? Since intentionality is not possible to be measured, some operational criteria can be considered as a requirement to qualify a communicative signal as functionally referential and intentional: the signal should be used socially (to be, first of all, considered as a communicative signal) and influenced by the recipient's visual direction of attention; moreover the sender of the signal should display gaze alternations between the recipient and the object or event to be communicated and getting-attention behaviors, and, finally, the sender should persist and elaborate the communication when the first attempt to manipulate the recipient failed. Dogs were submitted to an experimental study in which they could see a desirable food but they need their owner's cooperation in order to receive it. By manipulating the presence/absence of the owner/food, the position of the food (in two possible places), the owner's visual direction of attention and the owner's behavior regarding the outcome of the request (providing the food, half food or undesirable food) after a period that dogs communicated about the food, we could investigate whether these criteria of referentiality and intentionally were validated for dogs. It was found evidences that dogs use behaviors, especially gaze alternation between the 
owner and the food, as communicative signals in a functionally referential and intentional way. The present exhaustive work confirms and upgrades previous results; it also highlights that different set ups can lead to some differences of referential and intentional communicative behaviors in dogs. As for other studies of social cognition in animals, it does not allow disentangling whether the dog's adaptive behaviors are based on simple mechanisms or on a theory of mind of their owners; still, it shows in dogs similar properties of communicative behaviors than in captive apes.

Keywords: Dogs. Communication. Referentiality. Intentionality. 


\section{RESUMO}

Redigolo, C. S. (2013). Comunicação funcionalmente referential e intencional nos cães (Canis familiaris). Tese (Doutorado), Instituto de Psicologia, Universidade de São Paulo, São Paulo.

A exposição ao ambiente social humano ofereceu aos cães um nicho especial para desenvolver habilidades socio-comunicativas para cooperar com o ser humano. Tem sido exaustivamente estudada a habilidade dos cães de usar sinais comunicativos do ser humano. $\mathrm{O}$ presente estudo levanta uma questão sobre a produção de sinais pelos cães para se comunicar com o ser humano: Os cães são capazes de se comunicar usando sinais direcionados a algum item de interesse no ambiente e com "intenção" de manipular seus tutores de tal forma a recebê-lo? Como intencionalidade não é possível de mensurar, alguns critérios operacionais podem ser considerados como requisitos para qualificar um sinal comunicativo como funcionalmente referencial e intencional: o sinal deve ser usado socialmente (para ser, antes de mais nada, considerado um sinal comunicativo) e influenciado pela direção da atenção visual do receptor; além disso o emissor do sinal deve apresentar alternância de olhares entre o receptor e o objeto ou evento a ser comunicado e comportamentos de chamar a atenção, e, finalmente, o emissor deve persistir e elaborar a comunicação quando a primeira tentativa de manipular o receptor falhar. Cães foram submetidos a um estudo experimental em que eles podiam ver uma comida desejável mas precisavam da cooperação de seus tutores para recebêla. Manipulando a presença/ausência do tutor/comida, a posição da comida (em dois possíveis lugares), a direção da atenção visual do tutor e o comportamento do tutor quanto ao resultado do pedido (dar a comida, metade da comida ou uma comida indesejável) após um período em que os cães comunicavam a comida, pudemos investigar se esses critérios de referencialidade 
e intencionalidade eram válidos para os cães. Foram encontradas evidências de que os cães usam comportamentos, especialmente a alternância de olhares entre o tutor e comida, como sinais comunicativos de uma maneira funcionalmente referencial e intencional. O presente e exaustivo estudo confirma e atualiza estudos anteriores; ele também enfatiza que diferentes cenários podem levar a diferenças nos comportamentos referenciais e intencionais dos cães. Assim como em outros estudos sobre cognição social em animais, esse estudo não permite separar se os comportamentos adaptativos dos cães baseiam-se em mecanismos simples ou em uma teoria da mente do seu tutor; ainda assim, ele mostra nos cães propriedades dos comportamentos comunicativos similares aos dos pongídeos que vivem em cativeiro.

Palavras chaves: Cães. Comunicação. Referencialidade. Intencionalidade. 


\section{TABLE OF CONTENTS}

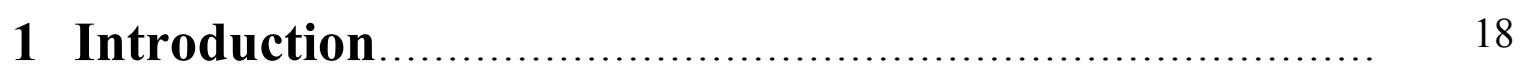

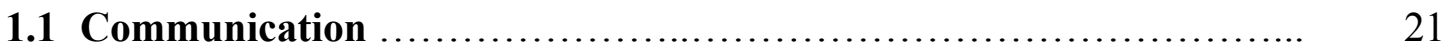

1.2 Referential communication...................................... 23

1.2.1 Referential communication based on calls......................... 25

1.2.2 Referential communication based on deictic behaviors............... 27

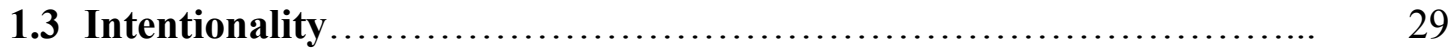

1.3.1 The development of intentionality in infants...................... 31

1.3.2 Referential and intentional pointing gesture in infants............... 32

1.4 Operational criteria to infer about referentiality and intentionality... 35

1.5 Referential and intentional communication in apes................. 37

1.6 Referential and intentional communication in dogs................. 41

1.7 Goals of this study and hypotheses............................... 48

2 Experiment 1 ................................................. 52

2.1 Material and Methods.......................................... 53

2.1.1 Participants.............................................. 53

2.1.2 Experimental settings...................................... 54

2.1.3 Familiarization phase....................................... 55

2.1.4 Experimental phase.......................................... 55

2.1.5 Behaviors collected and variables.............................. 58

2.1.6 Location collected and variables................................. 61

2.1.7 Location and behavior combined collected and variables............ 62

2.1.8 Statistical analysis.......................................... 63

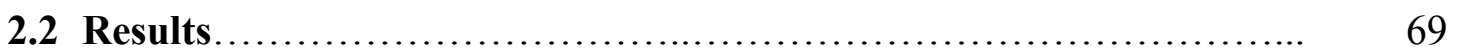

2.2.1 Comparisons among the pre-delivery phases..................... 69

2.2.2 Communication/Audience effect vs. Motivation..................... $\quad 70$

2.2 .3 Referentiality............................................. 72

2.2.4 Effect of the direction of attention.............................. 75

2.2 .5 Persistence ................................................. 77

2.2.6 Elaboration.................................................. 79 
3 Experiment 2 .

3.1 Material and Methods..................................................... 84

3.1.1 Participants......................................................... 84

3.1.2 Experimental settings............................................. 85

3.1.3 Familiarization phase.............................................. 86

3.1.4 Experimental phase ............................................. 86

3.1.5 Behaviors collected and variables................................... $\quad 88$

3.1.6 Location collected and variables.................................... $\quad 88$

3.1.7 Location and behavior combined collected and variables............. $\quad 89$

3.1.8 Statistical Analysis.................................................. $\quad 89$

3.2 Results................................................................. 91

4 Discussion ........................................................ 94

4.1 Communication/Audience effect vs. Motivation....................... 96

4.2 Referentiality............................................... 97

4.3 Effect of the direction of attention................................... 99

4.4 Persistence...................................................... 105

4.5 Elaboration................................................... 109

4.6 Gaze Alternation between the owner and food...................... 110

4.7 Final Remarks.................................................... 111

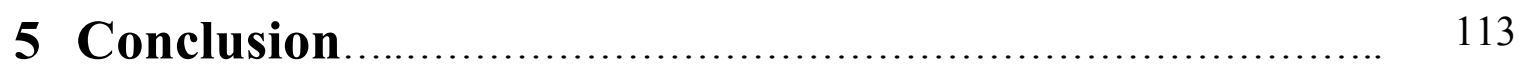

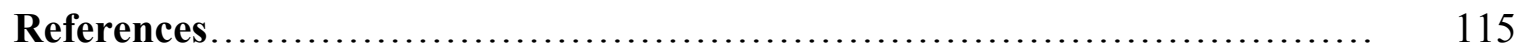

Supplementary 1 - Tables of Experiment 1................................... 129

Supplementary 2 - Tables of Experiment 2 ................................ 136

Supplementary 3 - Correction by the relative size of areas (Experiment 1)... 142 
Chapter 1 - Introduction 


\section{Introduction}

In his book "Kinds of minds" Dennet (1996) remembered that we share a common ancestor with all other mammals, reptiles, fishes, plants and even with macromolecules. All have bodies that follow a self-regulation. We are actually composed by a group of cells, and although each cell has a function and executes it in a systematic way, we do not expected that these cells will have a conscious or intentions to execute these tasks. Our cells are specialized and form different systems (eg. metabolic, immunologic, among others) that, each one with its function "communicates" with others by means of mediators. The neuronal system that appeared in some animals is a very competent innovation of the evolution that allows a more efficient exchange of information. Despite this information exchanges by means of mediators or neuronal systems, we also do not expect that all these complex systems will communicate each other intentionally. Then, Dennet (1996) suggested that an organism constituted by a group of unconsciousness parts can have consciousness, as we have. So the natural question is: what is necessary to produce consciousness and to have beliefs and plans? What is necessary to act and communicate intentionally? There is no simple answer.

Questions about intentions, desires, plans, beliefs and understandings are of interest of cognitive ethologists. Before Griffin (1976), classical ethologists usually explained animal behavior by using parsimonious explanations based only on conditioning and associative processes. Griffin was the pioneer in attributing mentalist interpretations for animal behaviors: he arose the possibility that animals can also possess subjective states since they sometimes present smart and planned behaviors. Zuberbuhler (2003) affirmed that analogies with human mental states, the anthropocentric approach, can help, although he called attention to the danger of assuming this posture when the species being studied have a 
considerably less complicated nervous system. Nowadays there is a clear tendency in the literature of cognitive ethology and psychology to use mentalist terms and interpretations for animal behavior. The crucial problem is that subjective states are not measurable and researches should concentrate and limit their conclusions to the behaviors that are observable; it seems more adequate to take careful conclusions without losing the perspective that complex mechanisms can be involved. Shettleworth (2010) defends that an interpretation based on learning and associative processes can be enough to explain the most of animal behavior. And she states that these processes also involve sophisticated mechanisms as well as the more "cognitive" mechanisms. Therefore, this author suggests that a cautious posture would be to interpret these mentalist terms by its functional meaning.

Traditionally, researchers interested in investigating animal cognition, defined by Shettleworth (2010) as a set of mechanisms by which animals acquire, store and process information of the environment, focused their studies on apes, our closest relatives. However, recently dogs (Canis lupus familiaris or Canis familiaris ${ }^{1}$ ) appeared to be a more suitable model than apes, specially for answering questions about communication, for many reasons that will be discussed along this text. The purpose of this current research is to investigate whether dogs are able to communicate with humans apparently referentially and intentionally. Hence, in order to better achieve this goal it is necessary to introduce basic concepts of communication, referentiality and intentionality.

\footnotetext{
${ }^{1}$ It is already established by the geneticists that the nearest living relative of the dogs is the gray wolf (Canis lupus), and dogs are usually categorized as a sub-species of wolves, Canis lupus familiaris, based on evidences that they can interbreed and that they are not sufficiently different for a species-level discrimination. However, another line of thought about definition of species, based on the adaptation to a specific niche, leads some researches to consider the dog as a different species (Canis familiaris) since dogs and wolves are adapted to different niches (Miklósi, 2007). This discussion is already controversial.
} 


\subsection{Communication}

Communication is a process that involves an interaction between two individuals, a sender who transmits a signal to a recipient and influences his behavior. It is not even necessary an active process, sometimes it is done in a passive way by the sender as, for example, the aposematic insects that transmit by its colour the message that they are not palatable and this information modifies the behavior of their predators that avoid them (Alcock, 2005). The function of a signal can be inferred by the recipient's response.

Shettleworth (2010) suggested that usually the recipient of a message can be thought as acting as a "mindreader" (as well as a user of the sender's signal), in the sense that he can anticipate the next step of the sender and respond appropriately. Sometimes the sender acts as if "manipulating" the recipient's behavior and even as "deceiving" in order to achieve its goal. Nevertheless, this does not imply that animals think and reflect about manipulating or deceiving, but instead they are probably behaving based on previous experiences.

The evolution of a new communicative signal and the adaptative value of a communication system for both sender and recipient of the signal are topics of interest for the evolutionary Ethology. According to Alcock (2005), if by transmitting a signal or by paying attention to it would decrease the fitness of the sender or the recipient, then it would be expected that the behavior of the sender would tend to cease since it would not be adaptative. According to Seyfarth et al. (2010a), if there is no benefit, on average, for the recipient to respond a signal, then recipients should evolve to ignore it, and finally signaling would not have a function to the signaler.

Signals can emerge from incidental movements that have originally given information about future actions and the selection may favor the recipients able to anticipate the future behavior of signaler (Scott-Phillips et al., 2011). For example, a dog can snort without the will (or 
intention) to show that it is thirst. However, the owner can interpret this behavior as thirst and gives him water. Gradually the dog learns that this signal influences its owner's behavior and it acquires a communicative function. The associative learning has, therefore, an important role in the development of communicative signals.

As this previous example, probably great amount of signals emerge by a process called ritualization (Scott-Phillips et al., 2011), in which a behavior or a cue that initially had a reason to exist independently of the effect that it could cause in other individual, becomes a signal if it elicits a reaction in a recipient that ends up to be positive for the one that displayed the behavior.

There are various modalities of communication (e.g., visual, sonorous and odorous) and each one presents costs and benefits. Sound is very flexible, varies in tone, volume and the harmonic structure, it is convenient, for example, for birds that live in dense forests. Odor is less flexible but represents smaller energy cost and last in the environment for more time, an advantage for territorialist animals. Colors printed in the animals body remain permanently and can be an advantage to attract females or a disadvantage if attract predators (Shettleworth, 2010). The visual communication depends on the visual perspective and attention of the recipient. What is important to note is that the production and reception of a signal depends on the perception system of the recipient and also the physical properties of the environment (Shettleworth, 2010; Alcock, 2005).

Production and "comprehension" (as wrote Seyfarth \& Cheney, 2010b; but could as well be "use") of a signal (measured by the individual's response and use of the signal) involve different mechanisms for the signalers and recipients. While "comprehension" is more flexible and can adapt with experience, depending on mechanisms of learning; vocal production, for example, is more constrained by the acoustic structures that animals is able to utter, depending on mechanisms of phonation (Seyfarth \& Cheney, 2010b). Many species of 
birds and mammals have a limited repertoire of acoustical vocalisations, but individuals can learn to respond to new sounds in new contexts throughout their lives.

Some examples in the literature strengthen this flexibility of "comprehension". Among dogs for example, Rico, a border collie breed dog, was able to learn labels of more than 200 different objects (Kaminski et al., 2004), Chaser, another border collie, was able to learn more than 1000 words (Pilley \& Reid, 2011), and, Sofia, a mongrel dog, was able to respond appropriately to object-action requests presented as single sentences and generalized the learning for different contexts (Ramos \& Ades, 2012).

On the other hand, even though production is more constrained, this does not mean that it is completely fixed. Some studies were successful in training animals to use an artificial wider repertoire of sign production, like, for example, signing bonobo (Pan paniscus) as Kanzi (Savage-Rumbaugh, 1994) and again the dog Sofia (Rossi \& Ades, 2008), that was also trained to use a keyboard with lexigrams to make requests. Nevertheless, undoubtedly in the wild the production is clearly less flexible and plastic than comprehension (Seyfarth \& Cheney, 2010b).

This study will focus on production of spontaneous signals by dog communicating with the owner in a naturalistic context of requesting food. Two important features of communication are of interest for this study, the referentiality and intentionality, so these features will receive a special attention in this work.

\subsection{Referential communication}

The referential communication involves three components: the signaler, the recipient and a referent. Signals emitted by animals that inform about objects or events in the environment are considered as referential signals (Evans, 1997). It is expected that the production of 
referential signals do not occur at a high rate in inappropriate contexts, for example the production of a call that supposedly refer to a certain kind of predator would not be used in the presence of another kind of predator; this property was called "production specificity" by Macedonia and Evans (1993). Moreover, the referential signal should be sufficient for a recipient to select an appropriate response, even in the absence of the object or event that elicited the signal (Shettleworth, 2010); for example, by hearing a call of a conspecific that supposedly refer to a certain kind of predator, the recipient should react with a specific escape response that will save its life from that predator, even if the predator is not visible; this property was named as "context independence” by Macedonia and Evans (1993).

Referential signals should be studied by taking into account that many factors are involved in their production: the physical properties of the stimulus, the environment, the sensory system of the recipient, the historical and social context. Evans (1997) pointed out that studies conducted in laboratories in which animals are placed in a completely novel environment provide conservative results for functional reference due to lack of historical context. This should also be taken into account when interpreting laboratory results.

It is not exclusive of the human language to communicate about environmental objects or events. Honeybees (Apis mellifera), for example, are well known for being able to communicate about the site of distant food sources by using the waggle dance (Von Frisch, 1955). According to Xitco et al. (2001) dolphins (Tursiops truncatus) in captivity are able to produce referential signs. Two bottlenose dolphins were observed using pointing and monitoring behaviors related to both caregiver and object. The posture while pointing and monitoring according to the authors were clearly different from inspecting behavior. They were most likely pointing to indicate food, and the pointing was more likely to include monitoring when the recipient was more distant; moreover, they pointed only in the presence of a human, suggesting that this behavior seems to be influenced by an audience effect and 
also by the attentional direction of the recipient. Still, many other mammals produce signals to refer about food, predators or in social contexts.

The most studied form of referential communication was the one based on calls in apes and monkeys. However, postural deictic behaviors are additionally considered as a referential communication, even having different properties.

\subsubsection{Referential communication based on calls}

Vocalisations and calls are used by animals mainly for three reasons: food discovery, predatory contexts and social interactions (Townsend \& Manser, 2012; Seyfarth et al., 1980; Slocombe \& Zuberbuhler, 2005; Slocombe \& Zuberbuhler, 2007). Chickens (Gallus gallus domesticus), for example, produce food calls to provide information about presence of food for their conspecifics which, in turn, respond with an anticipatory feeding movement (Evans \& Evans, 1999). For chimpanzees (Pan troglodytes) and bonobos, vocalisations seem to refer to distinct external events: they vocalise when finding food, and these food calls are adjusted to contexts: for example, more often when the source of food is divisible they use a different acoustically call when they find their preferred food, maybe a referential label (Zuberbuhler, 2008). However, Clay et al. (2012) suggested that food calling in mammals could be considered as referential signals only in a few number of species within primates, since some cases food calls are produced also in non-food contexts.

Several species produce acoustically different alarm calls for different predators, as for example, the well-studied vervet monkeys (Cercopithecus aethiops) (Seyfarth et al., 1980). These animals use different alarm calls when facing an eagle, a leopard or a python, and, each call elicits a different adaptative response by theirs conspecifics, that act accordingly to what they hear. According to Zuberbuhler (2003), it is unlikely that these calls are just expressing 
an emotional reaction to the presence of the predator, since by listening to a playback of eagle alarm calls, for example, it elicits a response to look at the sky and run for cover even in the absence of the visual stimuli of the predator. An audience effect was described for females that adjust the alarm calls according to the presence of their offspring (Cheney \& Seyfarth, 1985), and males, that call more often when females are present. Although infants and juveniles sometimes make mistakes in the usage of the calls, these mistakes are not completely at random: they use, for example, leopard alarms to other terrestrial mammals (Seyfarth \& Cheney, 1986; Seyfarth et al., 1980), and as the time passes by they acquire experience and their calls become more specific and accurate (Seyfarth \& Cheney, 1990), which emphasizes the role of ontogenesis in the alarm call's usage.

Concerning dogs, Faragó et al. (2010) showed that they produce different growl for different external social event and that this is meaningful for the recipients. By hearing a playback of "food guarding" growl, dogs spent less time in contact with the food than when they heard "play" growls or "threatening unknown human" growls. These authors suggested that the effect of food guarding growls could be interpreted in the functionally referential framework.

It is important to point out that not all studies on primates succeed to show an explicit relationship between the alarm calls and the response that it elicits (Fisher et al., 2001; Fisher \& Hammerschmidt, 2001; Fichtel \& Kappeler, 2002). Macedonia and Evans (1993) also called attention to the fact that alarm calls of ground squirrel (Spermophilus beecheyi) reflect differences in the response urgency instead of denoting a specific predator, and, then, cannot be considered referential.

On their side Seyfarth \& Cheney (1990) defended that vervet monkeys should have some representations of the objects or events denoted by different alarm calls. Furthermore, Diana monkey (Cercopithecus diana) and Campbell's monkey (Cercopithecus campbelli) seems to anticipate the presence of a particular predator type when hearing a certain conspecific alarm 
call (Zuberbuhler et al., 1999; Zuberbuhler, 2000). Although the leopard's growl and the monkey's leopard alarm calls are sounds acoustically different, monkeys respond as if they judge them to be similar, which indicate that the alarm calls relies on a semantic content of the signal rather than a simple acoustic perception.

The fact that the non-visually stimulus elicits the appropriate escape response for some animals suggest that the calls could be associated to a mental representation of the external object or event, however this conclusion remains controversial (Zuberbuhler, 2003). Whether the referential signals evokes the representation of the referent in the "mind" of the recipient is not possible to confirm, but some animals do act "as if" they understand the semantic content of the vocalisation (Townsend \& Manser, 2012).

Since the exact cognitive mechanism related to the alarm calls are unclear, to be parsimonious some researchers prefer to use the term "functionally referential" for non-human animals (Evans, 1997; Townsend \& Manser, 2012) in order to indicate that their abilities look like the referential communication in humans. Accordingly, it is considered that animals behave "as if" their signals provide sufficient information about external stimuli for a recipient selecting a response, without necessary assuming that there is a mental representation (for example, a concept of the class of the predator - Zuberbuhler et al., 1999).

\subsubsection{Referential communication based on deictic behaviors}

Differently from the alarm calls that can be used in the absence of the referent and allows for both sender and recipient to surpass the immediate sensory perception, the manual deixis or pointing, is a kind of nonverbal reference that requires the immediate sensory perception and joint visual attention (both sender and recipient's looking toward the same referent), and is used to direct the recipient's attention (Leavens, 2004a). The act of referring to something by 
means of gestures and deictic behaviors is the way that the human infant individual communicates with a recipient about something that is in his/her focus of attention and that he/she wants to share (Bruner, 1998). When the individual did not succeed in transmitting the message by means of these nonverbal referential behaviors, he/she should figure out what else he/she needs to do in order to achieve the goal of directing the recipient's attention to the referent.

Pollick and de Waal (2007) observed that some gestures communicate different messages or intentions depending on the social context. A chimpanzee, for example, stretches out an open hand toward others to "ask for help" in a fight or to require food. In the last example the gesture could be referential since it refers to a third entity in the environment (the food), even not being a pointing gesture with the extended finger (there is an anatomical difference between humans and apes in the shape of pointing: pointing gesture with index finger seems to be frequent only for language-trained apes, see Leavens, 2004a).

It is important to note that gestures are seldom produced in the absence of other communicative cues, such as gazing and vocalisations (Pollick \& de Waal, 2007), which suggest that studies on referential communication should integrate when possible multimodal behaviors. Not only the explicit manual gestures should be examined, but especially gaze following, which is also considered as a deictic cue to guide other's behaviors (Shepherd, 2010). It was already verified that in an object choice task, in which dogs had to chose between two containers (only one with food) based on the human's pointing gestures, when this cue was associated with gaze alternations between the recipient of the message and the target, the performance of the use of human's point by the animals increased (Miklósi \& Soproni, 2006).

Leavens et al. (2005b) stated that pointing gesture could be used to manipulate the recipient's behavior or to call the recipient's attention, but it would not be possible to assure by means of 
an observable behavior, that it would be, in fact, associated to a mentalist representational process.

\subsection{Intentionality}

Shettleworth (2010) stated that intentionality is a property of mental state, as well as beliefs and desires, plans and understandings. Tomasello et al. (2005), in turn, suggested that an intention would be a plan of action in order to achieve a goal. Intentionality would require the ability to reflect about ways of achieving goals and its consequences (Rochat, 2007).

Dennett (1983) proposed that intentionality should not be treated as a binary trait that animal possess or not, but instead as an attribute that presents a gradation. The zero-order of intentionality would be a simple response to a stimulus, which would represent the absence of intentionality. An animal that possesses beliefs, desires about other's behaviors would have a first-order of intentionality, and if, additionally, it has a concern about the other's mental states, the animal would have a second-order of intentionality. A third-order of intentionality would refer to a level in which the animal would want to make others believe in something, in another words, would consist in manipulating the other's mental states. When humans communicate, they assume that they are modifying not only the recipient's behavior but also his/her mental state (Shettleworth, 2010), therefore the human communication involves a third-order of intentionality. The theory of mind, imputing mental states to others, which would constitute a second order of intentionality, should be present, for example, in an intentional deception, and also when the individual communicates with intent to inform (Shettleworth, 2010). Intentional deception would imply a possibility of creating false beliefs, being, therefore, a way to manipulate other's mind. 
The deceiving behavior was already described for many animals. For example, in order to defend its nest, a plover (Charadrius melodus) is able to drive away from the nest while pretending a broken-wing as a strategy to distract a predator fox. This behavior is typically interpreted as a response to a stimulus, however its flexibility to achieve the goal challenges the parsimonious explanations (Ristau, 1991 cited by Shettleworth, 2010). Another wellknown example of deceiving, presented by Byrne (1995), is the subordinate male baboon (Papio hamadryas) that solicits sexual contact with a female when he is out of the dominant's sight, as if he possesses an understanding of what the dominant can see and believe. This behavior can be explained as having a high level of intentionality, however it is also possible to offer a parsimonious explanation, a result of previous experiences in which the subordinate would have not been punished when he was out of dominant's view. Griffin (1976) advocated that a parsimonious and more careful explanation based on associative processes (the so called "low-level" interpretation) should be challenged by a more complex and cognitive explanation (the "high-level" interpretation) when we want to explain the animal behavior. However, it is important to remember that the high-level interpretation cannot rely on observable behaviors. Besides, social learning of complex behavior may be accomplished through simple processes like classical or operant conditioning. Those mechanisms have an important role in modeling animal, including human, behaviors (Fragaszy \& Visalbergh, 2001).

All in all, the fundamental question is: what differentiates intentional from motivational or non-intentional action or communication? Since intentions are not directly measurable, researchers have no option other than inferring signalers' intentions through observable external behaviors like gestures, vocalisations or gaze direction. According to Cartmill and Byrne (2010), what seems to be wise is that the study of intentionality of communicative 
gestures should be restricted to behaviors that the recipient's reaction matches the presumed goal of the signaler. This is a good route.

\subsubsection{The development of intentionality in infants}

Rochat (2007) defended that intentionality emerges in infants as a by-product of reciprocal face-to-face communicative exchanges with their caregivers, which allows them to differentiate an accidental sneezing or coughing from contingent gazing and smiling.

According to Tomasello et al. (2005), 12-months-old infants "understand" (as said by the authors) when adults try to achieve goals that they keep trying persistently after failed attempts and stop when they succeed, which imply an understanding that adults have a perception of the environment and monitor their own actions.

On the other hand, from D'Entremont and Seamans (2007)'s point of view, 12-months-old infants would be able to read cues and determine where others are attending, but this would not imply that they understand others, like self, as intentional agents. This stage would require an understanding of the subjective experience of others and these authors defended that only 18-24-months-old infants appear to be aware of others' subjective experiences, believes, emotions and desires, and, therefore, only at this age, infants could recognize when other's visual perspective is different from their own.

For Tomasello et al. (2005), when infants engage in activities that involve themselves, the caregiver and some outside entity toward which both direct their actions, as for example giving or taking objects, that would require a joint attention (the infants' looking coordinated with other's looking toward the relevant outside objects), they are already in the triadic engagement phase. By seeking the joint attention of others, infants would reveal an ability of perceiving that others can see the same thing as themselves. 
Tomasello et al. (2005) go further and state that a next step would take place when infants would begin to understand one another as intentional, by forming what they called shared intentionality, which refers to a cooperative and coordinated action with a shared goal. It would require that both individuals involved should be mutually responsive to one another, with roles known by both. According to them, in a truly cooperative action with a shared goal, each individual would have goals with respect to the other's goals, in such a way that allowing role reversal and mutual helping, what these authors suggested it would be the critical difference between human intentional communication and the social interactions of other primates. They defend that this is unique for humans (Tomasello \& Rakoczy, 2003; Tomasello et al., 2005).

Not all researchers agree with this uniqueness defended by Tomasello et al. (2005). According to Boesch (2005) and Shepherd (2010), in theory, in order to coordinate and synchronize their movements with their group-mates, like for example during collaborative hunts, chimpanzees would use the intended movements of others. Recently Yamamoto et al. (2012) showed that chimpanzees use the information about the conspecific goals and help them appropriately: they are able to select an appropriate tool to give to a conspecific so that it could solve a task to obtain a juice reward. This result should be better investigated, but it could be an example outside the human species of join attention and a cooperative action.

\subsubsection{Referential and intentional pointing gesture in infants}

Various studies focused on the emergence of referentiality and intentionality in infants prior to the development of the language, at around 12-months-old, when they start to use deictic gestures, such as designating a target with referential intentions and cooperative purposes as 
an attempt to establish joint attention (Liszkowski, 2011; Tomasello \& Rakoczy, 2003; Tomasello et al.; 2005, Tomasello et al., 2007).

The production of pointing gestures comes after the ability to use pointing gesture emitted by humans and it would be a product of learning and social interaction with adults, i.e., it would require a comprehension of others' referential, social, and communicative intentions. Some authors suggested that infant at that age would "understand" people as intentional agents and would know what others see and intend (Liszkowski, 2011; Tomasello \& Rakoczy, 2003; Tomasello et al., 2005; Tomasello et al., 2007). This would require the ability of imputing mental states to others, a second order of intentionality according to Dennet (1983).

Legerstee and Barillas (2003) verified that infants who pointed produced more points, gazes and vocalisations when experimenter and infant were looking at different toys, an evidence that infants are taking into account the direction of the visual focus of the human when pointing, and that they use attention-getting behaviors to direct the attention to what they want.

When an adult does not react after infants point, infants persist in their communicative behaviors: they repeat the gesture, by alternating gazes between the event and the adult and increase vocalisations significantly more than when the adult does react by showing interest and sharing attention (Liszkowski et al., 2004). Moreover, infants point less when the adult is not attending to them and cannot see them (Liszkowski et al., 2008).

Additionally, according to Liszkowski et al. (2009), infants pointed as if to referring intentionally to a desirable target even when it was absent. These authors argue that referring to absent entities suggest that these entities exist on a mental level, and that would be an exclusive human skill. Besides, when infants had attended to an interesting event and it had ceased, they continued to point to that location (Liszkowski et al., 2007a). 
Two kind of pointing gesture in infants are described in literature (Baron-Cohen, 1999; Leavens at al., 2005b). The first one, the imperative gestures, would be used to request and manipulate the recipient's behavior, while the second kind of pointing, the declarative gestures, would be used to manipulate the recipient's mental state. Some authors indeed suggest that declarative pointing is found exclusively in human infants and it is the only one that should be considered as genuinely referential and intentional, which means that the pointing used to request would not be considered as intentional (Baron-Cohen, 1999).

On the other hand, Leavens (2004a) described several declarative pointings by languagetrained apes that, differently from other captivity apes, have a close emotional bonding with human caregivers. Moreover, he also pointed out that chimpanzees that use gestures usually also exhibit gaze alternation between the recipient of the message and the referent.

According to Leavens et al. (2005b) it would not be possible to assure, by means of observable behaviors, that even the pointing gesture used to call the attention of a recipient would be, in fact, associated to a complex mentalist representational process exclusively found in humans.

A request would also require coordination of attention and skills to engage in cooperative interaction (Goméz, 2007). Both types of pointing gestures would require an association between behaviors and a target through attention; the difference would reside on the goal for pointing: in the case of requesting, the goal would be to make the recipient do some action with the target, and in the case of declarative gesture the goal would be to make the recipient look at and emotionally react about the target.

When infants point, their caretakers respond emotionally (i.e., with behaviors acknowledged as positive to the sender). Then Leavens et al. (2005b) suggested that the emotional reaction of signaling about distant objects or events could be the main motivation for infants to engage in joint attention. From this point of view, if the initial motivation for infants to point would 
be the manipulation of their social caregiver's emotions, it would not be necessary to assume differences in the psychological process between two kinds of pointing, or to assume that pointing used to call the attention for some object or event would necessarily involve a mentalist concept of the recipient, that the other kind of pointing do not.

Finally, adults also point to request and they supposedly understand others' mental state (Liszkowski, 2007b). Given all these arguments, Leavens et al. (2005b) suggested that we could consider both kinds of gestures as non-verbal reference.

\subsection{Operational criteria to infer about referentiality and intentionality}

Based on observations and studies with human infants, Leavens et al. (2005b) described some operational criteria to consider a communicative signal as referential and intentional. They suggested that the sender of a signal is communicating referentially and intentionally when:

a) the signal is used socially, which means that there is an audience effect;

b) there is an influence of the recipient's visual direction of attention;

c) there are successive gaze alternations between the recipient and the object or event to be communicated;

d) the sender presents getting-attention behaviors;

e) there is persistence, and,

f) elaboration of communication when the first attempt to manipulate the recipient failed.

The rationalization of these criteria is as follow. The first criterion is necessary to assure that the signals are, in fact, communicative instead of just motivational. Comparisons between a situation with both recipient and object present in the same place and situations without one 
of them (recipient or object) allow evaluating the audience effect and the referentiality of the signals respectively: when the recipient is absent it is expected that sender's behaviors towards the object decrease and when the object is absent, the sender's behaviors towards the recipient should decrease. The comparison between the situations with the object present and absent allows investigating whether the sender's signals refers to the object.

In order to validate the second criterion the sender's behavior should be analyzed facing an "attentive" and a "non-attentive" recipient. To infer about what another individual sees, the sender must perceive and use his/her body posture, head and eyes, which would give information not only about how the recipient may respond given previous experiences, but also about the shared environment. The availability of eye contact should be a stimulus to a visual communication: by looking at the recipient's gaze it is possible to monitor his/her attention and reaction, which would show the use of other's direction of visual attention or learning of previous postural and outcome contingencies (Leavens et al. 2005b; Goméz, 2007).

As for criteria (c) and (d) we should analyze the situation in which both recipient and object are present in the same place. In this scenario, if we observe gaze alternation and attentiongetting behaviors ("strategies" to guide the recipient's attention to the object), this would indicate that the sender "understands" something about the basic relation between the signal and the causality, and therefore uses the communication signal as a referential tool. It is, in fact, this triangulation of attention between the sender of a signal, the recipient and the object, usually exhibits by means of gaze alternation, that best characterizes referential communication (Goméz, 2007).

Finally, persistence in communicating and the use of elaborated repertoire and new signals until the recipient responds are both mechanisms associated to intentional communication in humans. It is the way to become more "explicit" about the "intentions". In order to evaluate 
the persistence and elaboration criteria, the sender should experience different outcomes of its first attempt to communicate regarding the recipient's reaction. In order to validate the persistence criterion, the sender's behaviors should not decrease if the recipient does not react according to the sender's expectation, but decrease significantly if he/she does. Regarding elaboration, if the recipient does not respond to the sender's signals, it is expected that the sender presents a more elaborate repertoire of behaviors when compared to a situation in which the recipient react according to the sender's expectation, and eventually changes the strategy of communication by presenting different behaviors than the ones previously used.

These are observable and measurable criteria that are directly associated to what is considered a referential and intentional communication in humans; therefore, the validation of these criteria on other animals would provide strong evidences that their way of communicating about outside entities can be qualified as functionally referential and intentional.

\subsection{Referential and intentional communication in apes}

The use of pointing gestures with the right hand by infant is usually associated with the development of language, which supports the link between the left-hemisphere specialization for language and gestural communication. Interestingly, Hopkins et al. (2005) found that chimpanzees also prefer to use the right hand when communicating by means of gesture, an evidence that humans and chimpanzees could share lateralized specialization for use of manual gesture communication.

According to Tomasello et al. (2005), although in the wild apes do not present the same ability as humans to share experiences, interest and attention via declarative gesture and do not engage with others in collaborative activities with shared goals and joint intentions, apes 
that are raised in captivity become more like humans, which strengthen that the development of use of intentional action depends on social environment and interactions.

Liszkowski (2011) pointed out that, for apes in captivity, most gestures are ritualized during ontogenesis from individual actions and, consequently, are not shared with others, which means that they would not understand other's gestures. Moreover, chimpanzees would be more prone to compete than to cooperate, which is related to the evolutionary and ecological demands of their sociality (Hare \& Tomasello, 2004). These could be the reasons why they fail to use a human's pointing gesture indicating the location of a hidden food (Call et al. 2000; Hare \& Tomasello, 2004; Miklosi \& Soproni, 2006), which is an informative gesture intended to cooperate and guide the search of the individual. According to these results, we could conclude that apes would not "understand" human's informative pointing and intention, and then they would use themselves pointing gestures only to recruit help, but not to share attention and communicate their referential intents. Nevertheless, this is still controversial.

Gardner (2005), on the other hand, suggested that the comparison between infants that live in a very rich environment and chimpanzees that live in cages, usually under deprived social interactions conditions, is not a fair comparison. This author goes further and asserts that: "credible comparisons depend on comparable conditions". Following a similar line of thought, Boesch (2005) also defended that we should not try to validate the hypothesis about human uniqueness by considering only experimental data and disregarding observational data, treating them as mere anecdotes; this author defends that it would be more reasonable if we take into account what animals do in real life before taking our conclusions, since social and meaningful interactions are difficult to evoke in a laboratory.

Leavens and Hopkins (2007) pointed out that studies on apes that found effects of audience and visual direction of attention on communication have observed spontaneous and untrained communicative behaviors. On the other hand, studies that failed in this same goal have first 
exposed animals to operant training and then evaluated the response under different manipulations of observer's visual direction. The pre-training and unnatural context could have negative impact on the results.

The simplification of interpretation based on apes in captivity submitted to controlled experimental tests could be the reason of some negative results obtained by, for example, Povinelli \& Eddy (1996), in which chimpanzees reared in captivity failed to discriminate between a person with a bucket over his head and another one without it, and many other negative results already mentioned previously. This could also be the reason that leads Hare et al. (2002) and other authors to conclude that dogs are more skillful than great apes in many social tasks in which they must read human communicative signals (this will be better discussed in the next section) since dogs' natural habitat is, actually, the human environment. Besides the skepticism of some researchers, there are several studies suggesting that pointing gestures that emerges spontaneously in captivity, without explicit training (although the associative processes contributes) (Leavens et al., 2005a) follow the operational criteria mentioned in the previous section and can be consider as a form of functionally referential and intentional communication. More recently also wild chimpanzees were observed using pointing gestures and a referential communicative gesture to request grooming in a specific body area (Hobaiter \& Byrne, 2011; Pika \& Mitani, 2006).

Several studies reported that apes do not point in the absence of an observer (Call \& Tomasello, 1994; Leavens et al., 2004b) and that they adjusted the communication modality in line with the direction of the recipient's gaze (Leavens et al., 2004c; Leavens et al., 2010; Hopkins et al., 2007). They preferred to use visual signals when the recipient was facing them and used other modalities when the recipient was facing away (Tomasello et al., 1994). They were more prone to show begging behaviors towards humans when humans were oriented to the them with body and face; body orientation would be a more clear cue of direction of 
attention and indication of willingness to give food than more subtle signals, like for example the status of the eyes, open or closed (Kaminski et al., 2004). Although Hostetter et al. (2001) suggested that chimpanzees use vocalisations to attract human's attention and manipulate his/her attentional status, another study that investigated sequence of gestures revealed that when the recipient of the message was "inattentive", chimpanzees did not use at first a behavior to manipulate his attentional status before a second visual gesture but, instead, they preferred to use another strategy: they modified their location by moving around to face the experimenter, and, only then, they used visual gesture (Liebal et al., 2004).

Gaze alternation between food and the human has also been described on apes (Leavens et al., 2004b; Leavens et al., 2005b) and even in trained squirrel monkeys (Anderson et al., 2007) as a way of guiding other's attention.

Apes use pointing gestures followed by attention-getting behaviors and gaze alternations, and they persist until being rewarded (Leavens et al., 1996; Leavens et al., 1998; Russel et al., 2005; Zimmermann et al., 2009). Orangutans and gorillas were also described using a set of gestures flexibly with clear intentional meaning and functional consequences (Cartmill \& Byrne, 2010; Pika et al., 2003; Genty \& Byrne, 2010).

Genty et al. (2009) observed in gorillas persistence in goal-directed attempts if the expected result was not obtained. According to Cartmill et al. (2007) orangutans persisted in their communicative attempts when their goal was not met, but they distinguished between being partially understood and completely misunderstood (as said by the authors; but instead of "understood" it could as well be "rewarded"). After communicating about a desirable food, if half of the food was given, they were more likely to repeat gestures; on the other hand, in a total failure situation, they more often presented novel gestures. They also used pantomime to elaborate their messages, a gestural communication that involves physically acting out a message (Russon \& Andrews, 2010). 
In Leavens et al. (2005b) chimpanzees were presented to three experimental outcomes after communicating an inaccessible banana: (i) the experimenter gave the entire banana (control), or, (ii) the half-banana (partial success of communication), or, (iii) a chow instead of the banana (complete failure of communication). In the complete failure situation they presented more multiple gestures than when they were given the banana.

All things considered, although Tomasello's group affirmed that gestural communication of nonhuman primates shows few signs of referentiality and intentionality (Pika et al., 2007), many studies here described evidences that all observable and operational criteria required to qualify the communication as referential and intentional are present. Nevertheless, gestures on apes may neither be dismissed as simple conditioned reactions nor be recognized as fully equivalent to human referential and intentional gestures (Gómez, 2007).

\subsection{Referential and intentional communication in dogs}

A natural question that arises from these conclusions with apes is: are dogs able to communicate referentially and intentionally with human? The hard criticism and skepticism to a great amount of studies with captivity apes, lead us to conjecture that possibly dogs are, in fact, a better model than apes to investigate communicative skills: even though dogs are not so genetically close to us as great apes are, they developed throughout more than 30.000 years of domestication process (Davis and Valla, 1978; Galibert et al. 2011) social skills to cooperate with human, which makes this question plausible.

Furthermore, dogs developed a special and unique relationship with humans, an attachment pattern with their owners comparable to a child-mother attachment (Topal et al. 2005; PratoPrevide et al. 2003). The human environment is in fact the natural habitat of modern dogs; the experience and exposure to the human's social environment is usually compared to that of 
children (Miklósi \& Soproni, 2006). The extensive contact to humans during lifetime provided a favorable scenario for the dogs to develop functionally similar communicative skills, which suggests a possible convergent evolution (Miklósi et al., 2004).

Not surprisingly dogs present a readiness to follow (Soproni et al., 2001; Miklosi et al., 2003; Téglás et al., 2012) and direct (Miklosi et al., 2000; Miklosi et al., 2003; Gaunet, 2008) human gaze in a foraging situation, suggesting that they possibly share attention with humans, an ability that could have been selected and facilitated during the domestication process (Miklosi et al., 2003; Hare et al., 2002). The tendency of following the human's gaze is even higher when it was preceded by the expression of communicative and ostensive addressing by the human (Téglás et al., 2012). However, Agnetta et al. (2000) failed to show that dogs follow the human's gaze into empty space.

Dogs rely on the visual contact with human to monitor his desires and reactions and to respond appropriately to his gestural signals (Miklósi et al., 1998; Miklósi et al., 2003). The readiness to monitor human's attention cues could even overcome the one directed to their conspecifics (Range et al., 2009a; Range et al., 2009b).

Dogs also use body location of a human or a dog as a local enhancement cue (Udell et al., 2008a), which arises the question on whether they use their own body as a local enhancement cue to communicate what they want (Gaunet \& Deputte, 2011). They are also skillful in finding hidden food based on human's deictic gestures (Brauer et al., 2006; Hare \& Tomasello, 2005; Miklósi \& Soproni, 2006).

With all these skills to monitor gestures and signals of attention of a human partner, dogs become able to cooperate with humans in several activities like hunting and herding, among others (Hare et al., 2002; Miklósi, 2007; Hare \& Tomasello, 1999). The truly cooperative action with shared goals that is considered by Tomasello et al. (2005) as a requirement to attribute intentionality for infants, seems to be present in this interspecific relationship. 
There is an extensive discussion in the literature concerning the role of domestication, that is, phylogenesis, and the role of learning during the ontogenesis on this ability to respond to human's social cues, like pointing or gazing. The domestication hypothesis is supported by results that showed that puppies, from a very young age, are as competent as adults (Riedel et al, 2008; but see Wynne et al., 2008 that contradict it by reanalyzing their data), and, wolves after extensive socialization with humans fail to follow human's cues (Kubinyi et al., 2007; but see Udell et al., 2008b that contradict it). The subsequent selection for working in cooperation with continuous visual contact with their human partner (e.g. herding dogs, gundogs) also seemed to result in breeds that use human's social cues more efficiently compared to non-cooperative breeds of dogs (Gácsi et al., 2009; Wobber et al., 2009). However, the classification of breeds in cooperative or non-cooperative is not still well defined as pointed out by Passalacqua et al. (2011).

On the other hand, by living close to humans and depending on them on a daily basis for all, food, water, social interaction, dogs have all opportunities and motivation to learn how to $\mathrm{read} / \mathrm{use}$ human's cues (Reid, 2009). It is reasonable to admit that this pre-disposition to respond to human's social cues would be shaped during the lifetime and according to the environment and experiences (Riedel et al., 2008; Wynne et al., 2008; Udell \& Wynne, 2010; Dorey et al., 2010, Passalacqua et al., 2011). For example, agility dogs and search-and-rescue dogs are more proficient to use human's gaze as a communicative cue than untrained dogs (Marshall-Pescini et al., 2009).

Both explanations seem to be complementary instead of concurrent. Dogs may have a predisposition to be attentive to human social cues and willing to interact, which might be selected as a by-product of domestication, and also these abilities are constantly reinforced by the intensive social contact with humans during lifetime. 
Therefore, it has been claimed that dogs are able to use human communicative signals given the long history of domestication and extensive interaction during lifetime. We then hypothesized that maybe dogs could also be a more suitable model than apes to investigate the production of communicative signals toward humans and its characteristics as the referentiality and intentionality.

The role of domestication in the development of the dog's communicative production is also evident. When facing an unsolvable problem in a manipulation task to reach a piece of food, dogs spent more time gazing at the human and they started to gaze earlier than wolves (their closest relatives) with extended socialization with humans since very young (Miklósi et al., 2003).

There are few studies that explored the intentional and referential communication in dogs. In Miklósi et al. (2000), a target (a piece of food or a favourite toy) was hidden in one of three inaccessible places and dogs should show it to their owners, who was naive about where the target was, in order to receive it. In order to control for the motivational effects of both owner and target present in the room, two additional conditions were presented: only with target and only with the owner. Dogs tried to call the owner's attention to the place of the hidden target, they gaze more often at their owner when the target was present, and they gaze more often at the location of the target when the owner was present. When both owner and target were present dogs also used vocalisation and alternated gazes between the owner and the hidden target. The authors discussed that the "showing" behavior has both a directional component related to a target and an attention-getting component that intents to guide the recipient's attention to the target. The results, interpreted as functionally intentional communication, validate criteria a), c) and d) previously described.

Gaunet and Deputte (2011) also brought evidences to validate these criteria. Dogs witnessed the hiding of their toy in an inaccessible place, and were observed with regard to 
communicative deictic behaviors and to their position in relation to the toy's place. Experimental conditions included toy and owner present, only the toy or only the owner present. Results showed that gazing at the toy's place and gaze alternation between the owner and toy's place were used as functionally referential communicative behaviors; moreover dogs used their own position as a local enhancement signal.

In a study designed to investigate the sensitivity of dogs to a helper's "knowledge state" regarding the location of a hidden toy and a stick (a tool for getting the out-of-reach toy), Virányi et al. (2006) provided evidences that dogs were able to present communicative signals about the place of the toy, but rarely about the location of the stick. Moreover, dogs signaled the place of the toy more often if the helper had been absent during toy-hiding than when he witnessed the hiding.

Especially concerning the gaze alternation, in Gaunet (2008), after being trained to open a container in order to achieve a piece of food, dogs were presented to a test situation with the container locked. Dogs, irrespectively of being guide-dogs or pet dogs, gazed at their blind or sighted owners and alternated gazes between the owner and the container when they could not open it.

Besides, it is not only in requesting situations that dogs use gaze alternations; this behavior was also described as a social referential looking. Dogs searched for additional information from their owner by seeking out and monitoring the direction of their gaze, when faced with an ambiguous and fearful stimulus (Merola et al., 2012). Gaze alternation is therefore considered as an important aspect of dog's social cognition when interacting with humans.

There are convincing evidences that dogs tend to gaze at the human's face as a manner to communicate in situations of unsolvable tasks. This tendency may be reinforced and shaped by associative learning. Barrera et al. (2010) showed that in a situation of an unreachable but interested food, dogs gaze at the human's face in order to communicate what they want, the 
duration of gaze increased significantly during a reinforcement phase and decreased during an extinction phase when dogs were no longer reinforced. Interestingly, dogs that lived in shelters without constant contact with humans, displayed faster extinction of the gaze behavior than pet dogs, probably because pet dogs are frequently reinforced in their daily interaction with their owner and became more resistant for the extinction. These results were extended when comparing less sociable and more sociable dogs; the first group also gazed shorter at the experimenter during extinction trials (Jakovcevic et al., 2012).

Furthermore, many studies have shown that dogs take into account the observer's direction of attention to beg (Gácsi et al., 2004; Virányi et al., 2004) or to perform forbidden actions (Call et al., 2003). However, dogs are more sensitive to the direction of the head and face of the human rather than eyes (Gácsi et al., 2004; Yamamoto et al., 2011). Gaunet and Deputte (2011) varied the height of the target and the direction of gaze of the owner: the dogs looked at the owner differently according to these experimental manipulations: they positioned themselves as if they had learnt the better place to be seen or to see both the target and the owner.

In the presence of visual barriers, dogs prefer not to approach a forbidden food when they are viewed by a human (Brauer et al. 2004). Also Kaminski et al. (2009) revealed that dogs are sensitive to the human's visual access when asked to fetch a toy. Udell et al. (2011) recently suggested that in a perspective-taking task in which dogs should discriminate between an "attentive" and "inattentive" person, dogs are more prone to choose the "attentive" person when the other option was a situation faced in their environment, like a person reading a book, than when the other option was a situation never experienced before, when the "inattentive" person was with a bucket over the head. This result emphasized the role of the experience in the lifetime, but did not invalidate all evidences that dogs have, and can improve, the use of the visual perspective of others (or of previously learned contingencies 
between behaviors of others in particular contexts), which is considered as evidences in favour of the criteria b) previously described.

As far as we know, only one study has investigated the persistence and elaboration on dogs. In Gaunet (2010), 12 guide-dogs and 12 pet dogs participated to a study in which a desired toy was positioned in an inaccessible place and two experimental conditions were presented as an outcome of the dogs' communication: 1) a non-familiar object was returned or 2) the toy itself was returned. Both guide-dogs and pet dogs tried to call the owner's attention using gaze alternation between the toy and owner. Dogs exhibited persistence when the nonfamiliar object was returned, but they did no presented new behaviors, which was interpreted as an absence of elaboration in communication. Therefore, this study validated criterion e) of persistence, and challenged the criterion $\mathrm{f}$ ) of elaboration.

A dog-human artificial communication that showed indications of intentionality was presented by Rossi and Ades (2008). They trained a mongrel dog, Sofia, to communicate her desires such as, food, water, crate, walk, toy and petting, by pressing her paw in a keyboard with arbitrary signs (lexigrams). Many episodes of keyboard use were video-taped in naturalistic situations and the preceding and following behavior were observed. All objects associated to the keys were always in the room as well as the experimenter. It was found a significant correspondence between the preceding behavior directed to the object and the key pressed. Moreover, Sofia gazed at the experimenter frequently, especially after pressing a key, which suggests that the keyboard use is being associated to the behavior that produces in the experimenter, and it may also be a way of calling his attention. When the experimenter did not respond to the Sofia's request, she pressed repeatedly the same key until receiving what she wanted, a kind of persistence behavior. In addition, Sofia do not use the keyboard when alone, which means that she uses it only in social contexts, and, also the communication through the keyboard is influenced by the human visual access to it (Savalli, Resende \& Ades 
(in prep.); Savalli et al., 2009). Therefore, even being a case study, there are evidences that some features of the intentionality are present in this especial communication.

Besides most studies indicate strong evidences that dogs, in fact, communicate with their human partner what they want, a recent study failed to show whether dogs would be also able to communicate in order to inform the location of some hidden object that was important only for the human (Kaminsky et al., 2011). By manipulating the interest in objects that could be shared or not by dog and human, this study showed that the experimenter was able to find the object, based on dog's communicative behaviors, more frequently when dogs were interested themselves in the object than when only the experimenter was interested. This result suggested that dogs communicate to request what they themselves want but not to inform what would be of interest only for the human. However, when the owner of the dog replaced the position of the experimenter in this study, dogs were more motivated, as said by the authors, to indicate the location also of the object that their owners wanted; this was evidenced by the performance of the owner in using dogs' behaviors, and thus in finding the object. It is important to discuss that the outcome observed in this study relied on the human's ability to read the dog's communicative behavior, which do not necessary reflects the ability of the dog to communicate. Therefore, this result should be taken carefully and need further investigation regarding the dog's communicative behaviors.

\subsection{Goals of this study and hypotheses}

Additional studies are still required to validate all operational criteria described by Leavens et al. (2005b) in dogs, and to address the question to what extent they communicate referentially and intentionally. The goal of the present research was to investigate this question by means of a combination of experimental conditions reproducing a naturalistic situation, in which 
dogs needs to communicate with their owner in order to receive a desirable but inaccessible food. Dog's behaviors, especially gaze alternation and getting-attention behaviors, were analyzed in a first experiment when both food and owner were present in the room and when: (i) there is only food or (ii) only owner (the food was taken away from the room), (iii) the owner was back turned, (iv) after communicating the dog received the entire food, or (v) half of food, or, (vi) an undesirable food.

If dogs' behavior towards the food were communicative instead of motivational (i.e., if there was an audience effect), it was expected that when both owner and food were present in the room, more behaviors towards the food would happen than when the owner was absent. If dogs' behaviors were referential, it was expected that when owner and food were present, more communicative behaviors would happen than when the food was taken away, and it should be a transfer of behaviors towards the direction of the door through which the food was taken away.

If dogs were sensitive to the direction of owner's visual direction, when he/she has his/her back turned it was expected that they would modulate their visual and sonorous communicative behaviors in order to increase the odds of being responded. Three possible levels of sensitivity of the direction of owner's visual attention were suggested: 1) one would result in a decrease in the communicative behaviors, this would mean that dogs learned in the past that when the owner is not "attentive", the communication is not effective; 2) another one would result an enhancement or modification of some communication modalities with almost no change in the location, which means that, they would increase the use of sonorous communicative behaviors in order to call the owner's attention; 3) a last one would result in an adjustment of the position, by turn around the owner, so that they could be face-to-face and then present communicative behaviors in the same intensity than when the owner was in front position. 
If dogs meet the criterion of persistence, it was expected that the communicative behaviors would continue when they received half food or the undesirable food, but decrease when they received the entire food. Consequently, after receiving half food or the undesirable food, dogs would present more communicative behaviors than after receiving the entire food. Finally, if dogs meet the criterion of elaboration, a more elaborated repertoire of behaviors (multiple behaviors) would happen more often after receiving half food and the undesirable food than when entire food was given.

A second experiment investigated more carefully the effect of different visual direction of attention of the owner on the dog's communicative behaviors during this same situation in which there was an inaccessible food for the dog and it needed to communicate to their owner in order to receive it. For this experiment the owner was positioned in front of the setting, and in one condition he/she was visually following the dog, and, in the other five conditions he/she presented different degree of behavioral "inattentiveness" to the dog: looking ahead at a marked placed on the wall ahead, or, with eyes closed, or, looking at the sky only with the eyes but with the head ahead, or, gazing at the sky with the head, or, finally, reading a book.

Appropriate comparisons allowed evaluating the effect of different visual directions of the owner on the communicative dog's behaviors. We addressed the question whether dogs distinguish different orientation of body cues of the owner, eyes, head, gaze and availability of the gaze, and, whether dogs differentiate an owner whose gaze was always available from different static directions of visual attention. If dogs take into account the visual direction of the owner it was expected that in conditions during which the gaze of the owner was not directed at the dogs they would modulate their visual and sonorous communicative behaviors in order to increase the odds of being responded (cf. the same two first possibilities as for the back-turned condition of the experiment 1). Effects of the eyes, direction of head and gaze were tested with an expectancy that the more salient a signal would be, the more it would be 
used (see Gaunet, 2008). In the condition in which the owner was gazing at the sky it was especially interesting to investigate whether dogs would tend to gaze in the same direction, since studies show that dogs are able to follow the human's gaze in the horizontal plane (Teglás et al., 2012). 
Chapter 2 - Experiment 1 


\section{Experiment 1}

\subsection{Material and Methods}

\subsubsection{Participants}

Thirteen males and 16 females adult pet dogs (mean age: $5.81 \pm 3.25 \mathrm{yrs}$, Table 2.1 ) took part in the study on the basis of their owner's willingness to participate. Criteria for participating were that owners had to report motivation for food by their dog (i.e., they would sometimes spontaneously behave as requesting food), no signs of distress in unfamiliar places and when the owner leaves home, and only basic obedience training. Dogs were fed 5 to 6 hours before the experiment.

\begin{tabular}{llcc} 
Table 2.1 - Characteristics of the dogs & & \\
\hline Dog & Breed & Sex & Age (in years) \\
\hline Any & Beagle & $\mathrm{F}$ & 9.5 \\
Ash & Border Colie & $\mathrm{F}$ & 5.5 \\
Babi & Cocker & $\mathrm{F}$ & 12 \\
Bartholomeu & Labrador Retriever & $\mathrm{M}$ & 6 \\
Belinha & Shy-tsu & $\mathrm{F}$ & 1.5 \\
Cachorro & Mongrel & $\mathrm{M}$ & 3 \\
Cogumelo & Boxer & $\mathrm{M}$ & 2 \\
Dallas & Border Colie & $\mathrm{M}$ & 6.5 \\
Flavio Mauricio & Mongrel & $\mathrm{M}$ & 3 \\
Jake & Labrador Retriever & $\mathrm{M}$ & 2 \\
Joli & Labrador Retriever & $\mathrm{F}$ & 4 \\
Kiara & Golden Retriever & $\mathrm{F}$ & 3 \\
Lanai & Pitibull & $\mathrm{F}$ & 4 \\
Leao & Mongrel & $\mathrm{M}$ & 6 \\
Luna & Mongrel & $\mathrm{F}$ & 2 \\
Luna2 & Mongrel & $\mathrm{F}$ & 1.5 \\
Mancha & Mongrel+border & $\mathrm{F}$ & 8.8 \\
Mass & Mongrel & $\mathrm{F}$ & 7.5 \\
Nana & Schnauser & $\mathrm{F}$ & 5 \\
Nego & Mongrel & $\mathrm{M}$ & 8 \\
Netuno & American Staffordshire Terrier & $\mathrm{M}$ & 5.5 \\
Nikita & Beagle & $\mathrm{F}$ & 7 \\
Phoebe & Mongrel & $\mathrm{F}$ & 12 \\
Rambo & Mongrel & $\mathrm{M}$ & 11 \\
Rodolfo & Boxer & $\mathrm{M}$ & 3 \\
Serena & Golden Retriever & $\mathrm{F}$ & 6.75 \\
Teka & Labrador Retriever & $\mathrm{F}$ & 12 \\
Tom & Labrador Retriever & $\mathrm{M}$ & 4.5 \\
Wille & Mongrel & $\mathrm{M}$ & 6 \\
\hline & & & \\
& & & 3 \\
\hline
\end{tabular}




\subsubsection{Experimental settings}

Food brought by the experimenter was used. In the experimental room (Figure 2.1), there were two shelves, where the food would be placed; these were of two possible heights to make the food unreachable for dogs of different heights. The experiment was videotaped by two cameras for future behavioral analysis; a unidirectional microphone, placed in the center of the room and attached to a crossbar connecting the two sides of the room, was used. The owner carried a vibrator collar activated by a remote control for the experimenter (C.S.) to signal end of some trials as covertly as possible and to avoid getting the dog's attention as much as possible. Before the experiment started, some options of vegetables were offered to the dog and the most undesirable food was determined. Dogs were allowed to freely explore the experimental and the adjacent room before the familiarization phase. A helper (F. Torello) would bring the dog and the food into the room and then would leave through Door2.
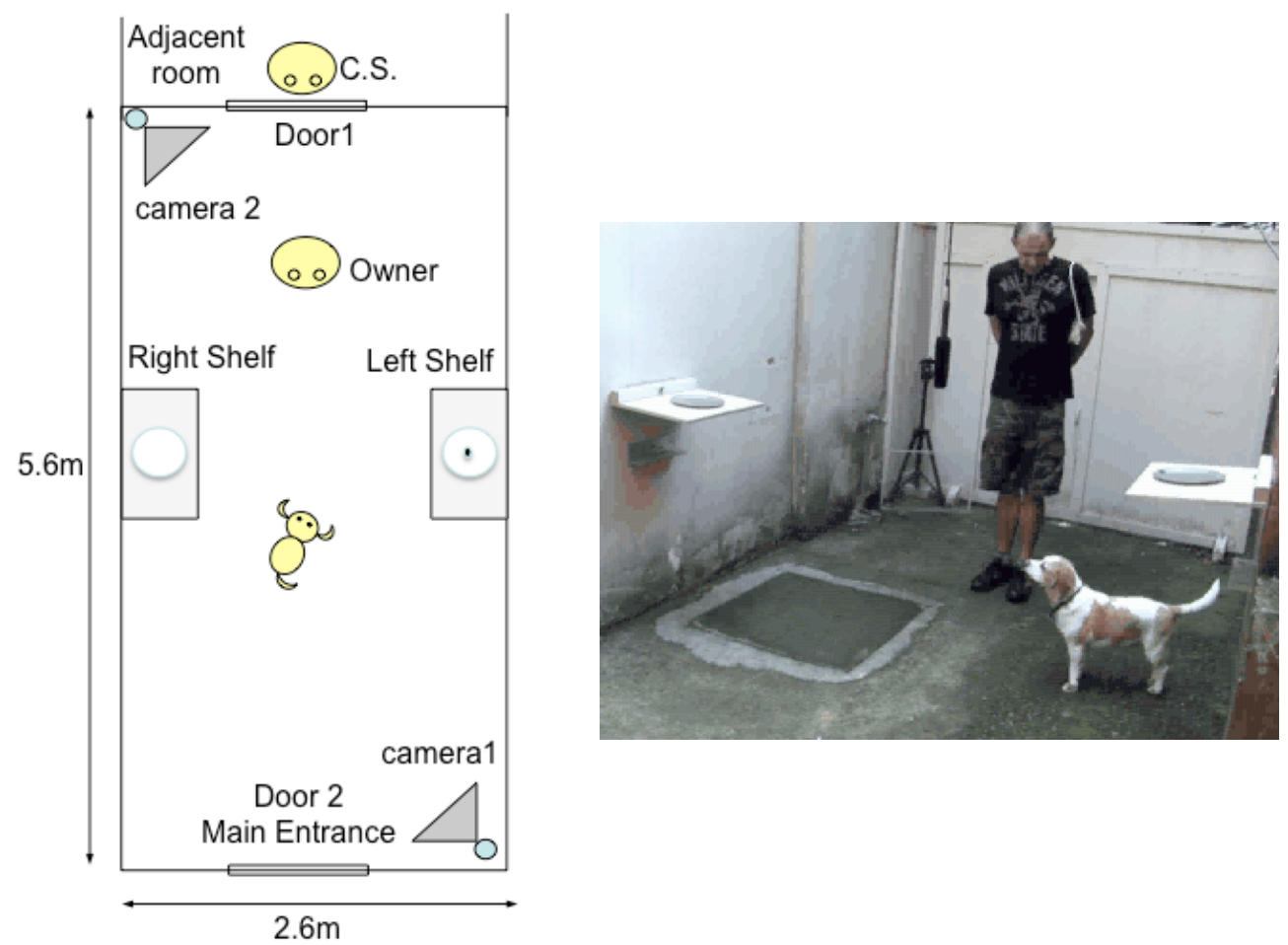

Figure 2.1. Experimental setting. 


\subsubsection{Familiarization phase}

During pre-tests, we observed that dogs remained some period of time focused on Door2 through which the helper went away, before turning to the food. In order to reduce the duration of each experimental condition and avoid fatiguing the dog, we included a familiarization phase that intended to show the dog that, although the helper was the one who would put the food on the shelf, the owner would be the food provider.

The owner stood at the location spotted for him/her (see Figure 2.1) and the helper stood in front of the owner on the other side of the room. The helper put the food on one of the shelves and returned to her place, then the owner immediately called the dog by its name, went towards that shelf, took the food and gave it to the dog. This procedure was repeated by alternating the shelves, until the dog looked at the owner just after the helper put the food on the shelf (average number of repetitions required to get to the criterion as observed by the helper: $11.2 \pm 3.9$ times).

\subsubsection{Experimental phase}

A rough explanation of the six conditions (Figure 2.2) was first given to the owner. All dogs were submitted to the six conditions sequentially during the same day; their order of presentation was counterbalanced across dogs using a block randomization (Kutner et al., 1996) as well as the side of the food (left or right) with the restriction that one side could not be used more than twice consecutively.

The experimenter remained in the adjacent room all the time for signalling and controlling the entries and exits in the experimental room of the helper, the owner and the dog. The body of the owner faced Door2 during all conditions except Owner Turned (defined bellow) during 
which he/she faced Door1; The conditions (see Figure 2.2 for procedural details) included a phase of placement of food or not, and a phase of dog exposition that were:

- Absence of food: a 30-second trial during which only the owner and the dog were present.

- Absence of owner: a 30-second trial during which only the food and the dog were present.

- Owner Turned: a 30-second trial during which the owner (back-turned), the food and the dog were present.

- Food condition: while the food and owner were present, a 30-second trial (pre-delivery phase -with food and owner) was followed by a 30 -second trial (post-delivery phase) after the food had been delivered to the dog by the owner.

- Half-Food condition: while the food and owner were present, a 30-second trial (pre-delivery phase - with food and owner) was followed by a 30-second trial (post-delivery phase) after only half food had been delivered to the dog by the owner while the other half had been returned to the shelf.

- Undesirable Food condition: while the food and owner were present, a 30-second trial (predelivery phase - with food and owner) was followed by a 30-second trial (post-delivery phase) after an undesirable food, placed behind the food before the dog entered the room, had been delivered to the dog by the owner, while the desirable food was left on the shelf.

The pre-delivery phases of Food, Half-Food and Undesirable Food conditions, that were procedurally identical will be called latter Food+Owner condition. 


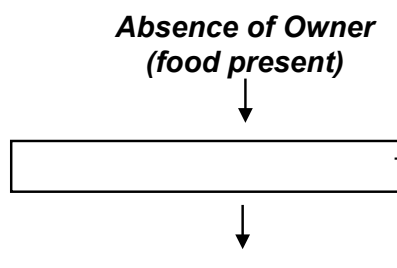

The $\mathrm{H}$ went towards one of the shelves, got the dog's attention, put the food on the shelf and left the room through Door2.

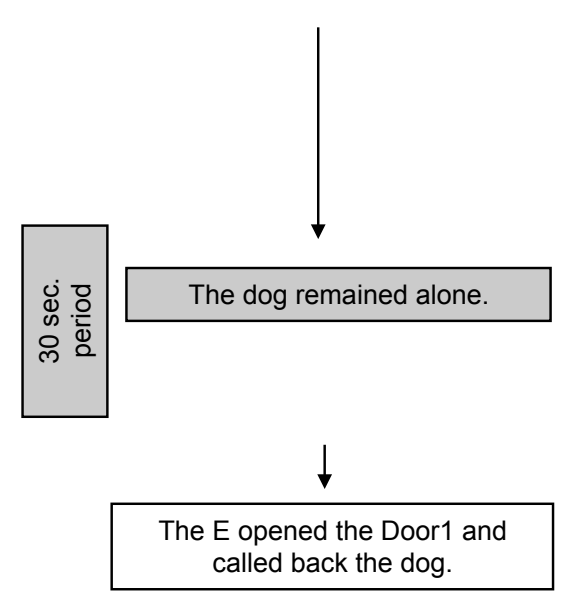

Food

(food \& owner present) $\downarrow$
Absence of Food

(owner present)

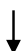

Owner Turned

The $\mathrm{H}$ took the dog to the experimental room with the food.

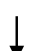

The $\mathrm{H}$ went in the direction of the middle of the 2 shelves, showed the food to the dog and went away with it through Door2.

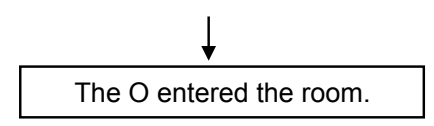

$\downarrow$

The $\mathrm{O}$ stood at his/her defined location, remained quiet, visually following the dog.

\section{$\downarrow$}

The E opened the Door1 and called back the $\mathrm{O}$ and the dog.
The $\mathrm{H}$ went towards one of the shelves, got the dog's attention, put the food on the shelf and left the room through Door2.

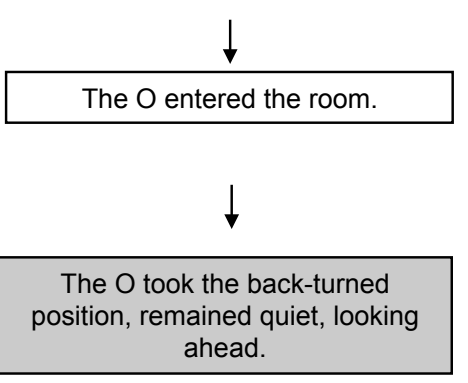

$\downarrow$

The E opened the Door1 and called back the $\mathrm{O}$ and the dog.

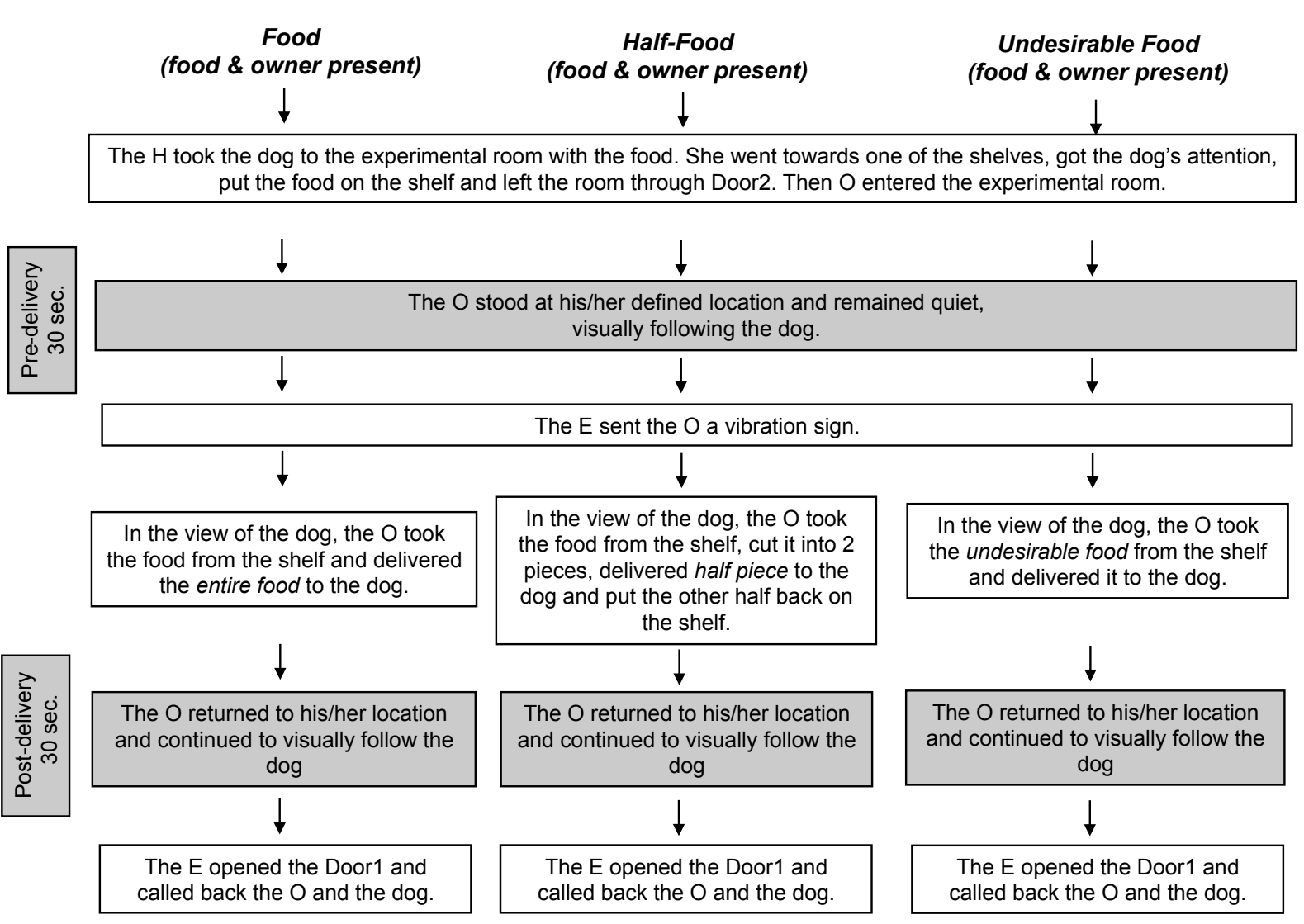

Figure. 2.2. Sequence of actions by the owner $(\mathrm{O})$, helper $(\mathrm{H})$ and experimenter $(\mathrm{E})$ for each condition. 
The experimental phase included intervals of approximately $5 \mathrm{~min}$. between conditions, during which the owner was briefed about the next condition, and lasted approximately 20 min. total. Dogs always received a piece of food in the end of each condition from the owner, in an adventitiously manner, so that they associate the present global context with availability of food from the part of the owner. Since conditions were presented in a random order between dogs, it is unlikely that adventitious food providing selectively affected the conditions (see Results section for confirmation when comparing the first and last predelivery phases among Food, Half-Food and Undesirable Food conditions, according to the order presented for each dog).

\subsubsection{Behaviors collected and variables}

We collected multimodal behaviors and locations of the dogs (see list below) with Actogram Kronos software (Octarés Edition). For each dog, overlapping behaviors (i.e. not mutually exclusive), with or without movements by the dog were defined (see Hare et al., 1998; Miklósi et al., 2000; Gaunet 2008, 2010; Gaunet \& Deputte, 2011):

- Gaze Owner: the dog's head/nose was oriented towards the owner's head face. It was used for all conditions, except Absence of Owner. For the Owner Turned condition, it follows that Gaze Owner happened only when the dog turned around the owner, in a position that it could gaze at the owner's face, i.e., from the Back area (see definition of areas bellow);

- Gaze Food: the dog's head/nose was oriented toward the food. It was used for all conditions except Absence of Food;

- Gaze Alternation between the owner and the food: it consisted in a gaze at the owner's face followed by a gaze at the food (or vice versa) (Leavens et al., 2004b; Leavens et al., 2005b) during Food, Half-Food, Undesirable Food and Owner Turned conditions. For the 
Owner Turned condition, it follows that this behavior happened only when the dog turned around the owner, in a position that it could gaze at the owner's face, i.e., from the Back area (c.f. definition of areas bellow);

- Gaze Door2: the dog's head/nose was oriented toward the Door2. It was used for Absence of Food and the pre-delivery phases of Food, Half-Food and Undesirable Food conditions;

- Gaze Alternation between the owner and the Door2: it consisted in a gaze at the owner's face followed by a gaze at the Door2 (or vice versa). It was used for Absence of Food and the pre-delivery phases of Food, Half-Food and Undesirable Food conditions;

- Gaze Shelves: the dog's head/nose was oriented toward one or the other shelf empty of food (see bellow for computing details). It was used for the Absence of Food condition only;

- Gaze Alternation between the owner and the shelves: it consisted in a gaze at the owner's face followed by a gaze at the shelves (or vice versa) (see bellow for computing details). It was used for the Absence of Food condition only;

- Gaze Owner's back head: the dog's head/nose was oriented toward the owner's back head. It was used for the Owner Turned condition only;

- Gaze Alternation between the owner's back head and the food: it consisted in a gaze at the owner's back head followed directly by a gaze at the food (or vice versa). It was used for the Owner Turned condition only;

- Vocalisation: the dog barked and/or whined. It was used for the pre-delivery phases of Food, Half-Food and Undesirable Food and Owner Turned conditions;

- Mouth Licking: the dog displayed a non-sonorous mouth licking behavior. It was used for the pre-delivery phases of Food, Half-Food and Undesirable Food;

- Sonorous Mouth Licking: the dog displayed a sonorous mouth licking behavior. It was used for all conditions; 
- Contact: the dog touched the owner with any part of its body. It was used for the predelivery phases of Food, Half-Food and Undesirable Food.

The total duration of the 30 -second trials was used to compute relative numbers and durations of all behaviors, except gaze alternation variables that were numbered. The relative duration and number of Gaze Shelves for Absence of Food was computed by taking the average of the relative durations or numbers for the gazes at the left and right empty shelf, for each dog. Likewise, the absolute number of gaze alternation between the owner and the shelves for Absence of Food was computed by taking the average of the numbers of the gaze alternation between the owner and the shelf left, and, between the owner and the shelf right.

For the study of elaborated behaviors, multiple behaviors were defined as Gaze Owner or Gaze Food combined with at least one additional behavior: Contact Owner, Sniff Food (the dog sniffed the food), Paw Food (the dog put the paw on the baited shelf), Point Food with Muzzle (the dog put the paw on the shelf with the muzzle oriented toward the food), Vocalisation, Mouth Licking sonorous or not. Firstly, the proportion of dogs that exhibited multiple behaviors or not for both pre and post-delivery phases of Food, Half-Food and Undesirable Food conditions were computed. Secondly, the absolute number of multiple behaviors for each phase and condition was recorded as complementary information. Finally, dogs were dichotomously classified as having either or not exhibited alternative behavior, i.e. a behavior exhibited during post-delivery phase not exhibited during pre-delivery phase; the proportions of dogs that exhibited alternative behaviors for Food, Half-Food and Undesirable Food conditions were computed. 


\subsubsection{Locations collected and variables}

In order to evaluate if dogs used their own location as a local enhancement signal (Gaunet \& Deputte, 2011), the duration spent in mutually exclusive areas (see Figure 2.3) were computed for each dog, using the location of the two anterior legs. A transparent mask with the areas drawn placed onto the computer screen was used. The areas used were:

- Food area: when the dog was in the $1.2 \mathrm{~m} \times 1.8 \mathrm{~m}$ rectangle closest to the baited shelf; it was used for all conditions except Absence of Food;

- Door2 area: when the dog was in the $0.8 \mathrm{~m} \times 1.1 \mathrm{~m}$ rectangle closest to Door2. It was used for Absence of Food and the pre-delivery phases of Food, Half-Food and Undesirable Food conditions;

- Shelves area: when the dog was in the areas of the shelves (see bellow for computing details) (two rectangles of $1.2 \mathrm{~m}$ x $1.8 \mathrm{~m}$ ). It was used for Absence of Food only;

- Back area: when the dog was in the $2.6 \mathrm{~m}$ x $0.8 \mathrm{~m}$ behind the position of the owner. It was used for the Owner Turned condition only.

The total duration of the 30 -second trials was used to compute relative duration of time spent in each area. The duration of time spent in the Shelves area for Absence of Food was computed by taking the average of the durations spent in the left and right area in order to correct its surface when compared to the Food area for other conditions. To make other surfaces comparable (e.g. Food area with Door2 area), a correction that represented an index of proportionality of surfaces was applied (see Supplementary 3 for computing details). 


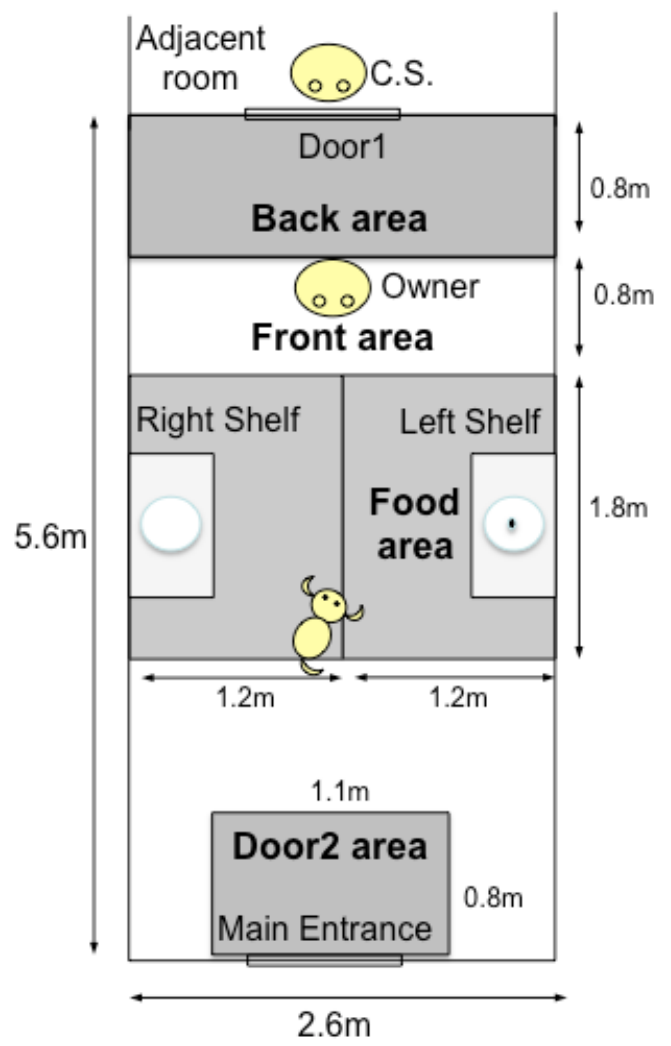

Figure 2.3. Division of the experimental room in the areas studied

\subsubsection{Location and behavior combined collected and variables}

The relative durations of time (related to the 30-second) of combinations of certain behaviors and locations were computed. These combinations were chosen on the basis of the variables for behaviors and location alone that appeared more than zero (see Statistical analysis section):

- Food area combined with Gaze Owner for all conditions except Absence of Owner, Absence of Food and Owner Turned, with Gaze owner's back head for Owner Turned, with Gaze Food for all conditions except Absence of Food, with Gaze Alternation between the owner and the food for all conditions except Absence of Owner, Absence of Food and Owner Turned, with Gaze Alternation between the owner's back head and the food for Owner Turned, and with Sonorous Mouth Licking for all conditions; 
- Door2 area combined with Gaze Door2 and with Gaze Alternation between the owner and the Door2 for Absence of Food;

- Shelves area combined with Gaze Owner, with Sonorous Mouth Licking, with Gaze Shelves and with Gaze Alternation between the owner and the shelves for Absence of Food;

- Back area combined with Gaze Owner, with Gaze Food and with Sonorous Mouth Licking for Owner Turned.

Note that for simplifying the text, we refer below to relative or absolute numbers and durations of variables as "numbers" and "durations".

\subsubsection{Statistical analysis}

All variables were analyzed by non-parametric tests (Hollander \& Wolf, 1998). In order to evaluate if there was a learning effect across conditions, the first and the last pre-delivery phases (for Food, Half-Food or Undesirable Food conditions), according to the order presented for each dog, were compared for 4 main relevant behaviors (durations of Gaze Owner, Gaze Food and Food area; numbers of Gaze Alternation), by the two samples Wilcoxon rank-signed test.

To control the stability of the experimental manipulations the three pre-delivery phases for Food, Half-Food or Undesirable Food conditions were compared using the Friedman's test regarding the following variables: the durations and numbers of Gaze Owner, Gaze Food, the numbers of Gaze Alternation between the owner and the food, the durations and numbers of Vocalisation, sonorous or not Mouth Licking and Contact, and the durations of time spent in the Food area. Since no differences were found (see Results section) the data of pre-delivery phases of these three conditions were pooled and called "Food+Owner" (see Figure 2.4). 


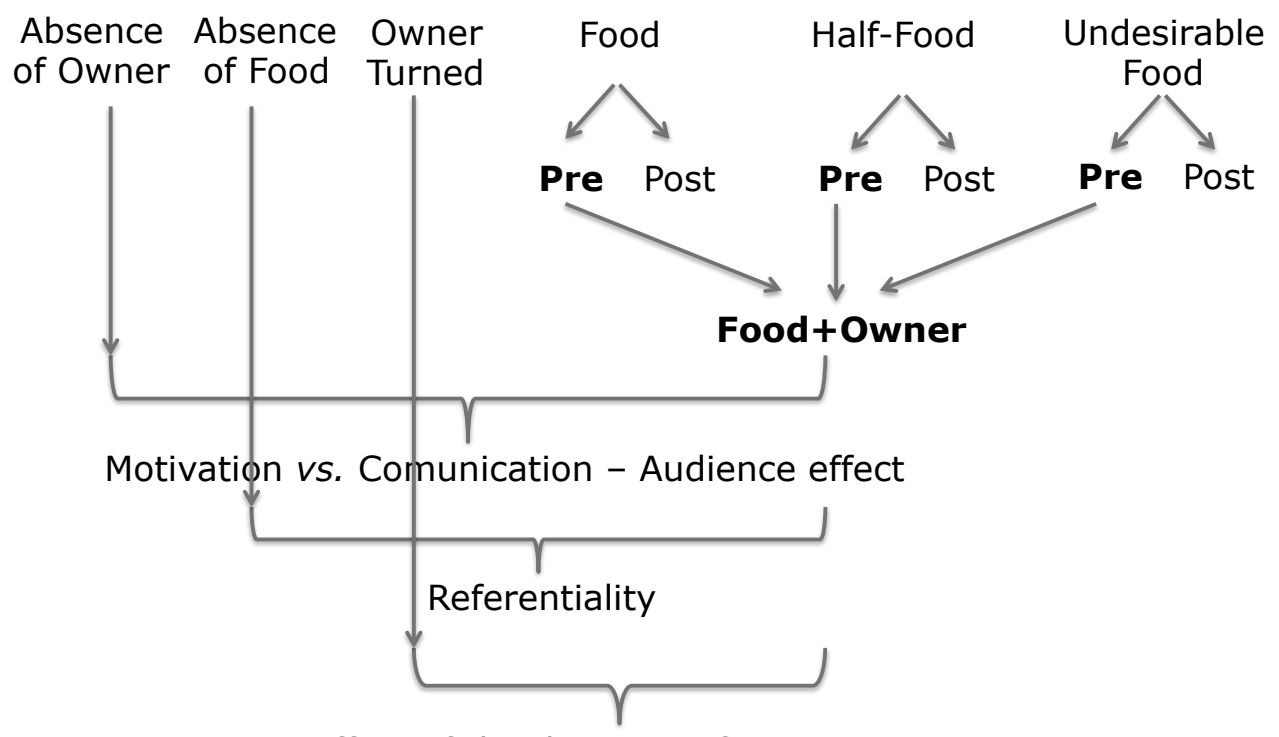

Effect of the direction of attention

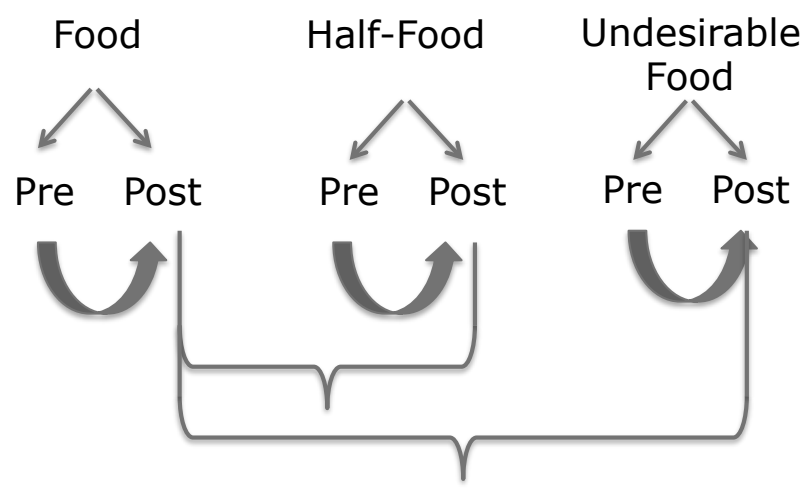

Persistence and Elaboration

Figure 2.4. Comparisons between the conditions to test the criteria of referentiality and intentionality.

To test the communication/audience effect $v s$. motivation, the durations and numbers of the same 14 variables as previously were tested as being significantly different from zero in Food+Owner condition; the one-sample Wilcoxon rank-signed test was applied.

All comparisons between two conditions regarding behaviors and locations (and the combinations of them) were done by means of two samples Wilcoxon rank-signed test.

Firstly, to test for communication/audience effect $v s$. motivation, Food+Owner was compared to Absence of Owner (see Figure 2.4) for the variables that were found more than zero. Secondly, to evaluate the referentiality of the variables that were more than zero, 
Food+Owner was compared to Absence of Food (see Figure 2.4); for that analysis, to the comparisons applied to the more than zero behaviors, we added additional comparisons:

- duration and number of Gaze Food during Food+Owner vs. those of Gaze Door2 during Absence of Food, and, the number of Gaze Alternation between the owner and the food during Food+Owner vs. between the owner and the Door2 during Absence of Food, to evidence if dogs would communicate about the food that was behind the door as they do when it was on the shelf;

- duration and number of Gaze Door2 and number of Gaze Alternation between the owner and Door2 during Food+Owner vs. during Absence of Food to evidence if dogs would be interested in the Door2 the same way in both conditions;

- duration and number of Gaze Food during Food+Owner vs. those of Gaze Shelves during Absence of Food, and, the numbers of Gaze Alternation between the owner and the food during Food+Owner vs. between the owner and the shelves during Absence of Food to evidence if dogs would refer more to the baited shelf than to empty shelves;

- duration of time spent in Door2 area during Food+Owner vs. during Absence of Food to evidence if dogs would spend more time in Door2 area when the food was behind Door2 than when it was in the room;

- duration of time spent in Food area during Food+Owner vs. in Door2 area during Absence of Food to evidence if dogs would use their bodies as referential cues to indicate the place of food (with sizes of both areas corrected);

- duration of time spent in Food area during Food+Owner vs. in Shelves area during Absence of Food to evidence if dogs would spend less time in the shelves area when there was no food (with sizes areas corrected).

Thirdly, to test the effect of the direction of attention Food+Owner was compared to Owner Turned (see Figure 2.4). To the more than zero behaviors, we added additional comparisons: 
- duration and number of Vocalisations, (although this behavior was not significantly greater than zero in Food+Owner, see Results) to evidence if dogs would increase this sonorous behavior in Owner Turned conditions in order to call the owner's attention;

- duration and number of Gaze Owner during Food+Owner vs. those of Gaze Owner's back head during Owner Turned, and, the number of Gaze Alternation between the owner and the food during Food+Owner vs. between the owner's back head and the food during Owner Turned to evidence if dogs would communicate more when their owners were facing the setting than when they were not;

- duration of time spent in Back area during Food+Owner vs. during Owner Turned to evidence if dogs would spent more time in Back area when their owners were turned back.

Fourthly and finally, to evaluate persistence (see Figure 2.4), for the more than zero behaviors were performed comparisons between pre vs. post-delivery phase for Food, Half-Food and Undesirable Food conditions, as well as comparisons between the post-delivery phases of Food and Half-Food conditions, and, of Food and Undesirable Food conditions.

For elaboration of behaviors (see Figure 2.4), to compare the proportion of dogs that exhibited multiple behaviors among the three pre-delivery phases in Food, Half-Food and Undesirable Food conditions, the Cochran's Q test was applied. The pre vs. post-delivery phases comparisons for Food, Half-Food and Undesirable Food condition, as well as the comparisons between the post-delivery phases of Food with Half-Food or Undesirable Food conditions were done by a McNemar's test. Regarding the number of multiple behaviors, the three predelivery phases of Food, Half-Food and Undesirable Food conditions were compared by Friedman's test, and the comparisons of pre vs. post-delivery phases as well as the comparisons between the post-delivery phases of Food with Half-Food or Undesirable Food conditions were done by two samples Wilcoxon rank-signed test. Finally, to compare the 
proportion of dogs that exhibited alternative behaviors during post-delivery phase not exhibited during pre-delivery phase between Food, Half-Food and Undesirable Food conditions, the Cochran's Q test was applied.

For the persistence and elaboration hypotheses, multiple comparisons were done for the same dependent variables ( 5 comparisons: 3 pre $v s$. post comparisons and 2 comparisons in post delivery-phases -i.e., Food vs. Half-Food and Food vs. Undesirable Food) and then false discovery rate correction was applied (FDR BL adjustment, Benjamini et al., 2001).

As for the analyses for behaviors and location alone, duration of time of the main location and behavior combinations (Food area with Gaze Owner, with Gaze Food, with Gaze Alternation between the owner and the food and with Sonorous Mouth licking) were at first evaluated whether occurring more than zero as an indication of communication/audience effect. Likely, as for the analyses of behaviors and location alone, firstly, to test for communication/audience effect, Food+Owner was compared to Absence of Owner for the combinations of Food area with Gaze Food and with Sonorous Mouth Licking. Secondly, to evaluate the referentiality of the combinations of location and behavior, the following comparisons were done:

- the combinations of Food area with Gaze Owner and with Sonorous Mouth Licking during Food+Owner $v s$. of Shelves area with Gaze Owner and with Sonorous Mouth Licking during Absence of Food, respectively;

- the combination of Food area with Gaze Food during Food+Owner vs. of Door2 area with Gaze Door2 during Absence of Food (corrected by the different sizes of areas);

- the combination of Food area with Gaze Alternation between the owner and the food during Food+Owner vs. of Door2 area with Gaze Alternation between the owner and the Door2 during Absence of Food (corrected by the different sizes of areas);

- the combination of Food area with Gaze Food during Food+Owner $v s$. of Shelves area with Gaze Shelves during Absence of Food; 
- the combination of Food area with Gaze Alternation between the owner and the food during Food+Owner vs. of Shelves area with Gaze Alternation between the owner and the shelves during Absence of Food.

Thirdly, to test the effect of the direction of attention on the combination of location and behavior the following comparisons for durations were done:

- the combination of Food area with Gaze Food, with Vocalisations and with Sonorous Mouth Licking during Food+Owner vs. during Owner Turned;

- the combination of Food area with Gaze Owner during Food+Owner vs. of Food area with Gaze Owner's back head during Owner Turned;

- the combination of Food area with Gaze Alternation between the owner and the food during Food+Owner vs. with Gaze Alternation between the owner's back head and the food during Owner Turned;

- the combination of Food area with Gaze Owner, with Gaze Food and with Sonorous Mouth Licking during Food + Owner vs. of Back area with Gaze Owner, with Gaze Food and with Sonorous Mouth Licking during Owner Turned, respectively (with size of areas corrected).

Fourthly, to evaluate persistence on combinations of Food area with Gaze Owner, Gaze Food, Gaze Alternation between the owner and the food and with Sonorous Mouth Licking, were performed comparisons between pre and post-delivery phases for Food, Half-Food and Undesirable Food conditions, as well as comparisons between the post-delivery phases of Food and Half-Food conditions, and, of Food and Undesirable Food conditions.

Finally, we studied elaborated behaviors for both the multiple and alternative (see above for definition) behaviors that happened in Food area. The proportion of dogs that exhibited multiple behaviors in Food area and the number of multiple behaviors in Food area were compared among the three pre-delivery phases in Food, Half-Food and Undesirable Food and 
between pre $v s$. post-delivery phases for three conditions, as well as between the post-delivery phases of Food with Half-Food or with Undesirable Food conditions. The proportions of dogs that exhibited alternative behaviors in Food area during post-delivery phase not exhibited during pre-delivery phase were also compared between the three conditions. The same statistical tests as for the analyses of behaviors and locations alone were used for the combination of location and behaviors (including FDR BL adjustment for persistence and elaboration).

For all statistical tests the SAS software 9.2, SAS Institute Inc., Cary, NC, USA and the significance level considered was 5\%.

Two trained observers recorded the occurrences of behaviors independently. The interobserver agreement was assessed for the most important behaviors and location by means of parallel coding of $34 \%$ of the sample for duration. Kendall's concordance coefficient was calculated for Food condition (by taking together the two phases). For Gaze Owner, Gaze Food, Gaze Door2 and Food area this yielded $W=0.99$, and for Door2 area this yielded $W=1$. Results indicated a good agreement between raters.

On the figures, data are represented by the boxplots, whiskers extend to the smallest and largest values and exclude outliers.

\subsection{Results}

\subsubsection{Comparisons among the pre-delivery phases}

The comparison of the first and the last pre-delivery phase for Food, Half-Food or Undesirable Food conditions, according to the order presented for each dog, for the durations 
and numbers of the four variables did not reveal any learning effect $(-52.5<\mathrm{T}<-14.5$, $0.264<\mathrm{p}<0.760$; see Supplementary 1 - Table 1$)$.

The three pre-delivery phases for Food, Half-Food and Undesirable Food conditions did not differ for the fourteen variables analyzed (duration: $0.13<\chi^{2}<2.82, d f=2,0.244<\mathrm{p}<0.937$; number: $0.40<\chi^{2}<4.01, d f=2,0.134<\mathrm{p}<0.820$; see Supplementary 1 - Table 2). Given these results, the data of pre-delivery phases of these three conditions were pooled by dog and by variable (using the median of the 3 values); this data set was named "Food+Owner" condition for comparisons with Absence of Owner, Absence of Food and Owner Turned condition.

\subsubsection{Communication/Audience effect vs. Motivation}

For Food + Owner, the durations and numbers of Gaze Owner, Gaze Food and Sonorous Mouth Licking were significantly greater than zero (duration: 10.5<T<217.5, $<<0.030$; number: $10.5<\mathrm{T}<217.5, \mathrm{p}<0.030)$ as well as the number of Gaze Alternations between the owner and the food $(T=162.5, \mathrm{p}<0.0001)$ and the duration in Food area $(T=189, \mathrm{p}<0.0001)$. Vocalisation, silent Mouth Licking and Contact did not differ from zero (for durations and numbers: $0.5<\mathrm{T}<5,0.125<\mathrm{p}<1.000)$, and were not analyzed afterwards, except for vocalisation that was analyzed only for investigating the effect of direction of owner's attention, since it is a sonorous behavior. See Supplementary 1 - Table 3 for descriptive measures and statistics.

The duration of Gaze Food was significantly greater when both owner and food were in the room than when the owner was absent $(\mathrm{T}=95.5, \mathrm{p}=0.037$; Figure 2.5$)$. The same result was found for the durations of Sonorous Mouth Licking and Food area $(13<\mathrm{T}<107$, $0.012<\mathrm{p}<0.031)$; no difference was found for the numbers of Gaze Food and Sonorous Mouth 
Licking $(9<\mathrm{T}<10.5,0.109<\mathrm{p}<0.803)$. See Supplementary 1 - Table 4 for descriptive measures and statistics.

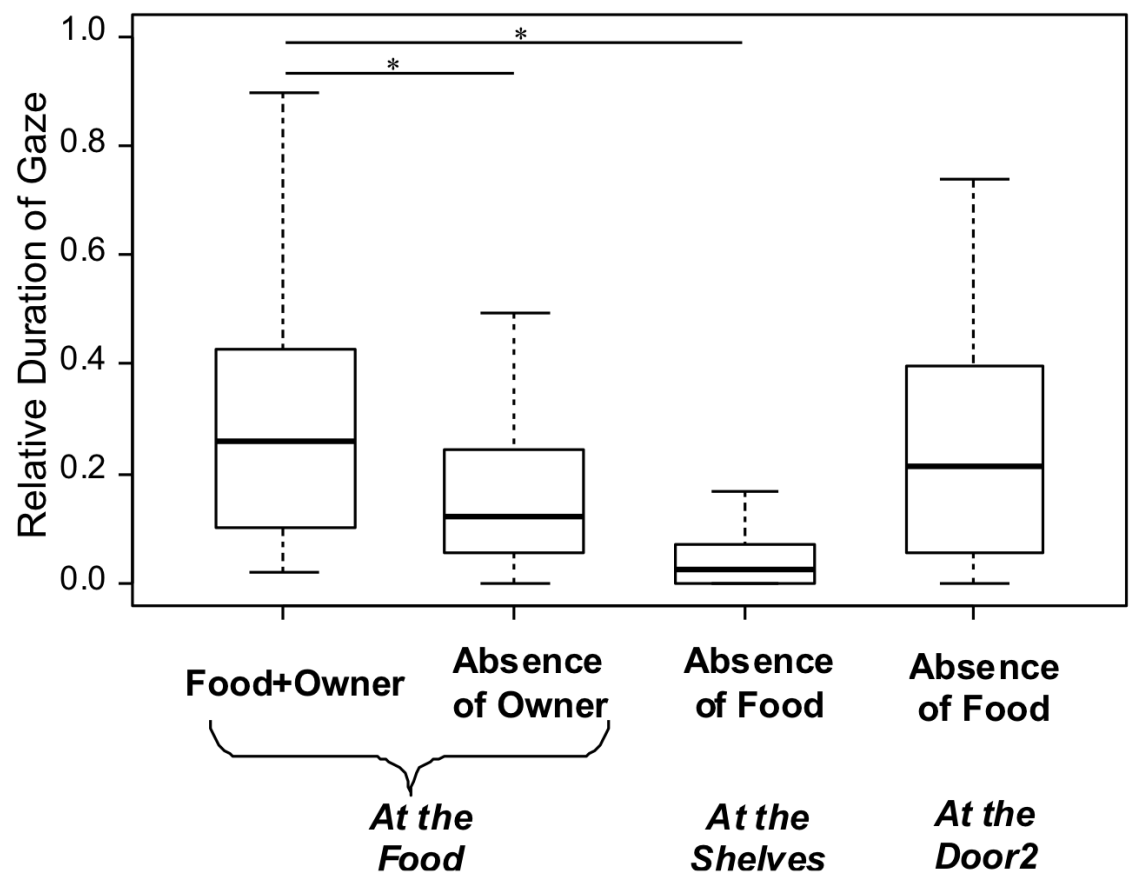

Figure 2.5. Relative duration of Gaze Food during Food+Owner and Absence of Owner, and, relative duration of Gaze Shelves and Gaze Door2 during Absence of Food.

The analyses of location and behavior combined showed that the durations of time spent in Food area combined with Gaze Owner, with Gaze Food and with Gaze Alternation between the owner and the food were significantly greater than zero during Food+Owner condition (duration: $68<\mathrm{T}<150, \mathrm{p}<0.0001$; see Supplementary 1 - Table 3). The combination of Food area with Vocalisation was not significantly greater than zero during Food+Owner condition $(\mathrm{T}=3, \mathrm{p}=0.250)$ and the combination of Food area with Sonorous Mouth Licking was not tested since no dog presented this combination; no other analyses were performed for these combinations except for investigating the effect of direction of owner's attention, since they are sonorous behaviors. 
The duration of time spent in Food area combined with Gaze Food did not differ when both owner and food were in the room or when the owner was absent $(\mathrm{T}=32, \mathrm{p}=0.452$; see Supplementary 1 - Table 4).

\subsubsection{Referentiality}

The duration of Gaze Owner when both food and owner were present was greater than when the food was absent $(\mathrm{T}=92.5, \mathrm{p}=0.043)$; the difference for numbers did not reach the significance level $(T=69, p=0.098)$. There was no effect of the absence of the food on the duration and number of Sonorous Mouth Licking (duration: $\mathrm{T}=6, \mathrm{p}=0.520$, number: $\mathrm{T}=0.5$, $\mathrm{p}=1.000$ ). See Supplementary 1 - Table 5 for descriptive measures and statistics of the Referentiality section.

The duration of Gaze Door2 (behind which was the food) during Absence of Food did not differ from that of Gaze Food during Food+Owner $(\mathrm{T}=5.5$, $\mathrm{p}=0.908$; Figure 2.5), while the number was smaller when the food was absent than present $(T=94, p=0.014)$. The number of Gaze Alternation between the owner and the food during Food+Owner was significantly greater than between the owner and the Door2 when the food went away with the helper $(\mathrm{T}=116, \mathrm{p}=0.003$; Figure 2.6).

The duration and number of Gaze Door2 during Food+Owner was significantly smaller than that during Absence of Food (duration: $\mathrm{T}=-124, \mathrm{p}=0.003$, number: $\mathrm{T}=-94.5, \mathrm{p}=0.028$ ). Likewise, the number of Gaze Alternation between the owner and the Door2 during Food + Owner was significantly smaller than during Absence of Food $(T=-87, p=0.0006)$.

The duration and number of Gaze Food during Food+Owner was significantly greater than those of Gaze Shelves during Absence of Food (duration: $\mathrm{T}=197, \mathrm{p}<0.0001$, Figure 2.5, number: $\mathrm{T}=186.5, \mathrm{p}<0.0001)$. The number of Gaze Alternation between the owner and the 
food when both were present was significantly greater than between the owner and the shelves when the food was absent $(\mathrm{T}=143, \mathrm{p}<0.0001$; Figure 2.6).

The duration of time spent at Door2 when the food went away with the helper was greater than when both food and owner were present $(T=-22.5, p=0.019)$, but still smaller than the time spent in the Food area during Food + Owner $(\mathrm{T}=103, \mathrm{P}=0.010)$. The duration of time spent in the Food area in Food + Owner was significantly greater than that spent in the Shelves area when the food was absent $(\mathrm{T}=158, \mathrm{p}<0.0001)$.

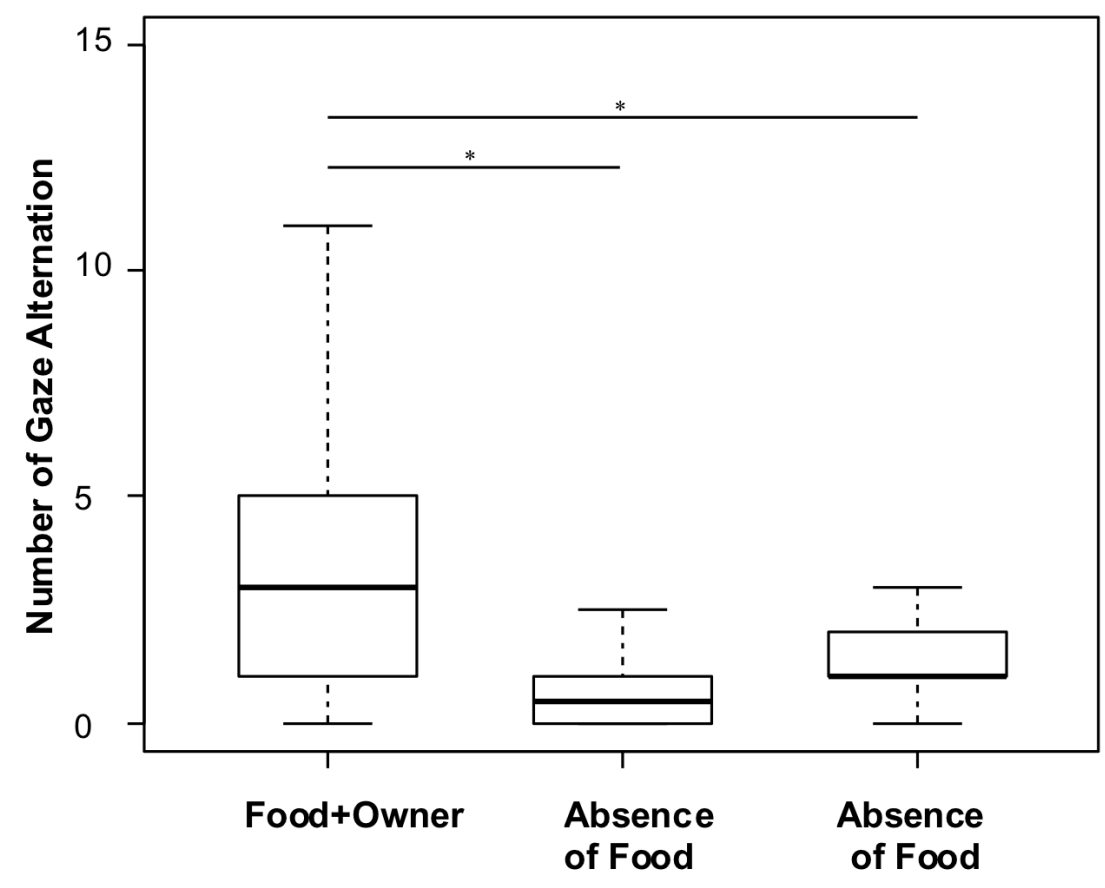

(Owner/Food) (Owner/Shelves) (Owner/Door2)

Figure 2.6. Numbers of gaze alternation: between the owner and the food during Food+Owner; between the owner and the shelves, and, between the owner and the Door2 during Absence of Food.

The analyses of location and behavior combined shows that the duration of time spent in Food area combined with Gaze Owner when both food and owner were present was greater than 
that spent in Shelves area combined with Gaze Owner when the food was absent $(T=92$, $\mathrm{p}=0.034)$.

The duration of time spent in Door2 area combined with Gaze Door2 during Absence of Food was greater than during the Food + Owner condition $(\mathrm{T}=-22.5, \mathrm{p}=0.004)$, but it did not differ from that spent in Food area combined with Gaze Food during Food+Owner $(\mathrm{T}=34.5$, $\mathrm{p}=0.273$; Figure 2.7a). However, the duration of time spent in Door2 area combined with Gaze Alternation between the owner and the Door2 during Absence of Food was significantly smaller than that spent in Food area combined with Gaze Alternation between the owner and the food during Food + Owner $(\mathrm{T}=68, \mathrm{p}<0.0001)$.

Finally, the durations of time spent in Food area combined with Gaze Food and with Gaze Alternation between the owner and the food when both food and owner were present were greater than those spent in Shelves area combined with Gaze Shelves (Figure 2.7b) and with Gaze Alternation between the owner and the shelves when the food was absent, respectively $(89.5<\mathrm{T}<143, \mathrm{p}<0.0003)$.

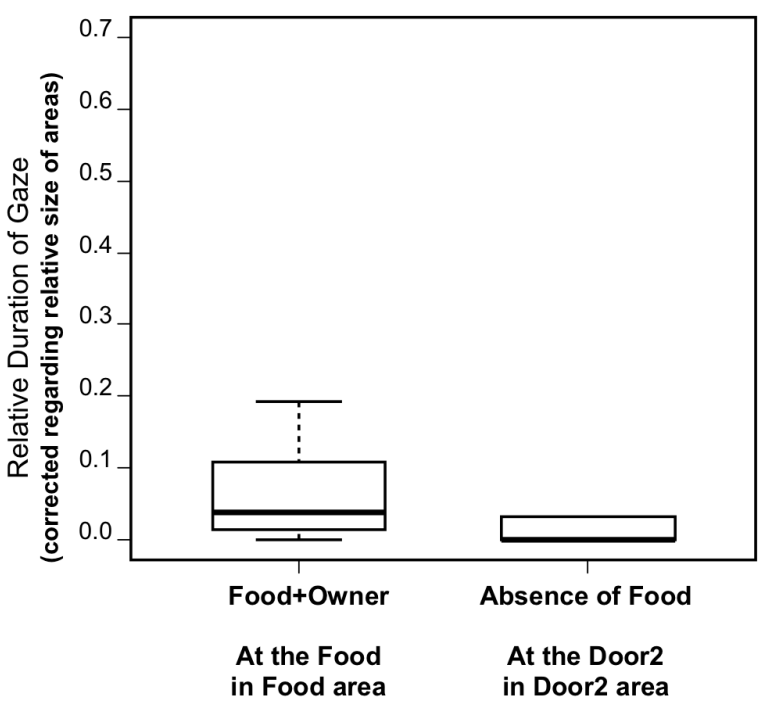

(a)

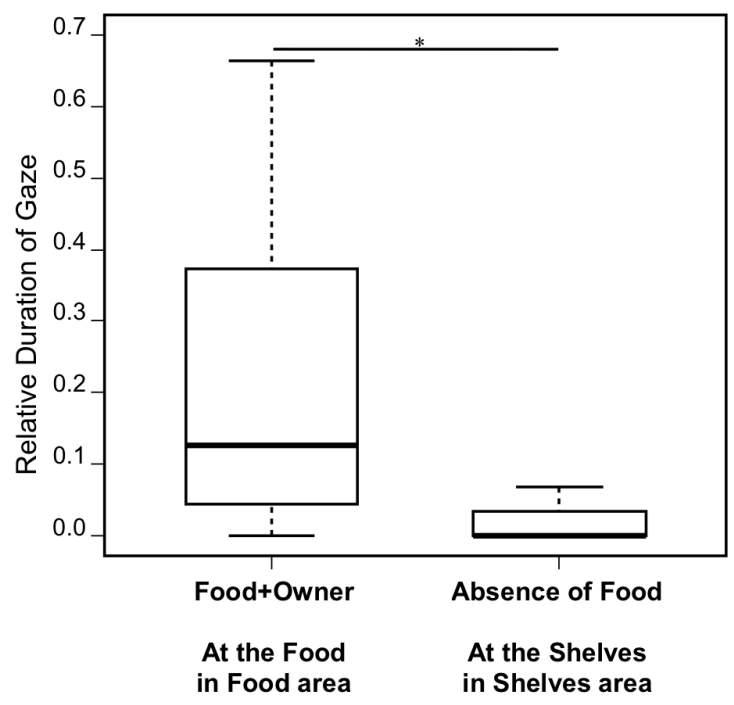

(b)

Figure 2.7. (a) Relative duration of Gaze Food in Food area during Food+Owner and of Gaze Door2 in Door2 area during Absence of Food, corrected regarding the relative size of areas; (b) Relative duration of Gaze Food in Food area during Food+Owner and of Gaze Shelves in Shelves area during Absence of Food. 


\subsubsection{Effect of the direction of attention}

The duration and number of Gaze Owner was significantly greater when the owner was facing the experimental layout than when he/she has his/her back turned (duration: $\mathrm{T}=175.5$, $\mathrm{p}<0.0001$, number: $\mathrm{T}=177, \mathrm{p}<0.0001)$. Similarly, the number of Gaze Alternation between the owner and the food during Food+Owner was significantly greater than during Owner Turned, i.e. when dogs were in the Back area $(T=166, \mathrm{p}<0.0001)$. The durations and numbers of Gaze Food, Vocalisation and Sonorous Mouth Licking did not differ between Food+Owner and Owner Turned conditions (duration: $-1.5<\mathrm{T}<30,0.526<\mathrm{p}<0.953$; number: $-2.5<\mathrm{T}<63.5$, $0.151<\mathrm{p}<1.000)$. See Supplementary 1 - Table 6 for descriptive measures and statistics for the effects of the direction of attention section.

The duration and number of Gaze Owner during Food+Owner was significantly greater than that of Gazes Owner's back head during Owner Turned (duration: $\mathrm{T}=153.5, \mathrm{p}=0.0003$, number: $\mathrm{T}=175.5, \mathrm{p}<0.0001)$; similarly, the number of Gaze Alternations between the owner and the food during Food+Owner was greater than between the owner's back head and the food during Owner Turned $(\mathrm{T}=99, \mathrm{p}=0.005$, Figure 2.8). 


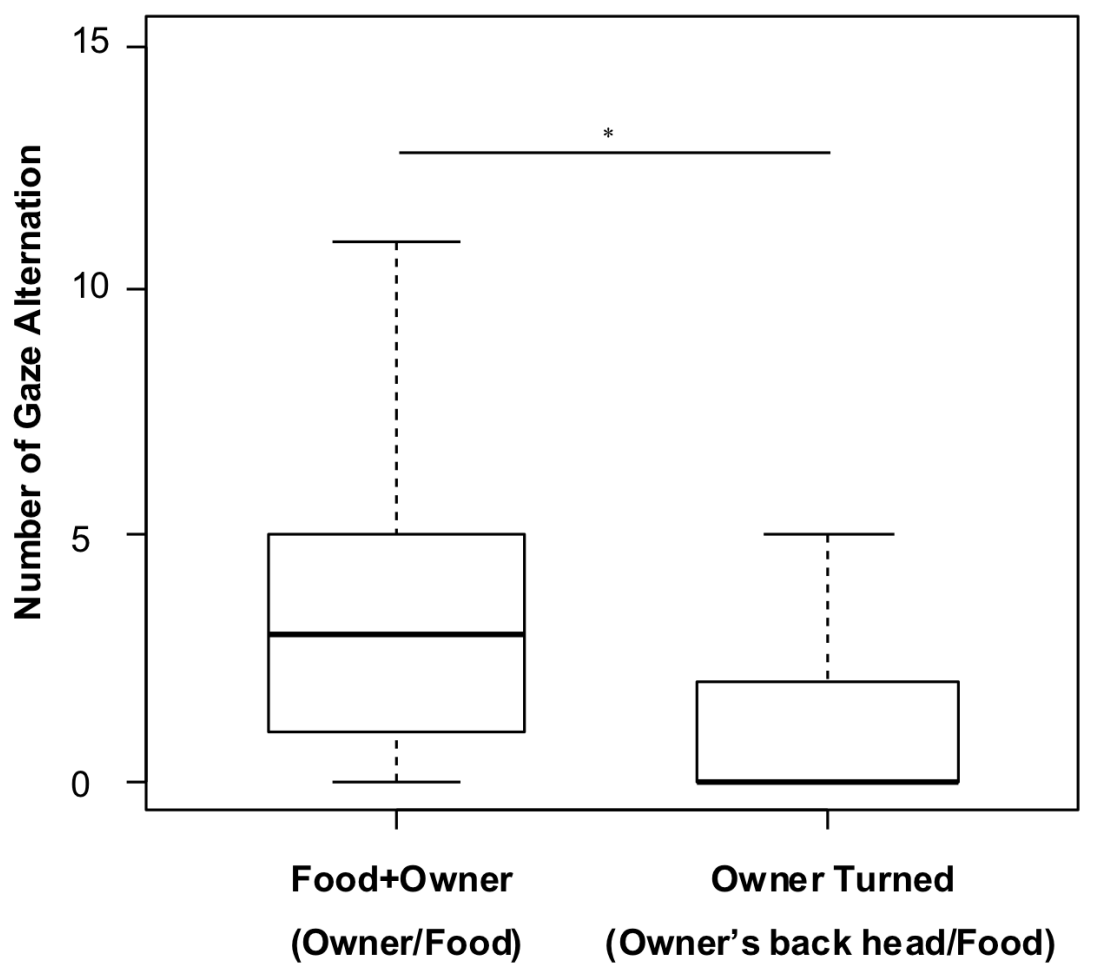

Figure 2.8. Numbers of gaze alternation between the owner and the food during Food+Owner and between the owner's back head and the food during Owner Turned.

The duration of time spent in Food area did not differ between Food+Owner and Owner Turned conditions $(\mathrm{T}=45, \mathrm{P}=0.339)$. However, dogs spent more time in the Back area during Owner Turned than during Food + Owner $(\mathrm{T}=-76, \mathrm{p}=0.017)$.

The analyses of location and behavior combined show that the duration of time spent in Food area combined with Gaze Food, with Vocalisation and with Sonorous Mouth Licking did not differ between Food + Owner and Owner Turned conditions $(-6.5<\mathrm{T}<0,0.125<\mathrm{p}<1)$.

The durations of time spent in Food area combined with Gaze Owner and with Gaze Alternation between the owner and the food during Food+Owner condition did not differ from those spent in Food area combined with Gaze Owner's back head and with Gaze 
Alternation between the owner's back head and the food during Owner Turned condition, respectively $(40<\mathrm{T}<74.5,0.090<\mathrm{p}<0.141)$.

The durations of time spent in Food area combined with Gaze Owner, with Gaze Food and with Gaze Alternation between the owner and food during Food+Owner condition were greater than those spent in Back area combined with Gaze Owner, with Gaze Food and with Gaze Alternation between the owner and the food during Owner Turned condition, respectively $(78.5<\mathrm{T}<136, \mathrm{p}<0.029)$. However, the duration of time spent in Food area combined with Sonorous Mouth Licking during Food+Owner condition did not differ from that spent in Back area combined with Sonorous Mouth Licking during Owner Turned condition $(\mathrm{T}=-5, \mathrm{P}=0.125)$.

\subsubsection{Persistence}

After FDR BL adjustment for both duration and number of Gaze Owner, neither pre vs. post comparisons for the three conditions nor comparisons between post-delivery phases of Food with Half-Food conditions, and, of Food with Undesirable Food conditions differed (duration: $-47.5<\mathrm{T}<105.5,0.020<\mathrm{p}<0.800$; number: $-9<\mathrm{T}<92.5,0.015<\mathrm{P}<0.916)$. See Supplementary $1-$ Table $7 \mathrm{a}$ for descriptive measures and statistics for the persistence effects on behaviors and location.

After FDR BL adjustment, the durations and numbers of Gaze Food decreased significantly from pre to post-delivery phases for both Food and Half-Food conditions (duration: $130<\mathrm{T}<157.5, \mathrm{p}<0.001$; number: $115.5<\mathrm{T}<155.5, \mathrm{p}<=0.003$ ), but they did not differ for Undesirable Food condition (duration: $\mathrm{T}=59, \mathrm{p}=0.184$, number: $\mathrm{T}=23.5, \mathrm{p}=0.513$ ). There was no difference between post-delivery phases of Food and Half-Food conditions for this behavior (duration: $\mathrm{T}=-17.5, \mathrm{p}=0.698$, number: $\mathrm{T}=78.5, \mathrm{p}=0.057$ ). However, while the 
duration of Gaze Food was significantly longer during post-delivery phase for Undesirable Food than for Food $(\mathrm{T}=101.5, \mathrm{p}=0.025)$, the numbers of this behavior did not differ after correction $(\mathrm{T}=80, \mathrm{p}=0.039)$.

After the FDR BL adjustment, the Gaze Alternation between the owner and the food significantly decreased from pre to post-delivery phase in Food condition $(T=107, p=0.004)$ while such difference was not found for Half-Food and Undesirable Food $(20<\mathrm{T}<21.5$, $0.551<\mathrm{p}<0.592$, see Figure 2.9). This behavior was significantly greater during post-delivery phase of Half-Food than of Food $(\mathrm{T}=110.5, \mathrm{p}=0.009)$, whereas no difference between postdelivery phases for Food and Undesirable Food conditions was found $(\mathrm{T}=62.5, \mathrm{p}=0.110)$.

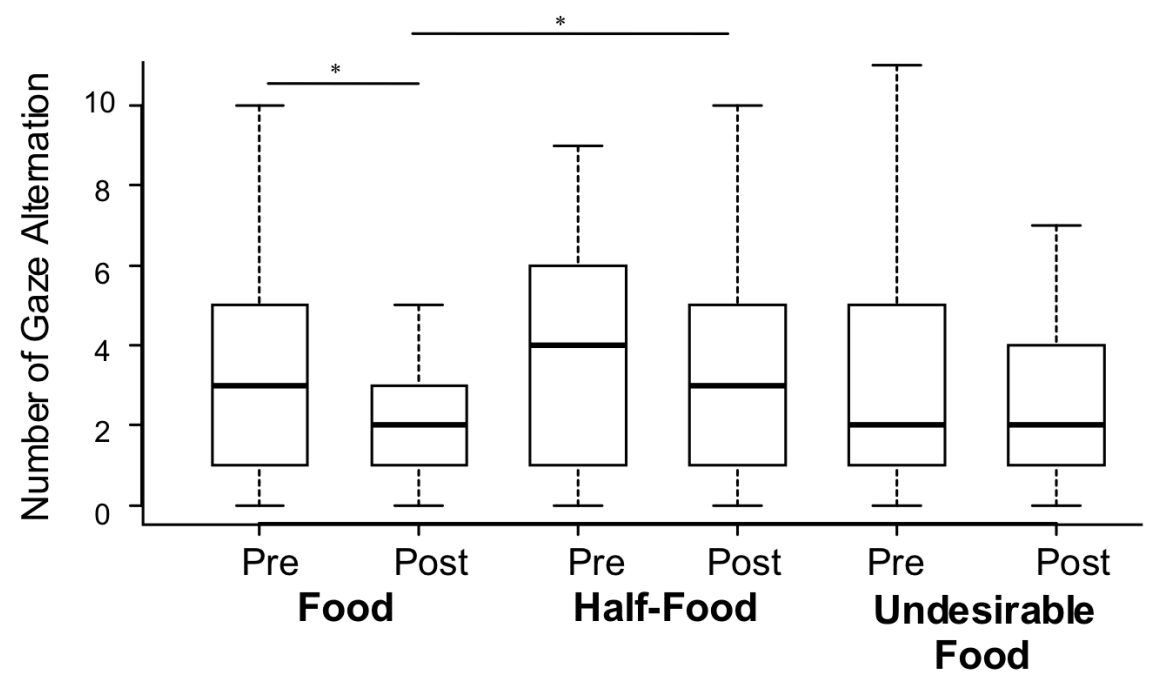

Figure 2.9. Number of Gaze Alternation between the owner and the food in the pre and post-delivery phases for Food, Half-Food and Undesirable Food conditions.

After FDR BL adjustment, the duration and number of Sonorous Mouth licking did not differ between pre and post-delivery phases for either conditions, as well as for the comparisons of post-delivery phase of Food condition with Half-Food condition (duration: $-16<\mathrm{T}<24.5$, $0.216<\mathrm{p}<0.844$; number: $-11.5<\mathrm{T}<14,0.215<\mathrm{p}<1$ ). However the duration and number of the Sonorous Mouth Licking were significantly greater during the post-delivery phase of Food 
condition than of Undesirable Food condition (duration: $\mathrm{T}=-26.5, \mathrm{p}=0.004$, number: $\mathrm{T}=-18$, $\mathrm{p}=0.008)$.

The duration of time spent in Food area did not differ between pre and post-delivery phases for neither conditions, as well as when comparing the post-delivery phases of Food with HalfFood or with Undesirable Food $(-50.5<\mathrm{T}<81,0.05<\mathrm{p}<0.842)$.

Related to the location and behavior combined analyses, after FDR BL adjustment, the duration of time spent in Food area combined with Gaze Owner and with Gaze Alternation between the owner and the food did not differ between pre and post-delivery phases for either conditions, as well as for the comparisons of post-delivery phase of Food condition with HalfFood condition, and of Food condition with Undesirable-Food condition $(-74<\mathrm{T}<86$, $0.018<\mathrm{p}<0.982$ ). See Supplementary 1 - Table $7 \mathrm{~b}$ for descriptive measures and statistics for persistence effects on the combined location and behaviors.

However, after FDR BL adjustment, the durations of time spent in Food area combined with Gaze Food decreased significantly from pre to post-delivery phases for both Food and HalfFood conditions $(86<\mathrm{T}<118, \mathrm{p}<=0.011)$, but it did not differ for Undesirable Food condition $(\mathrm{T}=5, \mathrm{p}=0.902)$. There was no difference between post-delivery phases of Food and HalfFood conditions for this combination of location and behavior in duration $(T=2.5, p=0.948)$; however, it was significantly longer during post-delivery phase for Undesirable Food than for Food $(\mathrm{T}=111, \mathrm{p}=0.003)$.

\subsubsection{Elaboration}

The proportion of dogs that exhibited multiple behaviors did not differ between the three predelivery phases $\left(\chi^{2}=0.20, d f=2, p=0.905\right.$; Figure 2.10$)$. See Supplementary 1 - Table 8 for descriptive measures and statistics for the elaboration analyses concerning this variable. 
After FDR BL adjustment, the proportion of dogs that exhibited multiple behaviors decrease significantly from pre to post-delivery phase for Food condition $\left(\chi^{2}=12, d f=1, \mathrm{p}<0.001\right)$, while such difference was not found for Half-Food and Undesirable Food conditions $\left(1.33<\chi^{2}<2.27, d f=1,0.132<\mathrm{p}<0.248\right)$. Additionally, significantly more dogs exhibited multiple behaviors after delivering the half food than the entire food $\left(\chi^{2}=6.40, d f=1\right.$, $\mathrm{p}=0.011$ ), but there was no significant difference after delivering the undesirable food and the entire food $\left(\chi^{2}=3.60, d f=1, p=0.058\right)$. See Supplementary 1 - Table 8 , left panel, first line.

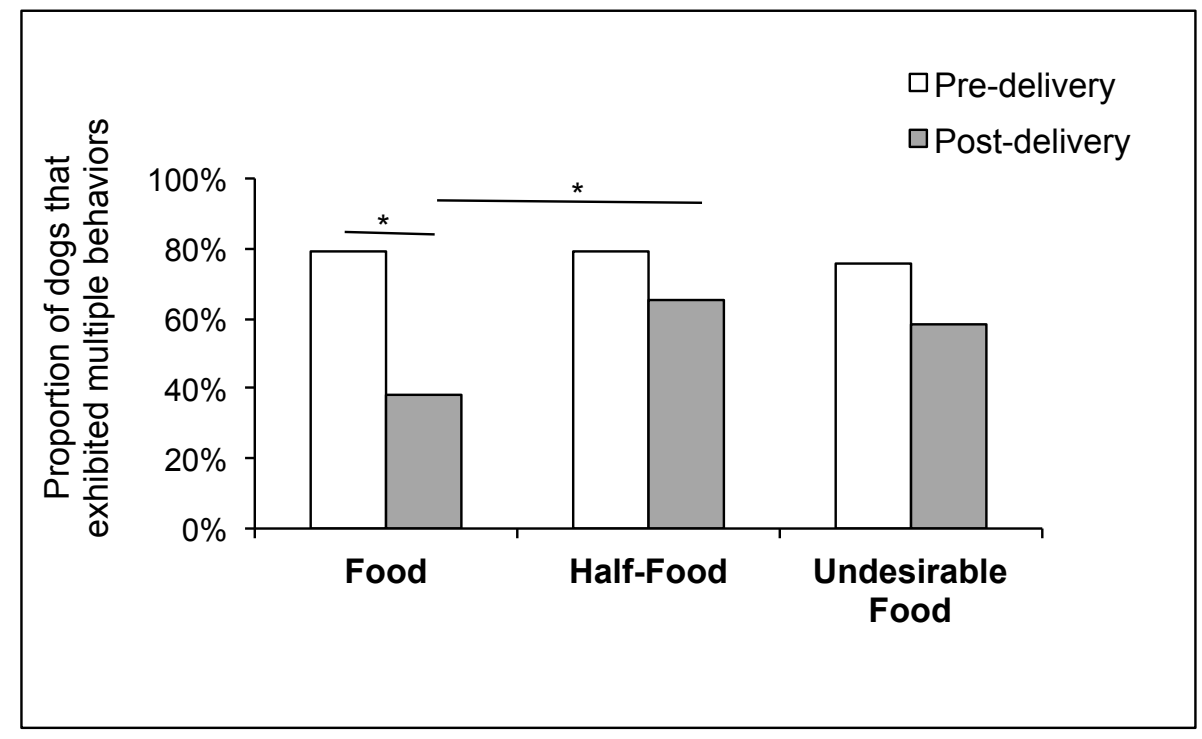

Figure 2.10. Proportion of dogs that exhibited multiple behaviors in each phase of Food, Half-Food and Undesirable Food conditions.

The number of multiple behaviors did not differ between the three pre-delivery phases $\left(\chi^{2}=0.06, d f=2, p=0.808\right.$; Figure 2.11). See Supplementary 1 - Table 9 for descriptive measures and statistics of these variables for elaboration analyses.

After FDR BL adjustment, the number of multiple behaviors decreased significantly from pre to post-delivery phase for Food condition $(T=-79, p=0.002)$, while such difference was not found for Half-Food and Undesirable Food condition $(-30.5<\mathrm{T}<-18,0.385<\mathrm{p}<0.450)$. Additionally, when comparing Half-Food with Food condition no difference was found 
$(\mathrm{T}=46.5, \mathrm{p}=0.039)$, but significantly more multiple behaviors were exhibited after delivering the undesirable food $(T=50, p=0.006)$ than the entire food. See Supplementary 1 - Table 9 (left panel, first line).

Finally, the proportion of dogs that exhibited alternative behaviors during post-delivery phase not exhibited during pre-delivery phase did not significantly differ between Food (31\%), Half-Food (44.8\%) and Undesirable Food (31\%) conditions $\left(\chi^{2}=1.9, d f=2, \mathrm{p}=0.390\right)$.

Among the total of 24 multiple behaviors registered in the post-delivery phase of Food condition, only $3(12.5 \%)$ of them (for 2 different dogs) included both types of Mouth Licks that happened within the first 10 seconds after eating the entire food; likewise, among the total of 46 multiple behaviors registered in the post-delivery phase of Half-Food condition, only $3(6.5 \%)$ of them (for 3 different dogs) included both types of Mouth Licks that happened within the first 10 seconds after eating the half of food. Since these behaviors could be just a reaction for the salivation or mouth-cleaning behavior, instead of communicative behaviors, all analyses for elaboration were performed again without these multiple behaviors. Although the difference between Food and Undesirable Food conditions became larger, after the correction of multiple comparisons, the general conclusions did not change from the previous analyses (see results in Supplementary 1 - Table 8 and 9, right panels, first line).

Regarding the percentage of dogs that exhibited multiple behaviors in the Food area, the three pre-delivery phases did not differ $\left(\chi^{2}=0.12, d f=2, \mathrm{p}=0.943\right)$. After FDR BL adjustment, the analyses did not reveal any difference between pre and post-delivery phases for all conditions, as well as between the post-delivery phases of Food and Half-Food, and, of Food and Undesirable Food $\left(1.29<\chi^{2}<4.45,0.035<\mathrm{p}<0.257\right.$; see Supplementary 1 - Table 8, left panel, second line). Likewise, regarding the number of multiple behaviors in the Food area, the three pre-delivery phases did not differ $\left(\chi^{2}=0.22, d f=2, \mathrm{p}=0.896\right)$. No difference was found between 
pre and post-delivery phases for all conditions, as well as between the post-delivery phases of Food and Half-Food, and of Food and Undesirable Food $(-44<\mathrm{T}<30.5,0.019<\mathrm{p}<0.552$; see Supplementary 1 - Table 9, left panel, second line).

Finally, the proportion of dogs that exhibited alternative behaviors during post-delivery phase not exhibited during pre-delivery phase in Food area was $20.7 \%$ for all conditions $\left(\chi^{2}=0\right.$, $d f=2, \mathrm{p}=1.000)$.

By removing the occurrences of multiple behaviors with both types of Mouth Licks during first 10 seconds of the post-delivery phases of Food and Half-Food conditions, general conclusions for elaborated behaviors in Food area also did not change (see results in Supplementary 1 - Table 8 and 9, right panel, second line).

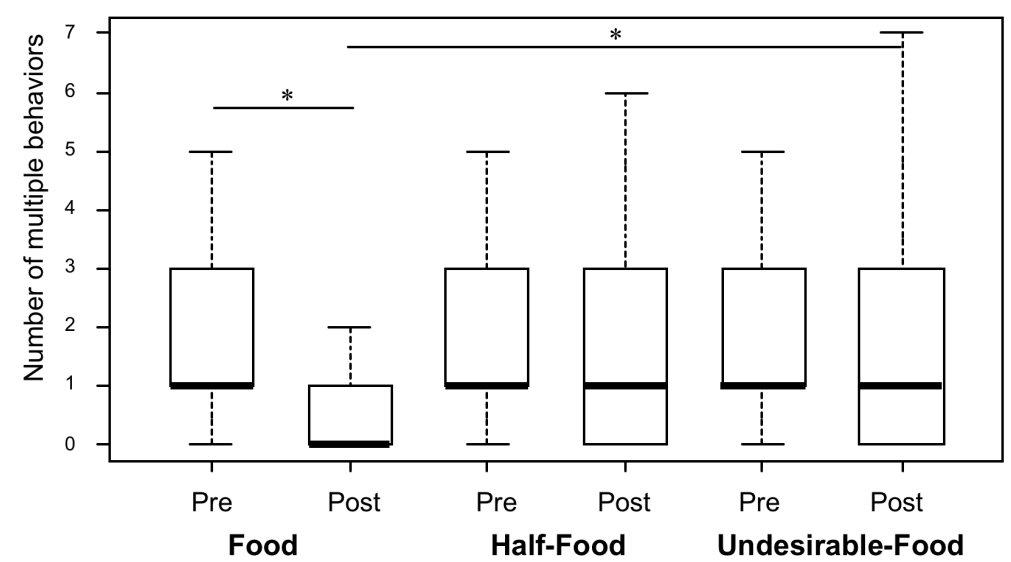

Figure 2.11. Number of multiple behaviors in each phase of Food, Half-Food and Undesirable Food conditions. 
Chapter 3 - Experiment 2 


\section{Experiment 2}

\subsection{Material and Methods}

\subsubsection{Participants}

Twelve males and 10 females adult pet dogs (mean age: $5.91 \pm 2.87$ yrs, Table 3.1 ) took part in the study on the basis of their owner's willingness to participate. Criteria for participating were that owners had to report motivation for food by their dogs (i.e., they would sometimes spontaneously behave as requesting food), no signs of distress in unfamiliar places and only basic obedience training. Moreover owners were not glasses users during their everyday life.

Dogs were fed 5 to 6 hours before the experiment.

\begin{tabular}{llcc} 
Table 3.1 - Characteristics of the dogs. & & \\
\hline Dog & Breed & Sex & Age (in years) \\
\hline Andrew & Golden & $\mathrm{F}$ & 7.5 \\
Baleia & Mongrel & $\mathrm{F}$ & 3 \\
Beetowen & Beagle & $\mathrm{M}$ & 8.8 \\
Cassio & Schnauser & $\mathrm{M}$ & 3 \\
Dama & Mongrel & $\mathrm{F}$ & 10 \\
Dog Sohum & Golden & $\mathrm{M}$ & 4 \\
Eros & Labrador & $\mathrm{M}$ & 9 \\
Fiona & Labradora & $\mathrm{F}$ & 8 \\
Gobi & Pitbull & $\mathrm{M}$ & 2 \\
Lua & Labrador & $\mathrm{F}$ & 9 \\
Mel & Mongrel & $\mathrm{F}$ & 8 \\
Milla & Golden & $\mathrm{M}$ & 7 \\
Moa & Golden & $\mathrm{F}$ & 2 \\
Moyka & Golden & $\mathrm{F}$ & 2.8 \\
Nino & Mongrel & $\mathrm{M}$ & 7 \\
Pinga & Border & $\mathrm{F}$ & 7.6 \\
Pitoco & Mongrel & $\mathrm{M}$ & 2 \\
Raposo & Mongrel & $\mathrm{M}$ & 2 \\
Serena & Cooker & $\mathrm{F}$ & 4.5 \\
Tigre & Labrador & $\mathrm{M}$ & 8.8 \\
Ze & Mongrel & $\mathrm{M}$ & 9 \\
Zebedeu & Border & $\mathrm{M}$ & 5 \\
\hline & & & \\
\hline
\end{tabular}




\subsubsection{Experimental settings}

The experimenter brought the food used in the experiment. In the experimental room (Figure 3.1), there were two shelves, where the food would be placed with two possible heights to make the food unreachable for dogs of different heights. The experiment was videotaped by two cameras for future registration of dog's behaviors. It was used a unidirectional microphone placed in the center of the room and attached to a crossbar connecting the two sides of the room. Dogs could explore the experimental and the adjacent room before starting the familiarization phase. A helper (C.S.) would bring the dog and the food into the experimental room and then would leave the room through Door2.

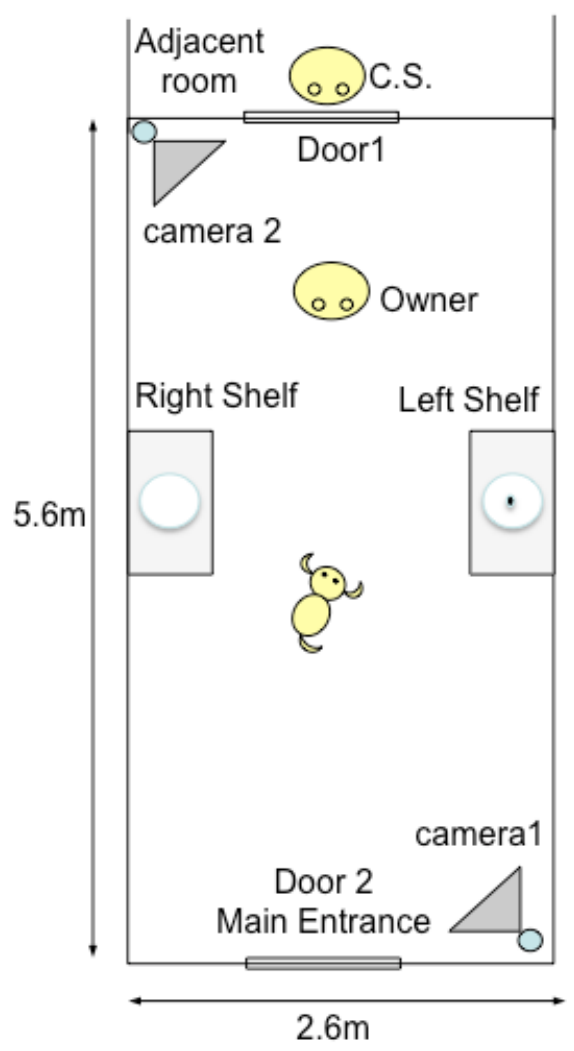

Figure 3.1. Experimental setting. 


\subsubsection{Familiarization phase}

A familiarization phase intended to show the dog that, although the helper was the one who would put the food on the shelf, the owner would be the food provider. The aim was to reduce the duration of each experimental condition and avoid fatiguing the dog.

The owner stood at the location defined for him/her (see Figure 3.1) and the helper stood in front of the owner on the other side of the room. The helper put the food on one of the shelves and returned to her place, then the owner immediately called the dog by its name, went towards that shelf and gave the food to the dog. This procedure was repeated by alternating the shelves, until the dog looked at the owner just after the helper put the food on the shelf (average number of repetitions required to get to the criterion as observed by the helper: $8.3 \pm$ 2.8 times).

\subsubsection{Experimental phase}

A rough explanation of the six conditions was first given to the owner. All dogs were submitted to the six conditions sequentially during the same day; their order of presentation was counterbalanced across dogs using a block randomization (Kutner et al. 1996) as well as the side of the food (left or right) with the restriction that one side could not be used more than twice consecutively.

The experimenter (A.) remained in the adjacent room all the time for signaling and controlling the entries and exits in the experimental room of the helper (C.S.), the owner and the dog. Each condition included a phase of placement of food and a phase of dog exposition. For the first phase, the helper took the dog to the experimental room with the food, and she next went towards one of the shelves, got the dog's attention, put the food on the shelf and left 
the room through Door2; then the owner entered the experimental room and stood at the location defined for him/her. For the second phase, it was manipulated the direction of eyes and head, the visibility of the eyes and the availability of the gaze:

-Visual Following: A 30-second trial during which the owner visually followed the dog with his/her gaze;

- Fixed Point: A 30-second trial during which the owner remained looking ahead at a mark point on the wall in front;

- Eyes Closed: A 30-second trial during which the owner remained facing ahead with the eyes closed;

- Eyes Up: A 30-second trial during which the owner remained with the head ahead, looking up with the eyes, in order to expose the white sclera of the eyes;

- Gaze Sky: A 30-second trial during which the owner remained gazing at the sky with the head;

- Gaze Book: A 30-second trial during which the owner remained gazing at a book.

At the end of each condition the helper opened the Doorl and called back the owner and the dog. The experimental phase included intervals approximately $5 \mathrm{~min}$. between conditions, during which the owner was briefed about the next condition, and lasted approximately 20 min. total. Dogs always received a piece of food in the end of each condition from the owner, in an adventitiously manner, so that they associate the present global context with availability of food from the part of the owner. Since conditions were presented in a random order between dogs, it is unlikely that adventitious food providing selectively affected the conditions (see Results section for confirmation when comparing the three first trials and three last trials according to the order presented for each dog). 


\subsubsection{Behaviors collected and variables}

We collected multimodal behaviors and locations of the dogs (see list below) with Actogram Kronos software (Octarés Edition). For each dog, overlapping behaviors (i.e. not mutually exclusive), with or without movements by the dog were defined (see Hare et al. 1998; Miklósi et al. 2000; Gaunet 2008, 2010; Gaunet \& Deputte 2011). All behaviors were recorded for all conditions:

- Gaze Owner: the dog's head/nose was oriented toward the owner's head face;

- Gaze Food: the dog's head/nose was oriented toward the food;

- Gaze Alternation between the owner and the food: it consisted in a gaze at the owner followed by a gaze at the food (or vice versa) (Leavens et al. 2004b, Leavens et al. 2005b);

- Vocalisation: the dog barked and/or whined;

- Mouth Licking: the dog displayed a non-sonorous mouth licking behavior;

- Sonorous Mouth Licking: the dog displayed a sonorous mouth licking behavior;

- Contact: the dog touched the owner with any part of its body;

- Gaze at the Sky: the dog's head/nose was oriented toward the sky.

The total duration of the 30 -second trials was used to compute relative numbers and durations of all behaviors, except gaze alternation that were numbered.

\subsubsection{Location collected and variable}

In order to evaluate whether dogs use their own location as a local enhancement signal (Gaunet \& Deputte, 2011) the duration spent in mutually exclusive areas were computed for each dog, 
using the location of the two anterior legs. Lines delimitating the areas close to the shelves were painted on the floor, and the variable of interested was:

- Food area: when the dog was in the $1.2 \mathrm{~m} \times 1.8 \mathrm{~m}$ rectangle closest to the baited shelf. The total duration of the 30 -second trials was used to compute relative duration of time spent in Food area.

\subsubsection{Location and behavior combined collected and variables}

The relative durations of time (related to the 30 -second) of combinations of certain behaviors and food area were computed. These combinations were:

- Food area combined with Gaze Owner, with Gaze Food, with Gaze Alternation between the owner and the food, with Vocalisations, with Sonorous Mouth Licking and with Gaze at the Sky for all conditions.

The combination of Food area with Contact Owner and silent Mouth Licking were not analysed since the first one was not possible to occur and the for last one only two dogs presented this behavior, which did not justify the analyses.

In order to simplify the text, we refer to relative or absolute numbers and durations of variables as "numbers" and "durations".

\subsubsection{Statistical analysis}

Non-parametric tests were performed (Hollander \& Wolf, 1998). The two samples Wilcoxon rank-signed test was used to compare conditions two by two.

In order to evaluate if there was a learning effect across conditions, the three first conditions pooled and the three last conditions pooled, according to the order presented for each dog, 
were compared for the 4 main relevant behaviors (durations of Gaze Owner, Gaze Food and Food area and numbers of Gaze Alternation), by the two samples Wilcoxon rank-signed test. It was first adressed whether dogs distinguish the different orientation of body cues of the owner. The comparisons of Fixed Point vs. Eyes Up, Fixed Point vs. Eyes Closed and Eyes Up vs. Eyes Closed intended to evidence the sensitivity to the eyes per se, direction and visibility and the combination of both as an exploration. Eyes Up vs. Gaze Sky intended to evidence the sensitivity to the direction of the head only, when the eyes remained up. The sensitivity to the direction of the gaze itself was adressed with Fixed Point vs. Gaze Sky, Fixed Point vs. Gaze Book and Gaze Sky vs. Gaze Book, though the hands and the book were added to direction of gaze for the two last comparisons. Finally, Fixed Point vs. Visual Following intended to evidence the sentitivity of the dogs to the mobility of the head and eye contact as a beacon toward the dog.

Additional comparisons between the Visual Following and the other conditions intended to investigate whether dogs differentiate an owner whose gaze was always available from different static directions of visual attention from the part of the owner.

Numbers and durations of the behaviors presented above, duration of time spent in Food area and durations for location and behavior combined were analysed.

For the multiple comparisons done for the same dependent variables the false discovery rate correction was applied (FDR BL adjustment, Benjamini et al. 2001).

For all statistical tests the SAS software 9.2, SAS Institute Inc., Cary, NC, USA and the significance level considered was 5\%.

Two trained observers recorded the occurrences of behaviors independently. The interobserver agreement was assessed for Gaze Owner, Gaze Food and Food area by means of parallel coding of $36 \%$ of the sample for duration. Kendall's concordance coefficient was calculated for Gaze Book, Visual Following and Eyes Closed conditions (pooling together the 
three conditions). For Gaze Owner, Gaze Food and Food area, the Kendall's concordance coefficient were, respectively, $W=0.95, W=0.88$ and $W=0.98$. Results indicated a good agreement between raters.

On the figures, data are represented by the boxplots, whiskers extend to the smallest and largest values and exclude outliers.

\subsection{Results}

The comparison of the first three conditions and the last three conditions, according to the order presented for each dog did not reveal any learning effect for the duration of Gaze Owner, Gaze Food and Food area, and, the number of Gaze Alternation $(-4<\mathrm{T}<48.5$, $0.117<\mathrm{p}<0.9$, see Supplementary 2 - Table 1$).$

All descriptive measures for the following analyses are presented in Supplementary 2 - Table 2.

Regarding the effects of different orientations of the owner's body cues, after the FDR BL adjustment, the results showed that dogs were more sensitive to the mobility of the head when compare to the head ahead for the duration of Gaze Owner $(\mathrm{T}=86.5, \mathrm{p}=0.0009)$; no other specific cue of the owner's body was preferentially used by the dogs to modulate any other behaviors (duration: $-65.5<\mathrm{T}<61.5, \quad 0.030<\mathrm{p}<1$; number: $-37.5<\mathrm{T}<70, \quad 0.019<\mathrm{p}<1$ ); see Supplementary 2 - Table 3a, 3b, 3c. No specific cue of the owner's body was preferentially used by the dogs to modulate the duration of time spent in Food area $(-30.5<\mathrm{T}<63.5$, $0.036<\mathrm{p}<0.626$; see Supplementary 2 - Table $3 \mathrm{c}$ ). Finally, for the analyses of location and behavior combined, after the FDR BL adjustment, the results also did not reveal any effects of the different orientation of body cues of the owner when the dogs were located at the Food area $(-48<\mathrm{T}<68,0.005<\mathrm{p}<1$; see Supplementary 2 - Table 4a, 4b). 
Regarding the effects of availability of the owner's gaze compared to the different static directions of visual attention, after the FDR BL adjustment, the results showed that the duration of Gaze Owner was significantly greater in Visual Following condition when compared to Gaze Sky and Gaze Book condition $(94.5<\mathrm{T}<102.5,0.0002<\mathrm{p}<0.0007$, Figure 3.2; see Supplementary 2 - Table 3a), the duration of Gaze Food was significantly greater in Visual Following than in Gaze Sky condition $(T=83, p=0.004$; see Supplementary 2 - Table 3a), and finally, the number of Gaze Alternation between the owner and the food was significantly greater in Visual Following than in Gaze Sky and Gaze Book condition $(61.5<\mathrm{T}<62.5,0.0005<\mathrm{p}<0.0014$; see Supplementary 2 - Table 3a and Figure 3.3). No other difference was found for any other behavior (duration: $-21.5<\mathrm{T}<62,0.027<\mathrm{p}<1$; number: $18.5<\mathrm{T}<72,0.005<\mathrm{p}<1$; see Supplementary 2 - Table 3a, 3b, 3c). The availability of the owner's gaze did not affect the duration of time spent in Food area $(-30.5<\mathrm{T}<61.5$, $0.029<\mathrm{p}<0.571$; see Supplementary 2 - Table $3 \mathrm{c}$ ). For the analyses of location and behavior combined, after the FDR BL adjustment, the results also did not reveal any effects of the availability of the owner's gaze $(-20<\mathrm{T}<63.5,0.009<\mathrm{p}<1$; see Supplementary 2 - Table $4 \mathrm{a}$, $4 b)$.

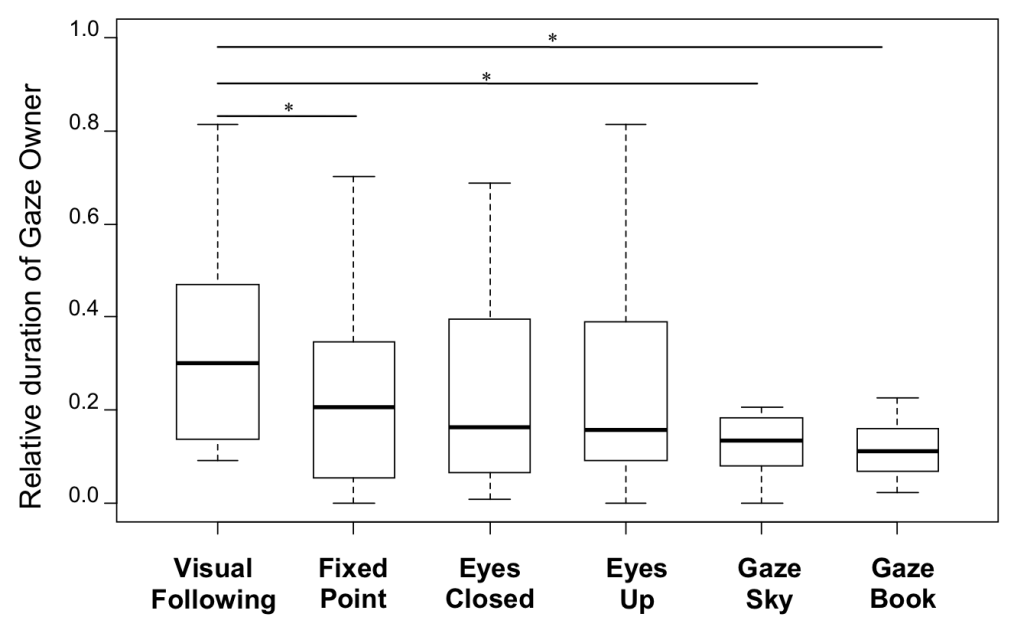

Figure 3.2. Relative duration of Gaze Owner according to the six experimental conditions. 


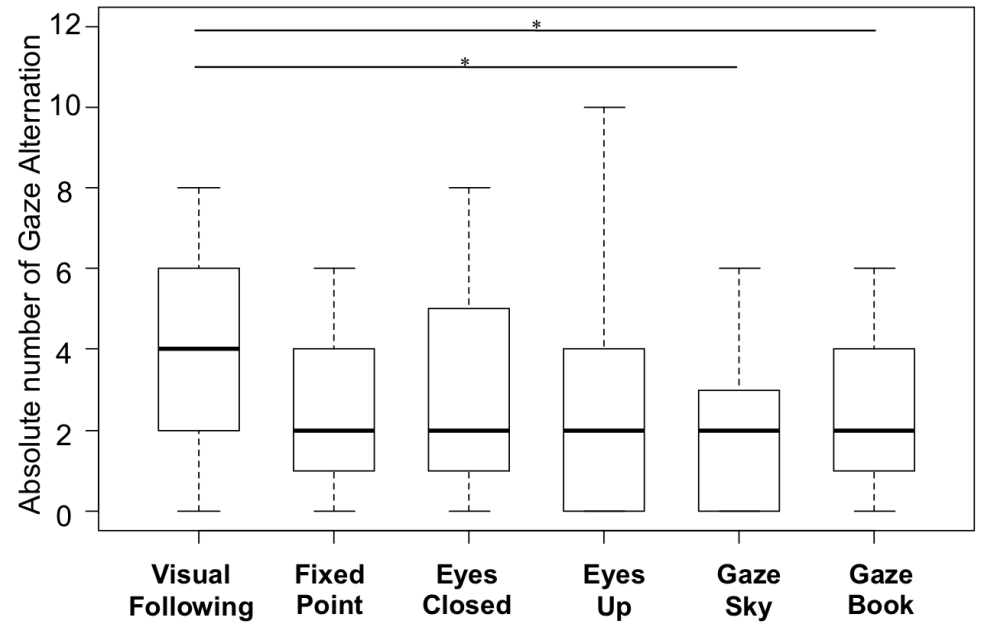

Figure 3.3. Absolute number of Gaze Alternation according to the six experimental conditions. 
Chapter 4 - Discussion 


\section{Discussion}

Previous studies have demonstrated that dogs need an audience to display communicative behaviors (Miklósi et al., 2000; Gaunet, 2011) and that they have a sensitivity to the human's direction of attention in different contexts (Call et al., 2003; Viranyi et al., 2004; Brauer et al.; 2004; Kaminsky, 2009). It has also been demonstrated that dogs present high rates of gaze alternation between a human and some referent of interest as a way to get the human's attention to it (Miklósi et al., 2000; Gaunet, 2008; Gaunet \& Deputte, 2011), and that they persist when the attempt to communicate fails (Gaunet, 2010).

Different to these previous studies, the current work used a single and larger sample to test the operational criteria described in section 1.4. Dogs were submitted to a naturalistic situation with desired but unreachable food and the results provided indications that, similar to apes (Leavens et al., 2004b; Leavens et al., 2005b), dogs also presented behaviors known to be involved in the "manipulation" of a social human partner and considered as referential and intentional communicative behaviors in order to receive that food.

By using two possible locations, it was possible to evaluate whether dog use a directional component towards the food. Additionally, the choice of having the food visible, contrarily to previous studies in dogs, is justified by the fact that the aim of this study was to focus on the communicative behaviors of a referent in an environment that was visible for both sender and recipient of the message. Indeed, the use of a hidden food to evaluate the criteria of referentiality and intentionality as in previous studies (Miklósi et al., 2000; Gaunet, et al., 2010; Gaunet \& Deputte, 2011) would imply an object permanence ability and working memory. Even though some studies have already shown that dogs possess a certain level of these abilities (Fiset et al. 2003; Fiset \& LeBlanc, 2007), this was not the focus of this current study and it would not be possible to assure that it would not interfere on dog's 
communicative behaviors.

This study also addressed, for the first time, the effect of the direction of the owner's body and visual direction of attention on dog's communicative signals. Finally, another novelty presented in the current study was the possibility to evaluate which strategy dogs would use facing a partial or a complete communication failure.

For each criterion addressed, we will present below the main results obtained and discuss them regarding previous studies.

\subsection{Communication/Audience effect vs. Motivation}

Results revealed that, in the co-presence of the owner and the food, dogs used gazes at the owner and gaze alternation between the owner and the food (whether or not in the food area), at a rate greater than zero.

In the same scenario it was also observed at a rate greater than zero that dogs remained in the food area as well as used gazes at the food (whether or not in food area) and sonorous mouth licks; for durations, these behaviors and location scored greater when the owner was present in the room than when he/she was absent.

The present results converge with previous studies (Miklósi et al., 2000; Gaunet \& Deputte, 2011) and confirm that gaze at the owner, gaze at the food, gaze alternation between the owner and the food, sonorous mouth licks and the use of the position in the food area (accompanied or not with gaze at the owner and gaze alternation) verified the criterion of communication/audience effect.

In the presence of the owner and the food, dogs did not use, at a rate significantly greater than zero, vocalisations (whether or not in the food area), silent mouth licks and contact, which is also in agreement with Gaunet and Deputte (2011). Since the sonorous mouth licks did not 
happened in the food area, no other analyses were performed for this combination of behavior and location, except for investigating the effect of direction of owner's attention, since it is a sonorous behavior.

The absence of owner had no effect on the combined use of food area with gaze at the food, even though having an effect on this behavior when analyzed regardless of location. This communicative behavior alone is not related to being close to the food but instead it is also a distal signal displayed far from the food.

\subsection{Referentiality}

Dogs gazed longer at the owner when the food was present in the room than when it was absent (whether or not in the food area). This shows that dogs referred visually to the owner, wherever in the room, as if trying to get his/her attention or waiting/seeking for any response. In Gaunet and Deputte (2011) gaze at the owner did not differ between similar conditions (presence or absence of a toy); however, in that study the owner was both the hider of the toy and the recipient, which could have led the dogs to maintain the gaze at the owner even in the absence of the toy in order to continue the interaction. In the current study, the fact that these two roles were played by different people allowed to emphasize the referentiality of the gaze at the owner. Additionally, this behavior, combined with positioning next to the food worked as if dogs used their own body as a local enhancement cue; this would be performed as if dogs were taking the visual perspective of the owner (cf. the comparison with gazes at the owner in the shelves area) or as if they had previously learned contingencies between behaviors of the receiver (e.g. oriented towards the dog and the food) and the outcome of their own behaviors (i.e. positioned at the food gazing at the owner). In agreement with this finding, previous studies evidenced an effect of owner's visual perspective on the dog's behavior in different 
contexts (Kaminski et al., 2009; Bräuer et al., 2004; Gaunet \& Deputte, 2011).

Dogs positioned themselves next to the baited shelf longer than next to the shelves in the absence of food condition. The gazes at the food in the co-presence of the owner and the food were significantly longer and more frequent than the gazes at the shelves when the food was absent (also when associated with respective areas in duration). Likewise, the number of gaze alternation between the owner and the food in the co-presence of the owner and the food was significantly more frequent than between the owner and the shelves when the food was absent (also when associated with respective areas in duration), showing the referential properties of both behaviors combined or not with being located at the food area.

Additionally, the time spent next to Door2 when the food was present was smaller than when the helper took the food away, that latter duration being also smaller than the time spent next to the food when it was present. This showed that location alone was not used as a referential cue when the food was away. However, dogs used gazes at Door2 and their own position combined with gazes at Door2 when the food was absent at the same rate regarding duration as they did towards the food when it was present. Thus, the duration of gaze at the food and this behavior associated with corresponding area diverted towards the Door 2 when the helper took the food away. In the same line, it is important to note that the time spent gazing at Door2 (whether or not being located at Door2) were significantly smaller when the food was present than absent, showing the referentiality of gazing at the target (being located or not at Door2) when the food was away. On the other hand, there was significant less gaze alternations between the owner and Door2 in the Absence of Food condition than between the owner and the food when the food was present (also when associated with respective areas), which means that the gaze alternations did not divert towards Door2 when the food was taken away.

Interestingly, similarly to the findings of Gaunet and Deputte (2011), gaze at the food, gaze 
alternation and the use of the position in the room do not have the same function when the food is not present. The gaze at Door2, the time spent next to this door and the combined behavior and location when the food was taken away may be a "waiting" reaction, while the gaze alternation in the food area may be used to request the food when it is present. Dogs acted as if it was not/less "worth" requesting the food when it was not accessible or getable by the owner or, if they had previously learnt that requesting out-of-reach food does not lead to a positive response.

Regarding the mouth licking behavior, even though it was earlier found to be a communicative behavior, it was not used referentially in the present study: there was no effect of the absence of food on this behavior (also when associated with the food area, which shows that mouth licks are rather displayed everywhere in room). Gaunet and Deputte (2011) found that there was no effect of the absence of the owner or of the toy on mouth licks and they suggested that this might be explained by the fact that the target was a toy and not food. In the current study with food as a target we also found no effect of the absence of food, but dogs displayed more mouth licks when the owner was present than when he/she was absent; therefore this behavior can be communicative, with food as the target, but not referential.

Our results confirmed the conclusions reached by Miklósi et al. (2000) and Gaunet and Deputte (2011) that the behaviors directed towards the food and at the owner are functionally referential behaviors.

\subsection{Effect of the direction of attention}

The criterion of influence of the direction of visual owner's attention was investigated in experiment 1 by manipulating the body orientation. 
The duration of time spent in the area close to the food did not differ when the owner was facing the experimental setting or had his/her back turned to it. However, dogs spent more time in the back area when the owner had his/her back turned than when facing the experimental setting. This suggests that dogs remained spending time in the food area and also adjusted their own position to be face-to-face with the owner as well.

Dogs gazed longer and more frequently at the owner's face, and also alternated more gazes when he/she was facing the experimental setting than when he/she had his/her back turned, showing that a change in orientation affects these behaviors in dogs (note that in order to gaze at the owner's face in Owner Turned condition, dogs have to be close to the owner, i.e., at their side or in front of them). The combined analyses of behavior and location additionally showed that in the food area the gazes at the owner's face and the gaze alternation between the owner's face and the food when he/she was facing the experimental setting were still longer than those when he/she had his/her back turned and dogs were in the back area.

We found that dogs gazed more frequently and longer at the owner's face and alternated more gazes with the owner's face when he/she was facing the experimental setting than with the owner's back head when he/she had his/her back turned. This suggest that gaze at the owner's face is rather an attention-getting-like behavior than a checking behavior. Moreover, since there was no such difference when dogs were in the food area, we can infer that the gazes at the owners and gaze alternations when he/she was facing the experimental setting also happened outside the food area. Finally, the durations of gazes at the food in the back area when the owner had his/her back turned were smaller than those in the area close to the food when the owner was facing the experimental setting, suggesting that they use less this behavior in the back area when the owner had his/her backed turned.

Therefore, dogs used the owner's body orientation to modulate their location in the environment. They tended to adjust their position by turning around the owner to be face-to- 
face in the Owner Turned condition, like chimpanzees in the study of Liebal et al. (2004), but they did not gaze at the owner's face and at the food as a way of getting his attention in that situation as much as they do when the owner was in facing position. There is a possible explanation for this lack of communicative behaviors towards food in the back area when the owner had his/her back turned: according to Viranyi et al. (2004) dogs differentiated their response between two conditions in which a instructor of a command "down" was oriented to a human partner or was oriented in the same direction but to an empty space, evidence that dog's response can be influenced by what is in the instructor's visual field. Moreover, in different contexts, Brauer et al. (2004) and Kaminsky et al. (2009) also showed evidences that dogs take into account what humans see or not. In our study, when the owner had his/her back turned the food was not in his/her visual field and, by considering these earlier results, the lack of communicative behavior towards the food when dogs were in back area would be an evidence that in a communicative situation about an entity in the environment, the dogs acted as if they had learned not to display behaviors with directional component towards a food that was not in the owner's visual field.

Finally, there was no effect of the direction of owner's body on the duration and number of gaze at the food (whether or not in the food area). Moreover, there was no effect of the direction of owner's body on the duration and number of sonorous mouth licks. Specifically in the food area, there was no occurrence of sonorous mouth licks in the co-presence of the owner and the food, and we found that also when the owner had his/her back turned this combination was not used. Although vocalisations were not used at a high rate when the owner and the food were present, we investigated whether they could increase when the owner had his/her back turned as a way to call the owner's attention. We found no difference between the two conditions when dogs were in food area or not, which means that dogs also did not use vocalisations when the owner had his/her back turned. A possible explanation for 
the absence of vocalisations could be that owners usually discourage dogs from barking and they could have learned that this behavior should be avoided independently of the context. These results are in agreement with Gaunet (2010) who also found that dogs did not use sound behaviors to get the owner's attention.

In summary, we found that the owner's body direction was a factor that influenced the use of referential communicative behaviors towards the food, especially the gaze alternation between the owner and the food and the gaze at the owner are rather an attention-getting-like behavior than a checking/anticipatory behavior.

A more detailed investigation that exposed dogs to the same naturalistic situation of an unreachable food was proposed in Experiment 2: it evaluated whether dogs modulate their communicative behavior according to cues from the owner's body, namely eyes, head, gaze and the availability of the gaze.

The first set of comparisons on Experiment 2 intended to isolate these cues (eyes, head, gaze and availability of the gaze) in order to identify what specific part of the owner's body dogs use preferentially to modulate their communicative behavior. It revealed that dogs gazed less at the owner in the Fixed Point condition when compared to the Visual Following condition. Since in both conditions the food was still in the owner's visual field, this difference may reflect a sensibility to the movement of the head and to the availability of the gaze. For all other behaviors and for the food area (as well as the combined analyses), no other difference was found: no other cue was used to modulate any other communicative behaviors.

The second set of comparisons on Experiment 2 intended to evaluate the effects of availability of the owner's gaze (Visual Following condition) compared to the different static directions of visual attention. It showed that dogs differentiate an owner whose gaze was available from conditions in which he/she was with the head and gaze oriented up or down: dogs gazed longer at the owner and alternated more gazes between the owner and the food when the 
owner was visually following them than when he/she was gazing at the sky or at a book; they also gazed longer at the food when owners were visually following them than when owners were gazing at the sky. For all other behaviors and for the food area (as well as the combined analyses) no other difference was found.

The conditions in which the owner was gazing at the sky or at a book represent, in fact, a more detectable absence of visual attention directed at the dog or at the food (or a situation that has been learned of being less positively answered by owners in the past - parsimonious hypothesis), since it involves a changing in direction of the head and gaze. This is in agreement with studies that showed a sensitivity of dogs to the orientation of the human's head in tasks of performing an action (Gácsi et al., 2004; Study 1 in Virányi et al., 2004), and when they had to chose between two unfamiliar women to beg for food, one of them trying to make eye contact while the other one with her head turned away from the dog (Study 2 in Virányi et al., 2004).

The fact that dogs did not differentiate the visibility and direction of the eyes is in agreement of Gaunet (2008) and Gaunet (2010). On those studies dogs from sighted owners and from blind owners behave similarly in an interactive situation, evidence that dogs do not show sensitivity to their owner's visual status. These studies suggest that possibly the visual status of the owner may be a too subtle cue to be used by dogs when they are communicating or that the experience of the guide dogs with a sighted family during their development is not erased with the experience of living with a blind owner.

It is important to mention that in their lives dogs have many opportunities to beg for food and it is possible that sometimes owners delivered a treat for their dogs even when they were not visually following them, for example when the owners were watching $\mathrm{TV}$, or in the table. This could also have masked a possible ability to differentiate subtle cues related to the eyes visibility and direction. 
Specially the conditions during which the owners were standing up with their eyes closed or their eyes up may not have been experienced by the dogs, and perhaps it could have elicited a strangeness or curiosity, which could also be an explanation for the tendency to continue gazing at the owner in these conditions at the same rate than when he/she was visually following the dog. As Udell et al. (2011) suggested, dogs seems to be more prone to discriminate an "attentive" person when the other option was a situation faced in their daily routine, like an owner reading a book, than when the other option was a situation never experienced before.

The situations that dogs were submitted to in this current study also involved a high level of excitement and this could contribute for dogs not differentiating subtle cues regarding the owner's eyes - see this suggestion by Gácsi et al. (2004) in a play context.

Gácsi et al. (2004) stated that the direction of the body and head plays a key role in recognizing human's direction of visual attention, while the eyes themselves might be less used. For humans the eyes play a central role in social interactions and communication, as well as in the recognition of direction of attention. However, as stated by Gácsi et al. (2004), since the human is the only primate that has a white sclera, which facilitates the visibility and recognition of the direction of the eyes, it would be reasonable to assume that the use of the eyes as cues of direction of visual attention would be a human trait. Povinelli and Eddy (1996) also found that chimpanzees do not use human's eyes as a cue of direction of visual attention. Then, among other species the recognition of the direction of visual attention relies on other cues rather the eyes.

It is suggested by some authors that dogs have been selected for having social-cognitive skills (Miklósi et al., 2003; Kubinyi et al., 2007; Riedel et al., 2008) and that they would be adapted to use human's social cues of direction of visual attention. Dogs, in fact, modulated their gazes at the owner and gaze alternation between the owner and the food when the owners 
were with head and gaze available or not. However, it is not necessary to interpret these results as a purely innate ability that implies "awareness" of human mental state. Wynne et al. (2008) suggests that domestication alone cannot be responsible for an individual's sensitivity to human cues. Dogs may learn about the implication of human body orientation and head direction in communicative interactions on their daily life experiences. Indeed, previous studies showed that dogs were able to improve the use of a gaze cue over the course of trials in an object choice task (Miklósi et al., 1998; Udell et al., 2008; Soproni et al., 2001; Hare et al., 1998). Additionally, trained gundogs seemed to learn quickly to interpret the head turn and the eye gaze (McKinley \& Sambrook, 2000), evidence that formalized training in obedience and hunting can improve the ability to learn to use different, subtle cues. Dogs can even learn to use another modality of communication, other than visual, when it is more suitable to their owner's visual status: in Gaunet (2008) guide dogs used more sonorous mouth licking than pet dogs in addition to the gazes, which could have been learned as a getting-attention behavior to get help from the blind owners. The role of experience seems to be relevant to modulate the dog's communicative behavior and their reactions to different direction of their owner's attention, which did not undermine the conclusion of this study that when communicating about an entity in the environment, dogs' behavior can be influenced by the owner's direction of body and head, being this ability inherited, learned or both.

\subsection{Persistence}

The comparison of dogs' communicative behaviors before and after receiving the entire food, half food or undesirable food, as well as between the post-delivery phases allow investigating whether there is persistence of communicative behaviors when attempts to manipulate the owner failed partially of completely. There are evidences of persistence for the two 
communicative behaviors directed towards the food, the gaze at the food (in agreement with Gaunet (2010)) and the gaze alternation between the owner and the food.

While the duration and number of gazes at the food decreased significantly after receiving the entire food, it did not decrease after receiving the undesirable food, showing persistence. In congruence, for the post-delivery phases dogs gazed significantly longer to the baited shelf when the attempt to communicate failed completely than when it was successful. A different result was observed when only half food was delivered: there was a significant decrease in the duration and number of gazes at the baited shelf after receiving half of the food. In congruence, for the post-delivery phases, dogs gazed similarly to the baited shelf when the attempt to communicate half-failed and when it was successful. Therefore, dogs did not persist with this behavior with the half-food delivery whereas they did with the delivery of undesirable food.

A different pattern was obtained regarding the gaze alternation between the owner and the food. Indeed, while the number of gaze alternations decreased significantly after receiving the entire food, there was no such decrease after receiving half food and the undesirable food, an evidence of persistence in these two situations. However, the comparisons between the postdelivery phases revealed that, in the partial failure condition, dogs alternated more gazes with the baited shelf than in the successful condition; while during the complete failure condition they alternated as much gazes as in the successful communication. These results show that dogs persisted for both half and undesirable food, being less prone to insist in case of undesirable food. Regarding the total failure of communication conditions we found a different result from Gaunet (2010), where the number of gaze alternations were greater during the pre-delivery phase than after returning an unfamiliar object to the dog (analogous to our undesirable food condition). This might be attributed to the nature of the target and to the duration spent by the dogs sniffing a totally new target, advocating for distinct differential 
values between desirable and undesirable food vs. toy and new object. Since this previous study did not evaluate the partial failure situation, the current research brings a novel information about the function of using the gaze alternation: it is indeed a referential and communicative behavior used to persist when the recipient of a message appeared to be available to cooperate. Additionally, not only dogs required a retrieval action from the part of the owner, they also required the entire food, i.e., the referent.

All in all, results observed for dogs in a "beg for food" situation were similar to findings for chimpanzees (Leavens et al., 2005b): gaze at the food and gaze alternation between the receiver and the food happened predominantly towards the food in each of the three predelivery phases and after delivery of half of the food or the undesirable food. However, they observed almost cessation of communicative behavior (gestures, vocalisations, among others) when desirable food was delivered as well as a gradual intensification of communicative behaviors as a function of the quantity to quality of food received. Gaze alternation was not analyzed in half-food conditions due to procedural issues (i.e., in the half-banana condition the other half of the food was placed into the experimenter's lab coat pocket and the little angular separation between the half-banana and the experimenter's face resulted in a small reliability). For dogs we observed that they used different strategies to persist depending on the outcome of the communication. This could be explained by a possible experience acquired during their lives: for undesirable food dog persisted for both behaviors - even though it was less noticeable for gaze alternations - as if, in the past, they had learned to "acknowledge" such a response from their owner (i.e., "being less cooperative" in such a situation). On the other hand, for the half-food condition, a different strategy was at play i.e., only gaze alternations were maintained, which may have been learned as sufficient for continuing to "manipulate" the owner when he/she had partially answered the request and "appeared willing to cooperate" by giving a piece of food. These results confirm in both cases not only 
persistence but also an ability to discriminate between being given food (the half one or the entire one) and not being given anything.

Across these three conditions the gaze at the owner and the use of food area were not differentially performed. However, sonorous mouth licks were displayed more (duration and number) after receiving the entire food than the undesirable one, but this could be a natural reaction or mouth-cleaning behavior after eating the food and thus there is no meaningful interpretation for this result related to the persistence hypothesis. Since mouth licking after eating is probably used for other function than the communicative one, caution is necessary to analyze this variable. For this reason, an adjustment was proposed for the elaboration analyses in order to prevent including mouth lickings after eating food, although it was not done for persistence at the present study.

All in all, receiving part of the food or an undesirable food did not suppress the behaviors towards the baited shelf, although the strategy changed depending on the outcome of the communication. This suggests that the decrease in communicative behaviors observed after receiving the entire food would, in fact, indicate that dogs perceived the attempt to communicate on that situation as a success, similarly to what happens to chimpanzees, although with a different pattern (Leavens et al., 2005b) that may be explained by the more cooperative abilities of dogs than chimpanzees with humans (Hare \& Tomasello, 2005).

Further, the combined analyses of location and behavior did not reveal any effect of persistence for the combinations of food area with gaze at the owner and with gaze alternation between the owner and the food. This implies that the persistence observed in the gaze alternation between the owner and the food did not happened specifically from the food area, but also outside this area. Regarding the combination of food area and gaze at the food the same pattern was observed as the gaze at the food alone; dogs thus used not only the behavior alone but also the behavior combined with their own body as an enhancement cue to persist 
after receiving the undesirable food.

\subsection{Elaboration}

We proposed three approaches to investigate the criterion of elaboration across the three conditions, Food, Half-Food and Undesirable Food. The first one was to evaluate the proportion of dogs that exhibited multiple behaviors, while the second one was to count the number of multiple behaviors. As proposed by Leavens et al. (2005b), the use of multiple behaviors after a communication failure would indicate that the individual would be using a more elaborate repertoire of behaviors. The third approach was to evaluate the proportion of dogs that exhibited an alternative behavior after the attempt to communicate failed partially or completely, i.e., a behavior not shown in the pre-delivery phase. This would indicate that dogs would change the strategy of communication when they fail at the first place, also an evidence of elaboration of communication.

Based on the first and second approach it was observed that, while after receiving the entire food the multiple behaviors decreased significantly (the proportion of dogs that used them and also their number per se), after receiving half of the food or an undesirable food more dogs continued presenting an elaborate repertoire of behaviors. However, in the post-delivery phase, the proportion of dogs that exhibited multiple behaviors when the communication partially failed was greater than when it was successful, which did not happened when the communication failed completely. Conversely, the number of multiple behaviors used when the communication failed completely was greater than when it was successful, which did not happen when the communication partially failed. By considering together both variables, there are evidences that dogs continued using an elaborated repertoire of behaviors when the communication failed partially or completely. 
On the other hand, the third approach did not agree with the previous ones: there were no differences across conditions regarding the proportion of dogs that exhibited alternative behaviors in post-delivery phases, which is in agreement to Gaunet (2010), who found no new communicative behaviors after the communication failed. We have then conflicting results depending on the approach of analysis adopted. However, the lack of alternative (or new) behaviors after the communication failed could be explained by the fact that dogs use since the beginning all their repertoire of behaviors in order to achieve their goals.

Leavens et al. (2005b) found that, regarding the number of behaviors (defined as the use of a different kind of behaviors at the same time), it was found that the possession of a half-banana or an undesirable food did not suppress the communication, which would mean elaboration for both outcomes. However, in the post-delivery phase significantly more chimpanzees exhibited multiple gestures after the complete communication failure than after the success, which did hot happen after the partial failure. This is a different behavior pattern when compared to dogs, since more dogs tended to use an elaborate repertoire of behaviors facing the partial failure. This tendency can also be a result of experience: their owners could have shown themselves more prone to deliver additional food after providing some.

\subsection{Gaze Alternation between the owner and the food}

For dogs, gaze alternations between the recipient of the message and the referent have an important role as a deictic and showing behavior (Miklósi et al., 2000).

Considering all results of this study together, we can conclude that the gaze alternation between the owner and the food was the most important communicative behavior used as an attention-getting behavior to request the food when it was present. It is also a referential behavior, since it refers indeed to the food and it is also influenced by the direction of the 
owner's body and head. Moreover, dogs persisted with gaze alternation when the attempt to manipulate their owners partially failed, and there is a tendency to persist after receiving the undesirable food.

One can argue that the gaze alternation between the owner and the food could be a way to monitor the human's activity in order to anticipate his/her behavior. However, we have evidences that this is not the case. If the gaze alternation was a simple anticipatory behavior instead of an attention-getting behavior it would be expected that dogs would alternate gazes with the owner independently of his/her position or direction of attention. However, the present study suggested that indeed dogs use gaze alternation between the owner and the food as an attention-getting behavior since they modulate this behavior according to the direction of the owner's body and head and display more frequently this visual behavior when the owner's visual direction of attention was favorable to see them.

\subsection{Final remarks}

Owners usually report that their dogs position themselves and gaze at them in order to indicate some desires like the place where the food is usually stored or the leash that they use when they go out for a walk. We found that the use of their own position with a communicative purpose and these gazes at the object of interest, at the owner and the gaze alternations between them is, in fact, functionally referential and intentional. This means that dogs are able to "show" for a human social partner a specific entity in the environment, by using a communication with a directional component towards this entity, as if they "intended" to manipulate their owner's behaviors to be cooperative and give them the object of interest (food in our case). However, by saying this we are not stating that they have a theory of mind 
about their owner's motives, or that this could reflect an "understanding" of their owner's mental state.

Our study submitted dogs to a naturalistic situation of requesting a non-reachable food and, as this has already happened in their lives, we cannot exclude that this request that has apparent intentional properties is a learned behavior. Bentosela et al. (2008) showed that even the gaze response can be quickly learned by dogs. However, the incidental learning in the experimental setting is not enough reason to explain the observed dog's behavior: we found no learning effect in both experiments. Additionally, our dogs were in a novel place and they were just submitted to one trial in each condition and, in order to investigate what kind of behaviors would emerge, the owners were asked to behave passively during trials, which probably was a novel situation faced by dogs when interacting with their owners in a similar situation. On the other hand, it is reasonable to assume that learning during day life plays a role in the development of functionally referential and intentional communicative behaviors in dogs.

The special communication established with the dog Sofia by means of lexigrams (Rossi \& Ades, 2008) is a good example of the role of learning: it showed that the dog's communicative behaviors can be trained. The performance of Sofia in requesting her desires in a keyboard according to the effect of the audience, of the "visual perspective" of the human towards the keyboard and the insistence of pressing the key when she was not answered are evidences that what characterizes a communication as referential and intentional can be learned. Nevertheless, since wolves socialized from a very young age are not able to alternate gazes and communicate with a human in the same way as dogs do (Miklósi et al., 2003), it is not possible to discard the fact that dogs may have a predisposition to be adjusted to humans' social cues and to their way to communicate. 
Chapter 5 - Conclusion 


\section{Conclusion}

Leavens et al. (2005b) suggest an operational perspective to evaluate the referential and intentional communication: if an audience and "visual attention" are required for an individual to exhibit a behavior and to coordinate the behavior orientation towards the interested item in the environment and the recipient, if he/she persists and elaborates it when facing a communication failure, then this behavior can be considered as an apparent intentional and referential communication, "about" a specific item of interest. By verifying these criteria for dogs, especially for the gaze alternation behavior, we brought exhaustive evidences that dogs do, in fact, communicate in a functionally referential and intentional way about an entity in the environment.

This study answer some questions and arises many others that can be addressed in the future, as for example, how the production of dog's communication is influenced by demographic features of the dog, as for example sex, age, breed, or by demographic features of the owner, as for example sex and age, and by the relationship established between them, since there is a huge variation in the way owners treat and interact with their dogs. Additionally, the role of the experience in the dog's life and level of training on dog's production of communication can also be investigated.

It is plausible to use "evo-devo" approach to explain dog's behavior. The role of ontogenesis and the learning is outright, but did not exclude a "predisposition" to communicate in this special manner (Miklósi et al., 2000). From an evolutionary perspective, communicating with humans and being especially able to learn cues from humans (i.e., to adjust to them) in order to request a food in an apparent referential and intentional way could have brought a selective advantage for dogs. 


\section{References}

Agnetta, B., Hare, B., \& Tomasello, M. (2000). Cues to food location that domestic dogs (Canis familiaris) of different ages do and do not use. Animal Cognition, 3, 107-112.

Alcock, J. (2005). Animal behavior: An evolutionary approach (8th ed.). Sunderland, MA: Sinauer Associates.

Anderson, J. R., Kuwahata, H., \& Fujita, K. (2007). Gaze alternation during "pointing" by squirrel monkeys (Saimiri sciureus)? Animal Cognition, 10, 267-271.

Baron-Cohen, S. (1999). The evolution of a theory of mind. In M. C. Corballis \& S. E. G. Lea (Eds.), The descent of mind: Psychological perspectives on hominid evolution (pp. 261-277). Oxford, England: Oxford University.

Barrera, G., Mustaca, A., \& Bentosela, M. (2010). Communication between domestic dogs and humans: Effects of shelter housing upon the gaze to the human. Animal Cognition, 14, 727-734.

Benjamini, Y., \& Hochberg, Y. (1995). Controlling the false discovery rate: A pratical and powerful approach to multiple testing. Journal of Royal Statistical Society, 57, 289-300.

Boesch, C. (2005). Joint cooperative hunting among wild chimpanzees: Taking natural observations seriously. Behavioral and Brain Sciences, 28, 692-793. [Open Peer Commentary of Tomasello et al. (2005). Understanding and sharing intentions: The origins of cultural cognition. Behavioral and Brain Sciences, 28, 675-735].

Brauer, J., Call, J., \& Tomasello, M. (2004). Visual perspective taking in dogs (Canis familiaris) in the presence of a barrier. Applied Animal Behavior Science, 88, 299-317.

Brauer, J., Kaminski, J., Riedel, J., \& Tomasello, M. (2006). Making inferences about the location of hidden food: Social dog, causal ape. Journal of Comparative Psychology, 120, 38-47. 
Bruner, J. S. (1998). Routes to reference. Pragmatics \& Cognition, 6, 209-227.

Byrne, R. (1995). The thinking ape. Oxford: Oxford University.

Call, J., \& Tomasello, M. (1994). Production and comprehension of referential pointing by orangutans (Pongo pygmeaus). Journal of Comparative Psychology, 108, 307-317.

Call, J., Agnetta, B., \& Tomasello, M. (2000). Social cues that chimpanzees do and do not use to find hidden objects. Animal Cognition, 3, 23-34.

Call, J., Brauer, J., Kaminski, J., \& Tomasello, M. (2003). Domestic dogs (Canis familiaris) are sensitive to the attentional state of humans. Journal of Comparative Psychology, 117, 257-263.

Cartimill, E. A., \& Byrne, R. W. (2007). Orangutans modify their gestural signaling according to their audience's comprehension. Current Biology, 17, 1345-1348.

Cartimill, E. A., \& Byrne, R. W. (2010). Semantics of primate gestures: Intentional meanings of orangutan gestures. Animal Cognition, 13(6),793-804.

Cheney, D. L., \& Seyfarth, R. M. (1985). Vervet monkey alarm calls: Manipulation through shared information? Behaviour, 94, 739-751.

Clay, Z., Smith, K. L., \& Blumstein, D. (2012). Food-associated vocalizations in mammals and birds: What do these calls really mean? Animal Behaviour, 83, 323-330.

D'Entremont, B., \& Seamans, E. (2007). Do infants need social cognition to act socially? An alternative look at infant pointing. Child Development, 78(3), 723-728.

Davis, S. J. M., \& Valla, F. R. (1978). Evidence for domestication of the dog 12.000 years ago in the Natufian of Israel. Nature, 276, 608-610.

Dennet, D. C. (1983). Intentional systems in cognitive ethology: The "Panglossian Paradigm" defended. Behavioral and Brain Sciences, 6(3), 343-355. 
Dennet, D. C. (1996). Kinds of mind. New York: Basic Books.

Dorey, N. R., Udell, M. A. R., \& Wynne, C. D. L. (2010). When do domestic dogs, Canis familiaris, start to understand human pointing? The role of ontogeny in the development of interspecies communication. Animal Behaviour, 79, 37-41.

Evans, C. S. (1997). Referential communication. Perspectives in Ethology, 12, 99-143.

Evans, C. S., \& Evans, L. (1999). Chiken food call are funcionally referential. Animal Behaviour, 58, 307-319.

Faragó, T., Pongrácz, P., Range, F., Virányi, Z., \& Miklósi, Á. (2010). "The bone is mine”: Affective and referential aspects of dog growls. Animal Behaviour, 79, 917-925.

Fichtel, C., \& Kappeler, P. M. (2002). Anti-predator behavior of group-living Malagasy primates: Mixed evidence for a referential alarm calling system. Behavioral Ecology and Sociobiology, 51, $262-275$

Fiset, S., Beaulieu, C., \& Landry, F. (2003). Duration of dogs' (Canis familiaris) working memory in search for disappearing objects. Animal Cognition, 6, 1-10.

Fiset, S., \& LeBlanc, V. (2007). Invisible displacement understanding in domestic dog (Canis familiaris): The role of visual cues in search behavior. Animal Cognition, 10, 211-224.

Fisher, J., Metz, M., Cheney, D. L., \& Seyfarth, R. M. (2001). Baboon response to graded bark variants. Animal Behaviour, 61, 925-931.

Fisher, J., \& Hammerschmidt, K. (2001). Funcional referents and acoustic similarity revisited: The case of Barbary macaque alarm calls. Animal Cognition, 4, 29-35.

Fragaszy, D. M., \& Visalbergh, E. (2001). Redognizing a swan. Psychologia, 44, 82-98. 
Gácsi, M., Miklósi, Á., Varga, O., Topál, J., \& Csányi, V. (2004). Are readers of our face readers of our minds? Dogs (Canis familiaris) show situation-dependent recognition of human's attention. Animal Cognition, 7(3),144-53.

Gácsi, M., McGreevy, P., Kara, E., \& Miklósi, Á. (2009). Effect of selection for cooperation and attention in dogs. Behavioral and Brain Function, 5-31.

Galibert, F., Quignon, P., Hitte, P., \& Andre, C. (2011). Toward understanding dog evolutionary and domestication history. Comptes Rendus Biologies, 334, 190-196.

Gardner A. R. (2005). Animal cognition meets evo-devo. Behavioral and Brain Sciences, 28, 699-700. [Open Peer Commentary of Tomasello et al. (2005). Understanding and sharing intentions: The origins of cultural cognition. Behavioral and Brain Sciences, 28, 675-735].

Gaunet, F. (2008). How guide-dogs of blind owners and pet dogs of sighted owners (Canis familiaris) ask their owners for food? Animal Cognition, 11, 475-483.

Gaunet, F. (2010). How do guide dogs and pet dogs (Canis familiaris) ask their owners for their toy and for playing? Animal Cognition, 13, 311-323.

Gaunet, F., \& Deputte, B. L. (2011). Functionally referential and intentional communication in the domestic dog: Effects of spatial and social contexts. Animal Cognition, 14, 849-860.

Genty, E., Breuer, T., Hobaiter, C., \& Byrne, R. W. (2009). Gestural communication of the gorilla (Gorilla gorilla): Repertoire, intentionality and possible origins. Animal Cognition, 12, 527-546.

Genty, E., \& Byrne, R.W. (2010). Why do gorillas make sequences of gestures? Animal Cognition, 13, 287-301. 
Gómez, J. C. (2007). Requesting gestures in captive monkeys and apes: Conditioned responses or referential behaviours? In K. Liebal, C. Müller, \& S. Pika (Eds.), Gestural communication in nonhuman and human primates (pp. 81-94). Amsterdam, Netherland: John Benjamins Publishing.

Griffin. D. R. (1976). The question of animal awareness. New York: Rockefeller University.

Hare, B., Call, J., \& Tomasello, M., (1998). Communication of food location between human and dog (Canis familiaris). Evolution of Communication, 2, 137-159.

Hare, B., \& Tomasello, M. (1999). Domestic dogs use human and conspecific social cues to locate hidden food. Journal of Comparative Psychololy, 113-173.

Hare, B., Brown, M., Williamson, C., \& Tomasello, M. (2002). The domestication of social cognition in dogs. Science, 298, 1634-1636.

Hare, B., \& Tomasello, M. (2004). Chimpanzees are more skilful in competitive than in cooperative cognitive tasks. Animal Behaviour, 68, 571-581.

Hare, B., \& Tomasello, M. (2005). Human-like social skills in dogs? Trends in Cognition Science, 9, 439-444.

Hobaiter, C., \& Byrne, R. W. (2011). The gestural repertoire of wild chimpanzess. Animal Cognition, $14,745-767$.

Hollander, M., \& Wolfe, A. W. (1998). Nonparametric statistical methods (2nd ed.). New York: John Wiley \& Sons.

Hopkins, W. D., Russell, J., Freeman, H., Buehler, N. Reynolds, E., \& Schapiro, S. J. (2005). The distribution and development of handedness for manual gestures in captive chimpanzees (Pan troglodytes). Psychological Science, 16(6), 487-493. 
Hopkins, W. D., Taglialatela, J. P., \& Leavens, D. A. (2007). Chimpanzees differentially produce novel vocalizations to capture the attention of a human. Animal Behaviour, 73, 281-286.

Hostetter, A. B., Cantero M., \& Hopkins, W. D. (2001). Differential use of vocal and gestural communication by chimpanzees (Pan Troglodytes). Journal of Comparative Psychology, 115, 337-343.

Jakovcevic, A., Mustaca, A., \& Bentosela M. (2012). Do more sociable dogs gaze longer to the human face than less sociable ones? Behavioral Processes, 90(2), 217-22.

Kaminski, J., Call J., \& Tomasello. M. (2004). Body orientation and face orientation: Two factors controlling apes' begging behaviour from humans. Animal Cognition, 7, 216-223.

Kaminski, J., Call, J., \& Fischer, J. (2004). Word learning in a domestic dog: Evidence for "fast mapping”. Science, 304, 1682-1683.

Kaminski, J. Brauer, J., Call, J., \& Tomasello, M. (2009). Domestic dogs are sensitive to the humans perspective. Behaviour, 146, 979-998.

Kaminski, J. Neumann, M., Bräuer, J., Call, J., \& Tomasello, M. (2011). Dogs, Canis familiaris, communicate with humans to request but not to inform. Animal Behaviour, 82, 651-658.

Kubinyi, E., Virányi, Z., \& Miklósi, Á. (2007). Comparative social cognition: From wolf to dog to humans. Comparative Cognition and Behavior Reviews, 2, 26-46.

Leavens, D. A., Hopkins, W. D., \& Bard, K. A. (1996). Indexical and referencial pointing in chimpanzees (Pan troglodytes). Journal of Comparative Psychology, 110, 346-353.

Leavens, D. A., Russell, J. L., \& Hopkins, W. D. (1998). Intentional communication by chimpanzees: A cross-sectional study of the use of referential gesture. Development Psychology, 34(5), 813822.

Leavens, D. A. (2004a). Manual deixis in apes and humans. Interaction Studies, 5(3), 387-408. 
Leavens, D. A., Hopkins, W. D., \& Thomas, R. K. (2004b). Referencial communication by chimpanzees (Pan troglodytes). Journal of Comparative Psychology, 118, 48-57.

Leavens, D. A., Hostetter, A. B., Wesley, J., \& Hopkins, W. D. (2004c). Tactical use of unimodal and bimodal communication by chimpanzees, Pan troglodytes. Animal Behaviour, 67, 467-476.

Leavens, D. A., Hopkins, W. D., \& Bard, K. (2005a). Understanding the point of chimpanzee pointing - Epigenesis and ecological validity. Current Directions in Psychological Science, 14(4), 185189.

Leavens, D. A., Russell, J. L., \& Hopkins, W. D. (2005b). Intentionality as measures in the persistence and elaboration of communication by chimpanzees (Pan troglodytes). Child Development, 76(1), 291-306.

Leavens, D. A., \& Hopkins, W. D. (2007). Multimodal concomitants of manual gesture by chimpanzees (Pan troglodytes): Influence of food size and distance. In K. Liebal, C. Müller, \& S. Pika (Eds.), Gestural communication in nonhuman and human primates (pp. 69-82). Amsterdam, Netherland: John Benjamins Publishing.

Leavens, D. A., Russell, J. L., \& Hopkins, W. D. (2010). Multimodal communication by captive chimpanzees (Pan troglodytes). Animal Cognition, 13, 33-40.

Legerstee, M., \& Barillas, Y. (2003). Sharing attention and pointing to objects at 12 months: Is the intentional stance implied? Cognitive Development, 18, 91-110.

Liebal, K., Call, J., \& Tomasello, M. (2004). Use of gesture sequences in chimpanzees. American Journal of Primatology, 64, 377-396.

Liszkowski, U., Carpenter, M., Henning, A., Striano, T., \& Tomasello, M. (2004). Twelve-month-olds point to share attention and interest. Developmental Science, 7(3), 297-307. 
Liszkowski, U., Carpenter, M., \& Tomasello, M. (2007a). Pointing out new news, old news, and absent referents at 12 months of age. Developmental Science, 10(2), F1-F7.

Liszkowski, U. (2007b). Human twelve-month-olds point cooperatively to share interest with and helpfully provide information for a communicative partner. In K. Liebal, C. Müller, \& S. Pika (Eds.), Gestural Communication in Nonhuman and Human Primates (pp. 121-138). Amsterdam, Netherland: John Benjamins.

Liszkowski, U., Carpenter, M., \& Tomasello, M. (2008). Twelve-month-olds communicate helpfully and appropriately for knowledgeable and ignorant partners. Cognition, 108(3), 732-739.

Liszkowski, U., Schäfer, M., Carpenter, M., \& Tomasello, M. (2009). Prelinguistic infants, but not chimpanzees, communicate about absent entities. Psychological Science, 20, 654-660.

Liszkowski, U. (2011). Three lines in the emergence of prelinguistic communication and social cognition. Journal of Cognitive Education and Psychology, 10(1), 32-43.

Macedonia, J. M., \& Evans, C. S. (1993). Variation among mammalian alarm call systems and the problem of meaning in animals signals. Ethology, 93, 177-193.

McKinley, J., \& Sambrook, T. (2000). Use of human-given cues by domestic dogs (Canis familiaris) and horses (Equus caballus). Animal Cognition, 3, 13-22.

Marshall-Pescini, S., Passalacqua, C., Barnard, S., Valsecchi, P., \& Prato Previde, E. (2009). Agility and search and rescue training differently affects pet dogs' behaviour in socio-cognitive task. Behavioural Processes, 78, 449-454.

Merola, I., Prato-Previde, E., \& Marshall-Pescini. S. (2012). Social referencing in dog-owner dyads? Animal Cognition, 15(2),175-185.

Miklósi, Á., Polgárdi, R., Topál, J., \& Csányi, V. (1998). Use of experimenter-given cues in dogs. Animal Cognition, 1, 113-128. 
Miklósi, Á., Polgárdi, R., Topál, J., \& Csányi, V. (2000). Intentional behavior in dog human communication: An experimental analysis of "showing" behaviour in the dog. Animal Cognition, 3, 159-166.

Miklósi, Á., Kubinyi, E., Topál, J., Gácsi, M., Virányi, Z., \& Csányi, V. (2003). A simple reason for a big difference: Wolves do not look back at humans, but dogs do. Current Biology, 13, 763-766.

Miklósi, Á., Topál, J., \& Csányi, V. (2004). Comparative social cognition: What can dogs teach us? Animal Behaviour, 67, 995-1004.

Miklósi, Á., \& Soproni, K. (2006). A comparative analysis of animals' understanding of the human pointing gesture. Animal Cognition, 9, 81-93.

Miklósi, Á. (2007). Dog behaviour, evolution and cognition. Oxford: Oxford University Press.

Passalacqua, C., Marshall-Pescini, S., Barnard, S., Lakatos, G., Valsecchi, P., \& Prato Previde, E. (2011). Human-directed gazing behaviour in puppies and adult dogs, Canis lupus familiaris. Animal Behaviour, 82, 1043-1050.

Pika, S., \& Mitani, J. (2006). Referential gestural communication in wild chimpanzees (Pan troglodytes). Current Biology, 16(6), R191-R192.

Pika, S., Liebal, K., Call, J., \& Tomasello, M. (2007). The gestural communication of apes. In K. Liebal, C. Müller, \& S. Pika (Eds.), Gestural communication in nonhuman and human primates (pp. 35-49). Amsterdam, Netherland: John Benjamins Publishing.

Pika, S., Liebal, K., \& Tomasello, M. (2003). Gestural communication in young gorillas (Gorilla gorilla): Gestural repertoire, learning, and use. American Journal of Primatology, 60, 95-111.

Pilley, J. W., \& Reid, A. K. (2011). Border collie comprehends object names as verbal referents. Behavioral Process, 86(2), 184-195. 
Pollick, A. S., \& de Waal, F. B. M. (2007). Ape gestures and language evolution. PNAS, 104(19), 8184-8189.

Povinelli, D. J., \& Eddy, T. J. (1996). What young chimpanzees know about seeing. Monographs of the Society for Research in Child Development, 61, 1-152.

Prato-Previde, E., Custance, D. M., Spiezio, C., \& Sabatini, F. (2003). Is the Dog-Human relationship an attachment bond? An observational study using Ainsworth's Strange Situation. Behaviour, $140,225-254$.

Ramos D., \& Ades C. (2012). Two-Item sentence comprehension by a dog (Canis familiaris). PLoS ONE 7(2): e29689. doi:10.1371/journal.pone.0029689

Range, F., Heucke, S. L, Gruber, C., Konz, A., Huber, L., \& Virányi, Z. (2009a). The effect of ostensive cues on dogs' performance in a manipulative social learning task. Applied Animal Behaviour Science, 120, 170-178.

Range, F., Horn, L., Bugnyar, T., Gajdon, G. K., \& Huber, L. (2009b). Social attention in keas, dogs, and human children. Animal Cognition, 12, 181-192.

Range, F., Hentrup, M., \& Virányi, Z. (2011). Dogs are able to solve a means-end task. Animal Cognition, 14, 575-583

Reid, P. J. (2009). Adapting to the human world: Dogs' responsiveness to our social cues. Behavioural Processes, 80, 325-333.

Riedel, J., Schumann, K., Kaminski, J., Call, J., \& Tomasello, M. (2008). The early ontogeny of human-dog communication. Animal Behaviour, 75, 1003-1014.

Rochat, P. (2007). Intentional action arises from early reciprocal exchanges. Acta Psychologica, 124, $8-25$. 
Rossi, A. P., \& Ades, C. (2008). A dog at the keyboard: Using arbitrary signs to communicate requests. Animal Cognition, 11, 329-338.

Russon A., \& Andrews, K. (2010). Orangutan pantomime: Elaborating the message. Biology Letters. doi:10.1098/rsbl.2010.0564

Russell, J. L., Braccini, S., Buehler, N. Kachin, M. J., Schapiro, S. J., \& Hopkins, W. D. (2005). Chimpanzee intentional communication is not contingent upon food. Animal Cognition, 8, 263272.

Savalli, C., Brandão, M. M., Domingues, T. S., Honório, M. A., \& Ades, C. (2009). Dog-human communication through a keyboard: Is human attentional state relevant? Journal of Veterinary: Clinical Applications and Research, 4(2), 55.

Savalli, C., Resende, B. D., \& Ades C. (in preparation). Are dogs sensitive to the human's visual perspective and signs of attention when using a keyboard with arbitrary symbols to communicate?

Savage-Rumbaugh, S., \& Lewin, R. (1994). Kanzi: The ape at the brink of the human mind. New York: John Wiley \& Sons.

Scott-Phillips, T. C., Blythe, R. A., Gardner, A., \& West, S. A. (2011). How do communication systems emerge? Proceedings of the Royal Society B, doi:10.1098/rspb.2011.2181.

Seyfarth, R. M., Cheney, D. L., \& Marler, P. (1980). Vervet monkey alarm calls: Semantic communication in a free-ranging primate. Animal Behaviour, 28, 1070-1094.

Seyfarth, R. M., \& Cheney, D. L. (1986). Vocal development in vervet monkeys. Animal Behaviour, $34,1640-1658$.

Seyfarth, R. M., \& Cheney, D. L. (1990). The assessment by vervet monkeys of their own and another species'alarm calls. Animal Behaviour, 40, 754-764. 
Seyfarth, R. M., \& Cheney, D. L. (2003). Meaning and emotion in animal vocalizations. Annals of New York Academy Science, 1000, 32-55.

Seyfarth, R. M., Cheney, D. L., Bergman, T., Fischer, J., Zuberbühler, K., \& Hammerschmidt, K. (2010a). The central importance of information in studies of animal communication. Animal Behaviour, 80, 3-8.

Seyfarth, R. M., \& Cheney, D. L. (2010b). Production, usage and comprehension in animal vocalizations. Brain and Language, 115, 92-100.

Shepherd, S. V. (2010). Following gaze: Gaze-following behavior as a window into social cognition. Frontiers in Integrative Neuroscience, 4(5), 1-13.

Shettlleworth, S. J. (2010). Cognition, evolution and behavior (2nd ed). New York: Oxford University.

Slocombe, K. E., \& Zuberbuler, K. (2005). Functionally referential communication in a chimpanzee. Current Biology, 15, 1779-1784.

Slocombe, K. E., \& Zuberbuhler, K. (2007). Chimpanzees modify recruitment screams as a function of audience composition. PNAS, 104 (43), 17228-17233.

Soproni, K., Miklósi, Á., Topál, J., \& Csányi, V. (2001). Comprehension of human communicative signs in pet dogs (Canis familiaris). Journal of Comparative Psychology, 115, 122-126.

Téglás, E., Gergely, A., Kupán, K., Miklósi, Á., \& Topál, J. (2012). Dogs’ gaze following is tuned to human communicative signals. Current Biology, 22, 1-4.

Tomasello, M., Call, J., Nagell, K., Olguin, R., \& Carpenter, M. (1994). The learning and use of gestural signals by young chimpanzees: A trans-generational study. Primates, 35, 137-154.

Tomasello, M., \& Rakoczy, H. (2003). What makes human cognition unique? From individual to shared to collective intentionality. Mind \& Language, 18(2), 121-147. 
Tomasello M., Carpenter M., Call, J., Behne, T., \& Moll, H. (2005). Understanding and sharing intentions: The origins of cultural cognition. Behavioral and Brain Sciences, 28, 675-735.

Tomasello, M., Carpenter, M., \& Liszkowski, U. (2007). A new look at infant pointing. Child Development, 78(3), 705-722.

Topál, J., Gácsi, M., Miklósi, Á., Virányi, Z., Kubinyi, E., \& Csányi, V. (2005). Attachment to humans: A comparative study on hand-reared wolves and differently socialized dog puppies. Animal behaviour, 70, 1367-1375.

Townsend, S. W., \& Manser. M. B. (2012). Functionally referential communication in mammals: The past, present and the future. Ethology, 118, 1-11.

Wobber, V., Hare, B., Koler-Matznick, J., Wrangham, R., \& Tomasello, M. (2009). Breed differences in domestic dogs' (Canis familiaris) comprehension of human communicative signals. Interactions Studies, 10, 206-224.

Wynne, C. D. L., Udell, M. A. R., \& Lord, K. A. (2008). Ontogeny's impacts on human-dog communication. Animal Behaviour, 76, e1-e4.

Udell, M. A. R., Giglio, R. F., \& Wynne, C. D. L. (2008a). Domestic dogs (Canis familiaris) use human gestures but not nonhuman tokens to find hidden food. Journal of Comparative Psychololy, 122, 84-93.

Udell, M. A. R., Dorey, N. R., \& Wynne, C. D. L. (2008b). Wolves outperform dogs in following human social cues. Animal Behaviour, 76, 1767-1773.

Udell, A. R., \& Wynne, C. D. L. (2010). Ontogeny and phylogeny: Both are essential to humansensitive behaviour in the genus Canis. Animal Behaviour, 79, e9-e14.

Udell, M. A. R., Dorey, N. R., \& Wynne, C. D. L. (2011). Can your dog read your mind? Understanding the causes of canine perspective taking. Learning Behaviour, 39, 289-302. 
Virányi, Z., Topál, J., Gácsi, M., Miklósi, Á., \& Csányi, V. (2004). Dogs respond appropriately to cues of human's attentional focus. Behavioural Processes, 66, 161-172.

Virányi, Z., Topál J., Miklósi Á., \& Csányi V. (2006). A non-verbal test of knowledge attribution: A comparative study on dogs and children. Animal Cognition, 9, 13-26.

Von Frisch, K. (1955). The dancing bees. NewYork: Harcout, Brace and World.

Xitco, J. M. J., Gory, J. D., \& Kuczaj, S. A. (2001). Spontaneous pointing by bottlenose dolphins (Tursiops truncatus). Animal Cognition, 4, 115-123.

Yamamoto, M., Ohtanib, N., \& Ohtab, M. (2011). The response of dogs to attentional focus of human beings: A comparison between guide dog candidates and other dogs. Journal of Veterinary Behavior, 6, 4-11.

Yamamoto, S., Humleb, T., \& Tanakac, M. (2012). Chimpanzees' flexible targeted helping based on an understanding of conspecifics' goals. PNAS, 109(9), 3588-3592.

Zimmermann, F., Zemke, F., Call, J., \& Gómez, J. C. (2009). Orangutans (Pongo pygmaeus) and bonobos (Pan paniscus) point to inform a human about the location of a tool. Animal Cognition, 12, 347-358.

Zuberbuhler, K., Cheney, D. L., \& Seyfarth, R. M. (1999). Conceptual semantics in a nonhuman primate. Journal of Comparative Psychology, 113, 33-42.

Zuberbuhler, K. (2000). Interspecific semantic communication in two forest monkeys. Proceedings of the Royal Society B, 267, 713-718.

Zuberbuhler, K. (2003). Referential signaling in non-human primates: Cognitive precursors and limitations for the evolution of language. Advances in the Study of Behavior, 33, 265-307.

Zuberbuhler, K. (2008). Referentiality and concepts in animal cognition. In Encyclopedia of neuroscience. Oxford: Oxford University. 


\section{Suplementary 1 - Tables of Experiment 1}

Table 1 - Medians (Interquartile ranges - IQR) for the relative durations and numbers of the variables and the two-sample Wilcoxon rank signed tests for the comparisons of the first and last pre-delivery phases for Food, Half Food or Undesirable Food condition ( $=29$ dogs).

\begin{tabular}{lcccc}
\hline Behaviors/ & \multicolumn{2}{c}{ Median (IQR) } & & \\
\cline { 2 - 4 } Location & $\begin{array}{c}\text { First pre-delivery } \\
\text { phase }\end{array}$ & $\begin{array}{c}\text { Last pre-delivery } \\
\text { phase }\end{array}$ & $\boldsymbol{T}$ & $\boldsymbol{p}$ \\
\hline Gaze Owner (duration) & $0.22(0.19)$ & $0.24(0.23)$ & -52.5 & 0.264 \\
Gaze Food (duration) & $0.23(0.37)$ & $0.21(0.28)$ & -14.5 & 0.760 \\
Gaze Alternation (number) & $2(5)$ & $3(5)$ & -30 & 0.339 \\
\hline Food area (duration) & $0.45(0.72)$ & $0.52(0.63)$ & -32 & 0.452 \\
\hline
\end{tabular}

Table 2 - Medians (Interquartile ranges - IQR) for the relative durations and numbers of the variables, and the Friedman tests for the comparisons of the three pre-delivery phases of Food, Half-food and Undesirable (Und.) Food conditions ( $\mathrm{n}=29$ dogs; ddl=2).

\begin{tabular}{|c|c|c|c|c|c|c|c|c|c|c|}
\hline \multirow{2}{*}{$\begin{array}{l}\text { Behaviors/ } \\
\text { Location }\end{array}$} & \multicolumn{3}{|c|}{$\begin{array}{c}\text { Duration: } \\
\text { Median (IQR) }\end{array}$} & \multirow[b]{2}{*}{$\chi^{2}$} & \multirow[b]{2}{*}{$p$} & \multicolumn{3}{|c|}{$\begin{array}{c}\text { Number: } \\
\text { Median (IQR) }\end{array}$} & \multirow[b]{2}{*}{$\chi^{2}$} & \multirow[b]{2}{*}{$p$} \\
\hline & Food & Half-food & Und. Food & & & Food & Half-food & Und. Food & & \\
\hline Gaze Owner & $0.22(0.25)$ & $0.27(0.30)$ & $0.24(0.25)$ & 2.69 & 0.261 & $0.17(0.13)$ & $0.17(0.10)$ & $0.13(0.10)$ & 0.40 & 0.820 \\
\hline Gaze Food & $0.29(0.36)$ & $0.26(0.34)$ & $0.20(0.36)$ & 2.48 & 0.289 & $0.17(0.17)$ & $0.17(0.20)$ & $0.10(0.17)$ & 4.01 & 0.134 \\
\hline $\begin{array}{l}\text { Gaze Alternation } \\
\text { owner/food }\end{array}$ & - & - & - & & & $3(4)$ & $4(5)$ & $2(4)$ & 1.94 & 0.378 \\
\hline Vocalisation & $0(0)$ & $0(0)$ & $0(0)$ & 1.35 & 0.508 & $0(0)$ & $0(0)$ & $0(0)$ & 0.60 & 0.741 \\
\hline Mouth licking & $0(0)$ & $0(0)$ & $0(0)$ & 1.12 & 0.572 & $0(0)$ & $0(0)$ & $0(0)$ & 1.23 & 0.542 \\
\hline $\begin{array}{l}\text { Sonorous Mouth } \\
\text { licking }\end{array}$ & $0(0)$ & $0(0.04)$ & $0(0)$ & 2.43 & 0.297 & $0(0)$ & $0(0.03)$ & $0(0)$ & 2.98 & 0.226 \\
\hline Contact & $0(0)$ & $0(0)$ & $0(0)$ & 2.82 & 0.244 & $0(0)$ & $0(0)$ & $0(0)$ & 2.00 & 0.368 \\
\hline Food area & $0.49(0.82)$ & $0.49(0.70)$ & $0.48(0.69)$ & 0.13 & 0.937 & - & - & - & & \\
\hline
\end{tabular}


Table 3 - Medians (Interquartile ranges - IQR) for the relative durations and numbers for the variables (including the combinations of location and behaviors), and the one-sample Wilcoxon rank signed tests to evaluate whether the variables differ from zero in the pre-delivery phase with Food + Owner $(\mathrm{F}+\mathrm{O})$ condition $(\mathrm{n}=29$ dogs). Significant differences are in bold.

\begin{tabular}{|c|c|c|c|c|c|c|c|}
\hline & & \multirow{2}{*}{$\begin{array}{c}\text { Duration: } \\
\text { Median (IQR) } \\
\text { F+O }\end{array}$} & \multirow[b]{2}{*}{$T$} & \multirow[b]{2}{*}{$p$} & \multirow{2}{*}{$\begin{array}{c}\text { Number: } \\
\text { Median (IQR) } \\
\text { F+O }\end{array}$} & \multirow[b]{2}{*}{$\boldsymbol{T}$} & \multirow[b]{2}{*}{$p$} \\
\hline & & & & & & & \\
\hline \multirow{7}{*}{ 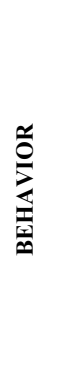 } & Gaze Owner & $0.24(0.21)$ & 217.5 & $<0.0001$ & $0.13(0.10)$ & 217.5 & $<0.0001$ \\
\hline & Gaze Food & $0.26(0.33)$ & 217.5 & $<0.0001$ & $0.13(0.10)$ & 217.5 & $<0.0001$ \\
\hline & $\begin{array}{l}\text { Gaze Alternation } \\
\text { owner/food }\end{array}$ & - & - & - & $3(4)$ & 162.5 & $<0.0001$ \\
\hline & Vocalisation & $0(0)$ & 5.0 & 0.125 & $0(0)$ & 5.0 & 0.125 \\
\hline & Mouth Licking & $0(0)$ & 5.0 & 0.125 & $0(0)$ & 5.0 & 0.125 \\
\hline & Sonorous Mouth Licking & $0(0)$ & 10.5 & 0.030 & $0(0)$ & 10.5 & 0.030 \\
\hline & Contact & $0(0)$ & 0.5 & 1.000 & $0(0)$ & 0.5 & 1.000 \\
\hline LOC. & Food Area & $0.48(0.67)$ & 189 & $<0.0001$ & - & - & - \\
\hline \multirow{5}{*}{ 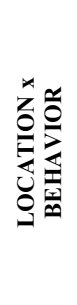 } & Food area x Gaze Owner & $0.08(0.18)$ & 150 & $<0.0001$ & - & - & - \\
\hline & Food area x Gaze Food & $0.13(0.33)$ & 126.5 & $<0.0001$ & - & - & - \\
\hline & $\begin{array}{l}\text { Food area x Gaze } \\
\text { Alternation owner/food }\end{array}$ & $1(3)$ & 68 & $<0.0001$ & - & - & - \\
\hline & Food area $\mathrm{x}$ Vocalisations & $0(0)$ & 3 & 0.250 & - & - & - \\
\hline & $\begin{array}{l}\text { Food area x Sonorous } \\
\text { Mouth Licking }\end{array}$ & All zero & \multicolumn{2}{|c|}{ Not tested } & - & - & - \\
\hline
\end{tabular}

Table 4 - Medians (Interquartile ranges - IQR) for the relative durations and numbers of the variables (including the combinations of location and behaviors), and the two-sample Wilcoxon rank signed tests for the comparisons of pre-delivery phase with Food + Owner $(F+O)$ and Absence of Owner $(A O)$ conditions $(n=29$ dogs $)$. Significant differences are in bold.

\begin{tabular}{|c|c|c|c|c|c|c|c|c|c|}
\hline & & \multicolumn{2}{|c|}{$\begin{array}{c}\text { Duration: } \\
\text { Median (IQR) }\end{array}$} & \multirow[b]{2}{*}{$T$} & \multirow[b]{2}{*}{$p$} & \multicolumn{2}{|c|}{$\begin{array}{c}\text { Number: } \\
\text { Median (IQR) }\end{array}$} & \multirow[b]{2}{*}{$T$} & \multirow[b]{2}{*}{$p$} \\
\hline & & $\mathbf{F}+\mathbf{O}$ & AO & & & $\mathbf{F}+\mathbf{O}$ & AO & & \\
\hline 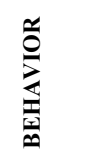 & Gaze food & $0.26(0.33)$ & $0.12(0.20)$ & 95.5 & 0.037 & $0.13(0.10)$ & $0.10(0.13)$ & 9 & 0.803 \\
\hline LOC. & Food area & $0.48(0.68)$ & $0.16(0.28)$ & 107 & 0.012 & - & - & - & - \\
\hline
\end{tabular}


Table 5 - Medians (Interquartile ranges - IQR) for the relative durations and numbers of the variables (including the combinations of locations and behaviors), and the two-sample Wilcoxon rank signed tests for the comparisons of pre-delivery phase with Food + Owner $(\mathrm{F}+\mathrm{O})$ and Absence of Food (AF) conditions $(\mathrm{n}=29$ dogs). Significant differences are in bold.

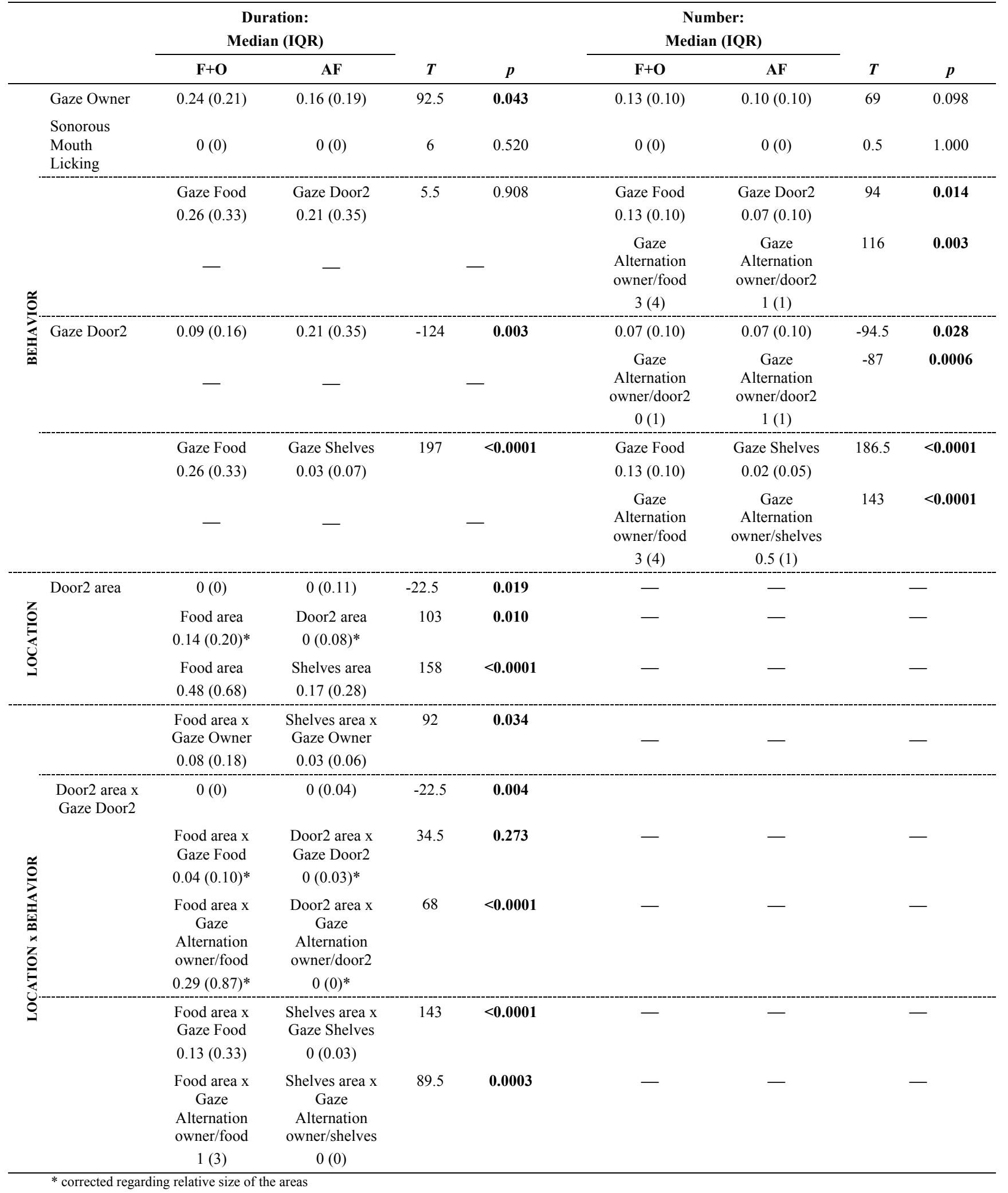


Table 6 - Medians (Interquartile ranges - IQR) for the relative durations and numbers of the variables (including the combinations of locations and behaviors), and the two-sample Wilcoxon rank signed tests for the comparisons of pre-delivery phase with Food + Owner $(\mathrm{F}+\mathrm{O})$ and Owner Turned (OT) conditions $(\mathrm{n}=29$ dogs). Significant differences are in bold.

\begin{tabular}{|c|c|c|c|c|c|c|c|c|c|}
\hline & & \multicolumn{2}{|c|}{$\begin{array}{c}\text { Duration: } \\
\text { Median (IQR) }\end{array}$} & \multirow[b]{2}{*}{$T$} & \multirow[b]{2}{*}{$p$} & \multicolumn{2}{|c|}{$\begin{array}{c}\text { Number: } \\
\text { Median (IQR) }\end{array}$} & \multirow[b]{2}{*}{$T$} & \multirow[b]{2}{*}{$p$} \\
\hline & & $\mathbf{F}+\mathbf{O}$ & OT & & & $\mathbf{F}+\mathbf{O}$ & OT & & \\
\hline \multirow{7}{*}{ 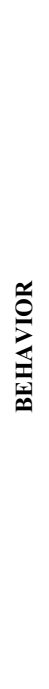 } & Gaze Owner & $0.24(0.21)$ & $0.04(0.10)$ & 175.5 & $<0.0001$ & $0.13(0.10)$ & $0.03(0.07)$ & 177 & $<0.0001$ \\
\hline & Gaze Food & $0.26(0.33)$ & $0.15(0.29)$ & 30 & 0.526 & $0.13(0.10)$ & $0.10(0.13)$ & 63.5 & 0.151 \\
\hline & & - & - & & - & $\begin{array}{c}\text { Gaze } \\
\text { Alternation } \\
\text { owner/food } \\
3(4)\end{array}$ & $\begin{array}{c}\text { Gaze } \\
\text { Alternation } \\
\text { owner/food } \\
0(0)\end{array}$ & 166 & $<0.0001$ \\
\hline & Vocalisations & $0(0)$ & $0(0)$ & -1.5 & 0.813 & $0(0)$ & $0(0)$ & 2.5 & 0.625 \\
\hline & $\begin{array}{l}\text { Sonorous } \\
\text { Mouth licking }\end{array}$ & $0(0)$ & $0(0.02)$ & -1 & 0.953 & $0(0)$ & $0(0)$ & -2.5 & 1.000 \\
\hline & & $\begin{array}{c}\text { Gaze Owner } \\
0.24(0.21)\end{array}$ & $\begin{array}{c}\text { Gaze Owner's } \\
\text { back head } \\
0.11(0.16)\end{array}$ & 153.5 & 0.0003 & $\begin{array}{c}\text { Gaze Owner } \\
0.13(0.10)\end{array}$ & $\begin{array}{c}\text { Gaze Owner's } \\
\text { back head } \\
0.07(0.10)\end{array}$ & 175.5 & $<0.0001$ \\
\hline & & - & - & & — & $\begin{array}{c}\text { Gaze } \\
\text { Alternation } \\
\text { owner/food } \\
3(4)\end{array}$ & $\begin{array}{c}\text { Gaze } \\
\text { Alternation } \\
\text { owner's back } \\
\text { head/food } \\
0(2)\end{array}$ & 99 & 0.005 \\
\hline \multirow{2}{*}{ 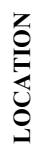 } & Food area & $0.48(0.68)$ & $0.31(0.71)$ & 45 & 0.339 & - & - & & - \\
\hline & Back area & $0(0.12)$ & $0.07(0.38)$ & -76 & 0.017 & - & - & & - \\
\hline \multirow{9}{*}{ 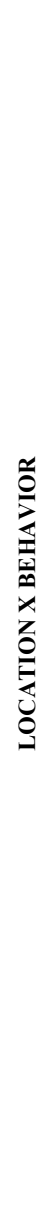 } & $\begin{array}{l}\text { Food area } x \\
\text { Gaze Food }\end{array}$ & $0.13(0.33)$ & $0.12(0.27)$ & -6.5 & 0.873 & - & - & & - \\
\hline & $\begin{array}{l}\text { Food area } \mathrm{x} \\
\text { Vocalisations }\end{array}$ & $0(0)$ & $0(0)$ & 0 & 1.000 & - & - & & - \\
\hline & $\begin{array}{l}\text { Food area } \mathrm{x} \\
\text { Sonorous } \\
\text { Mouth licking }\end{array}$ & $0(0)$ & $0(0)$ & -5 & 0.125 & - & - & & - \\
\hline & & $\begin{array}{c}\text { Food area x } \\
\text { Gaze Owner } \\
0.08(0.18)\end{array}$ & $\begin{array}{c}\text { Food area x } \\
\text { Gaze Owner's } \\
\text { back head } \\
0.03(0.11)\end{array}$ & 74.5 & 0.090 & - & - & & - \\
\hline & & $\begin{array}{c}\text { Food area } x \\
\text { Gaze } \\
\text { Alternation } \\
\text { owner/food } \\
1(3)\end{array}$ & $\begin{array}{c}\text { Food area x } \\
\text { Gaze } \\
\text { Alternation } \\
\text { owner's back } \\
\text { head/owner } \\
0(1)\end{array}$ & 40 & 0.141 & - & - & & - \\
\hline & & $\begin{array}{l}\text { Food area x } \\
\text { Gaze Owner } \\
0.04(0.09)^{*}\end{array}$ & $\begin{array}{c}\text { Back area x } \\
\text { Gaze Owner } \\
0(0.02)^{*}\end{array}$ & 89 & 0.029 & - & - & & - \\
\hline & & $\begin{array}{c}\text { Food area } x \\
\text { Gaze Food } \\
0.06(0.18)^{*}\end{array}$ & $\begin{array}{c}\text { Back area } x \\
\text { Gaze Food } \\
0(0)^{*}\end{array}$ & 136 & $<0.0001$ & - & - & & - \\
\hline & & $\begin{array}{c}\text { Food area x } \\
\text { Gaze } \\
\text { Alternation } \\
\text { owner/food } \\
0.47(1.41)^{*}\end{array}$ & $\begin{array}{c}\text { Back area } x \\
\text { Gaze } \\
\text { Alternation } \\
\text { owner/food } \\
0(0)^{*}\end{array}$ & 78.5 & 0.0001 & - & - & & - \\
\hline & & $\begin{array}{c}\text { Food area } \mathrm{x} \\
\text { Sonorous } \\
\text { Mouth licking } \\
0(0)^{*}\end{array}$ & $\begin{array}{c}\text { Back area x } \\
\text { Sonorous } \\
\text { Mouth licking } \\
0(0)^{*}\end{array}$ & -5 & 0.125 & - & - & & - \\
\hline
\end{tabular}


Table $7 \mathrm{a}$ - Medians (Interquartile ranges - IQR) for the relative durations and numbers of the variables and the two-sample Wilcoxon rank signed tests for the comparisons between pre and post-delivery phases for Food, Half-food and Undesirable food (Und. Food), as well as, for the comparisons between the post-delivery phases ( $n=29$ dogs). Significant differences are in bold. After the FDR BL adjustment, only the p-values shown in italics remain statistically significant.

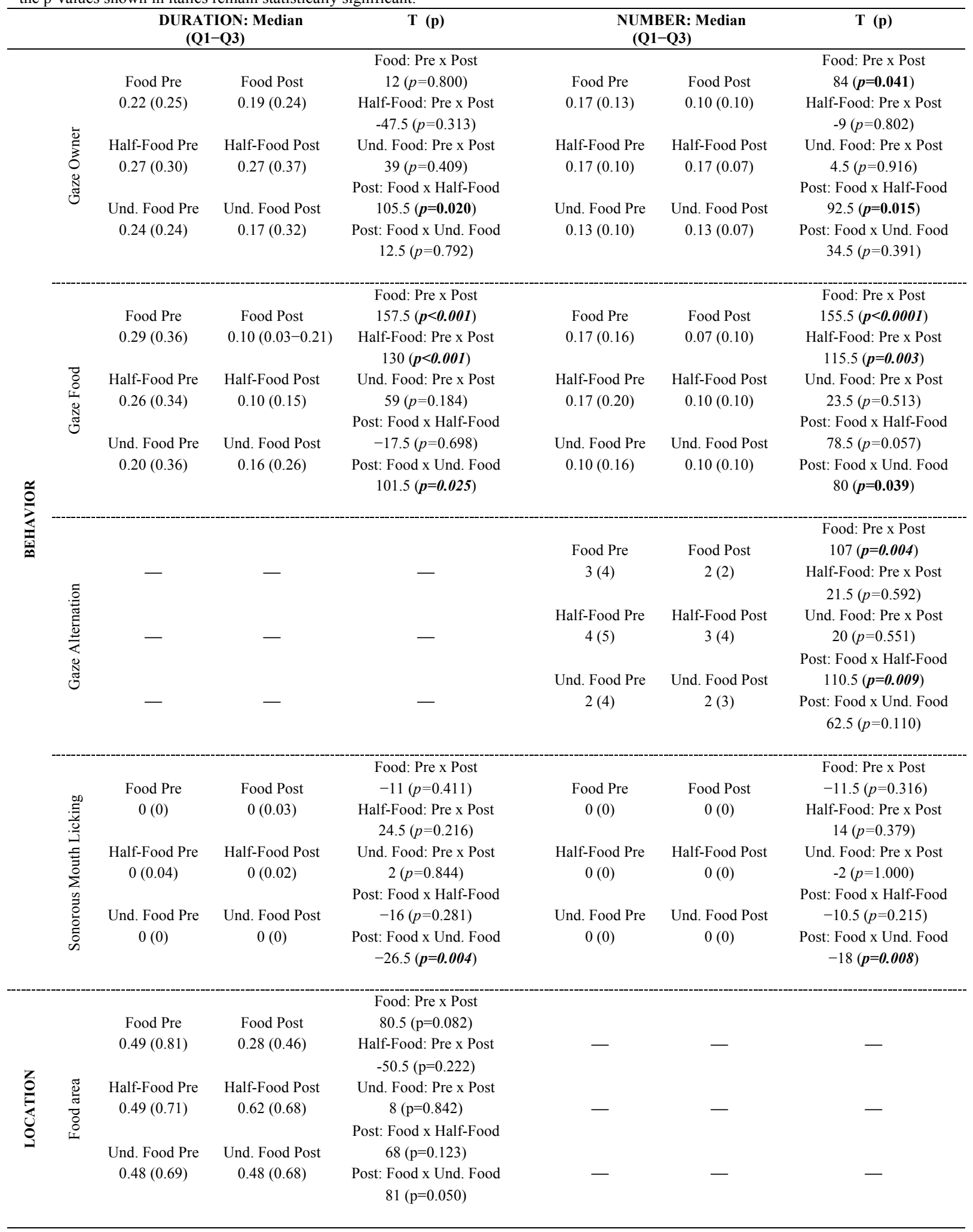


Table $7 \mathrm{~b}$ - Medians (Interquartile ranges - IQR) for the relative durations and numbers of the combinations of location and behaviors, and the two-sample Wilcoxon rank signed tests for the comparisons between pre and post-delivery phases for Food, Half-food and Undesirable food (Und. Food), as well as, for the comparisons between the post-delivery phases $(\mathrm{n}=29$ dogs). Significant differences are in bold. After the FDR BL adjustment, only the p-values shown in italics remain statistically significant (continuation)

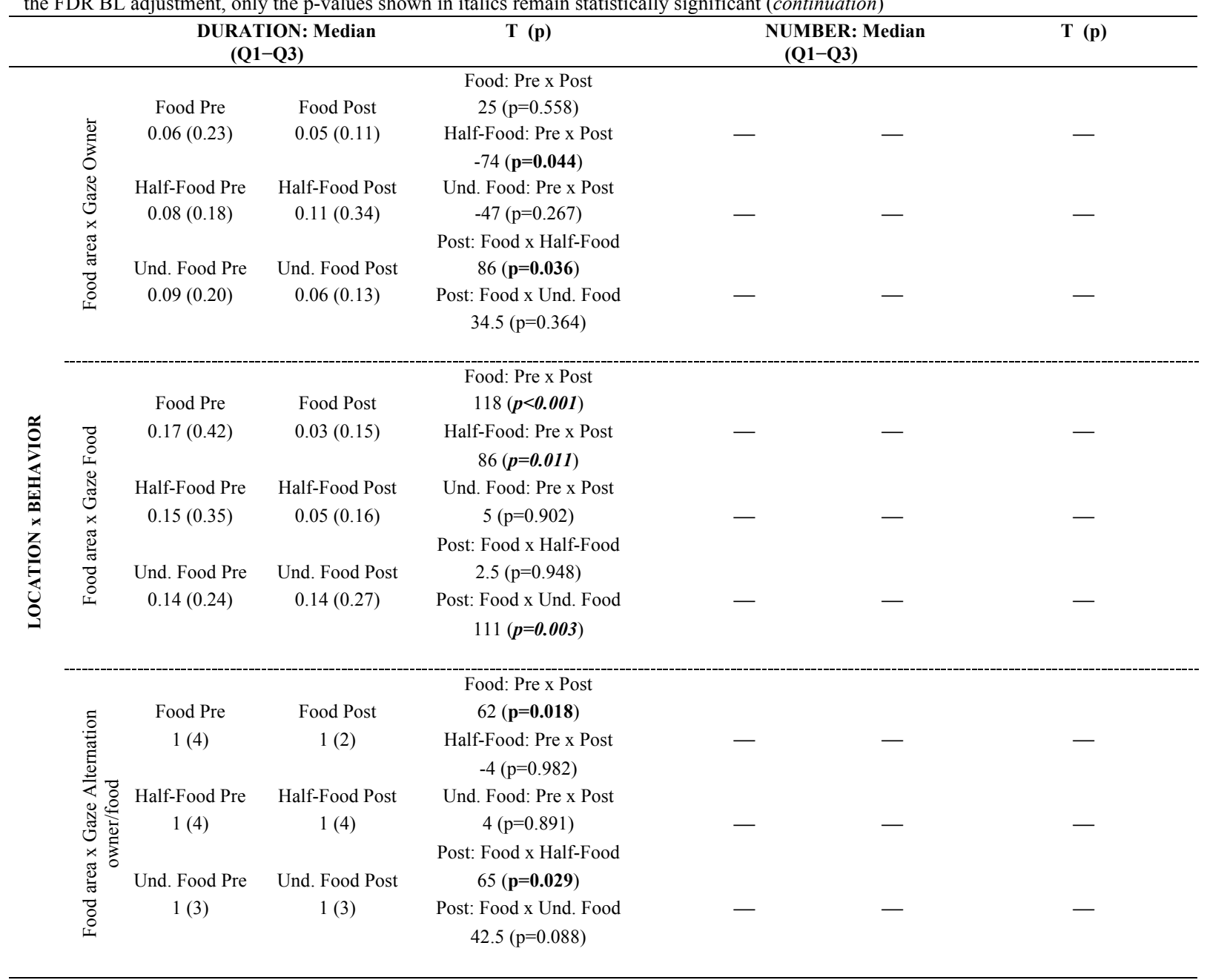


Table 8 - Percentages of dogs that exhibited multiple behavior (MB) in all areas or in Food area alone, and the Mc Nemar's test for the comparisons between pre and post-delivery phases for Food, Half-food and Undesirable food (Und. Food), as well as, for the comparisons between the post-delivery phases ( $\mathrm{n}=29$ dogs). Significant differences are in bold. After the FDR BL adjustment, only the p-values shown in italics remain statistically significant.

\begin{tabular}{|c|c|c|c|c|c|c|}
\hline & $\%$ of dogs $t$ & hibited MB & $\chi^{2}(\mathrm{df}=1, p)$ & $\begin{array}{l}\% \text { of dogs that ex } \\
\text { occurrences of bot } \\
\text { the first } 10 \text { sect }\end{array}$ & $\begin{array}{l}\text { MB by removing } \\
\text { of mouth licks in } \\
\text { ter eating food }\end{array}$ & $\chi^{2}(\mathrm{df}=1, p)$ \\
\hline \multirow{6}{*}{ 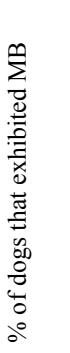 } & & & Food: Pre x Post & & & Food: Pre x Post \\
\hline & Food Pre & Food Post & $12(\boldsymbol{p}<0.001)$ & Food Pre & Food Post & $14(p<0.001)$ \\
\hline & $79.3 \%$ & $37.9 \%$ & $\begin{array}{c}\text { Half-Food: Pre x Post } \\
1.33(p=0.248)\end{array}$ & $79.3 \%$ & $31.0 \%$ & $\begin{array}{c}\text { Half-Food: Pre } \mathrm{x} \text { Post } \\
2.27(p=0.132)\end{array}$ \\
\hline & Half-Food Pre & Half-Food Post & Und. Food: Pre x Post & Half-Food Pre & Half-Food Post & Und. Food: Pre x Post \\
\hline & $79.3 \%$ & $65.5 \%$ & $2.27(p=0.132)$ & $79.3 \%$ & $62.1 \%$ & $2.27(p=0.132)$ \\
\hline & $\begin{array}{c}\text { Und. Food Pre } \\
75.9 \%\end{array}$ & $\begin{array}{c}\text { Und. Food Post } \\
58.6 \%\end{array}$ & $\begin{array}{l}\text { Post: Food x Half-Food } \\
6.40(\boldsymbol{p}=\mathbf{0 . 0 1 1}) \\
\text { Post: Food x Und. Food } \\
3.60(p=0.058)\end{array}$ & $\begin{array}{c}\text { Und. Food Pre } \\
75.9 \%\end{array}$ & $\begin{array}{c}\text { Und. Food Post } \\
58.6 \%\end{array}$ & $\begin{array}{c}\text { Post: Food x Half-Food } \\
7.36(\boldsymbol{p}=\mathbf{0 . 0 0 7}) \\
\text { Post: Food x Und. Food } \\
\quad 6.40(\mathbf{p}=\mathbf{0 . 0 1 1})\end{array}$ \\
\hline \multirow{9}{*}{ 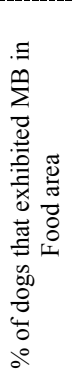 } & & & Food: Pre x Post & & & Food: Pre x Post \\
\hline & Food Pre & Food Post & $4.45(\mathbf{p}=\mathbf{0 . 0 3 5})$ & Food Pre & Food Post & $5.33(\mathbf{p}=\mathbf{0 . 0 2 1})$ \\
\hline & $55.2 \%$ & $31.0 \%$ & Half-Food: Pre x Post & $55.2 \%$ & $27.6 \%$ & Half-Food: Pre x Post \\
\hline & & & $1.60(p=0.206)$ & & & $1.60(p=0.206)$ \\
\hline & Half-Food Pre & Half-Food Post & Und. Food: Pre x Post & Half-Food Pre & Half-Food Post & Und. Food: Pre x Post \\
\hline & $55.2 \%$ & $41.4 \%$ & $1.60(p=0.206)$ & $55.2 \%$ & $41.4 \%$ & $1.60(p=0.206)$ \\
\hline & & & Post: Food x Half-Food & & & Post: Food x Half-Food \\
\hline & Und. Food Pre & Und. Food Post & $1.29(\mathrm{p}=0.257)$ & Und. Food Pre & Und. Food Post & $2(\mathrm{p}=0.157)$ \\
\hline & $58.6 \%$ & $44.8 \%$ & $\begin{array}{c}\text { Post: Food x Und. Food } \\
2.67(p=0.103)\end{array}$ & $58.6 \%$ & $44.8 \%$ & $\begin{array}{c}\text { Post: Food x Und. Food } \\
3.57(p=0.059)\end{array}$ \\
\hline
\end{tabular}

Table 9 - Medians (Interquartile ranges - IQR) for the absolute number of multiple behaviors (MB) in all areas or in Food area alone, and the two-sample Wilcoxon rank signed tests for the comparisons between pre and post-delivery phases for Food, Half-food and Undesirable food (Und. Food), as well as, for the comparisons between the post-delivery phases $(n=29 \mathrm{dogs})$. Significant differences are in bold. After the FDR BL adjustment, only the p-values shown in italics remain statistically significant.

\begin{tabular}{|c|c|c|c|c|c|c|}
\hline & \multicolumn{2}{|c|}{$\begin{array}{c}\text { Number of MB } \\
\text { Median (Q1-Q3) }\end{array}$} & $\mathbf{T}(\mathbf{p})$ & \multicolumn{2}{|c|}{$\begin{array}{l}\text { Number of MB by removing } \\
\text { occurrences of both types of mouth licks } \\
\text { in the first } 10 \text { seconds after eating food } \\
\text { Median }(\mathrm{Q} 1-\mathrm{Q} 3)\end{array}$} & $T(p)$ \\
\hline \multirow{9}{*}{ 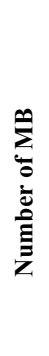 } & & & Food: Pre x Post & & & Food: Pre x Post \\
\hline & Food Pre & Food Post & $-79(p=0.002)$ & Food Pre & Food Post & $-89(\boldsymbol{p}<\boldsymbol{0 . 0 0 1})$ \\
\hline & $1(2)$ & $0(1)$ & Half-Food: Pre x Post & $1(2)$ & $0(1)$ & Half-Food: Pre x Post \\
\hline & & & $-30.5(p=0.385)$ & & & $-45.5(p=0.136)$ \\
\hline & Half-Food Pre & Half-Food Post & Und. Food: Pre x Post & Half-Food Pre & Half-Food Post & Und. Food: Pre x Post \\
\hline & $1(2)$ & $1(3)$ & $-18(p=0.450)$ & $1(2)$ & $1(2)$ & $-18(p=0.450)$ \\
\hline & & & Post: Food x Half-Food & & & Post: Food x Half-Food \\
\hline & Und. Food Pre & Und. Food Post & $46.5(\mathbf{p}=\mathbf{0 . 0 3 9})$ & Und. Food Pre & Und. Food Post & $\begin{array}{c}46.5(\mathbf{p}=\mathbf{0 . 0 3 9}) \\
\text { P. }\end{array}$ \\
\hline & $1(2)$ & $1(3)$ & $\begin{array}{l}\text { Post: Food x Und. Food } \\
50(\boldsymbol{p}=\mathbf{0 . 0 0 7})\end{array}$ & $1(2)$ & $1(3)$ & $\begin{array}{l}\text { Post: Food x Und. Food } \\
48(\boldsymbol{p}=\mathbf{0 . 0 0 4})\end{array}$ \\
\hline \multirow{8}{*}{ 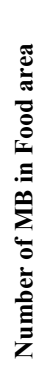 } & & & Food: Pre x Post & & & Food: Pre x Post \\
\hline & Food Pre & Food Post & $-44(\mathbf{p}=\mathbf{0 . 0 1 9})$ & Food Pre & Food Post & $-45(\mathbf{p}=\mathbf{0 . 0 1 7})$ \\
\hline & $1(2)$ & $0(1)$ & Half-Food: Pre x Post & $1(2)$ & $0(1)$ & Half-Food: Pre x Post \\
\hline & Half-Food Pre & Half-Food Post & Und. Food: Pre x Post & Half-Food Pre & Half-Food Post & Und. Food: Pre x Post \\
\hline & $1(2)$ & $0(1)$ & $-13(p=0.552)$ & $1(2)$ & $0(1)$ & $-13(p=0.552)$ \\
\hline & & & Post: Food x Half-Food & & & Post: Food x Half-Food \\
\hline & Und. Food Pre & Und. Food Post & $18.5(p=0.159)$ & Und. Food Pre & Und. Food Post & $22.5(p=0.120)$ \\
\hline & $1(2)$ & $0(2)$ & Post: Food x Und. Food & $1(2)$ & $0(2)$ & Post: Food x Und. Food \\
\hline
\end{tabular}




\section{Suplementary 2 - Tables of Experiment 2}

\begin{tabular}{|c|c|c|c|c|}
\hline \multirow{2}{*}{$\begin{array}{l}\text { Behaviors/ } \\
\text { Location }\end{array}$} & \multicolumn{2}{|c|}{ Median (IQR) } & \multirow[b]{2}{*}{$T$} & \multirow[b]{2}{*}{$p$} \\
\hline & $\begin{array}{l}\text { First three } \\
\text { conditions }\end{array}$ & $\begin{array}{l}\text { Last three } \\
\text { conditions }\end{array}$ & & \\
\hline Gaze Owner (duration) & $0.16(0.28)$ & $0.16(0.16)$ & 8.5 & 0.790 \\
\hline Gaze Food (duration) & $0.22(0.23)$ & $0.18(0.24)$ & -4 & 0.900 \\
\hline Gaze Alternation (number) & $2.5(4)$ & $2(3)$ & 5.5 & 0.837 \\
\hline Food area (duration) & $0.43(0.43)$ & $0.26(0.25)$ & 48.5 & 0.117 \\
\hline
\end{tabular}

Table 2 - Medians (Interquartile ranges - IQR) for the relative durations and number of the variables $(\mathrm{n}=22 \mathrm{dogs})$.

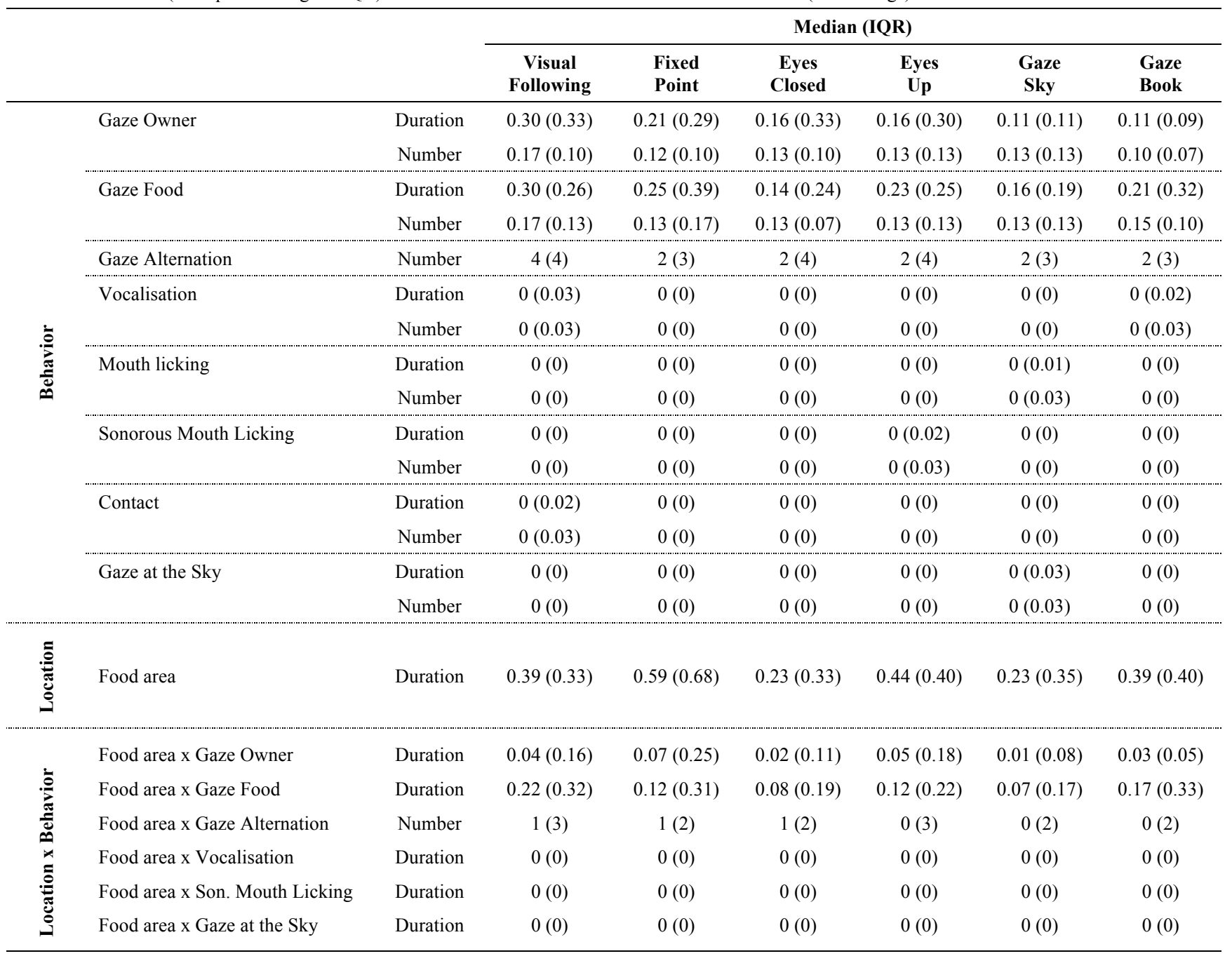


Table 3a - Multiple comparisons for the relative duration and number of the behaviors and the two-samples Wilcoxon rank signed tests $(\mathrm{n}=22$ dogs). Significant differences are in bold. After the FDR BL adjustment, only the p-values shown in italics remain statistically significant.

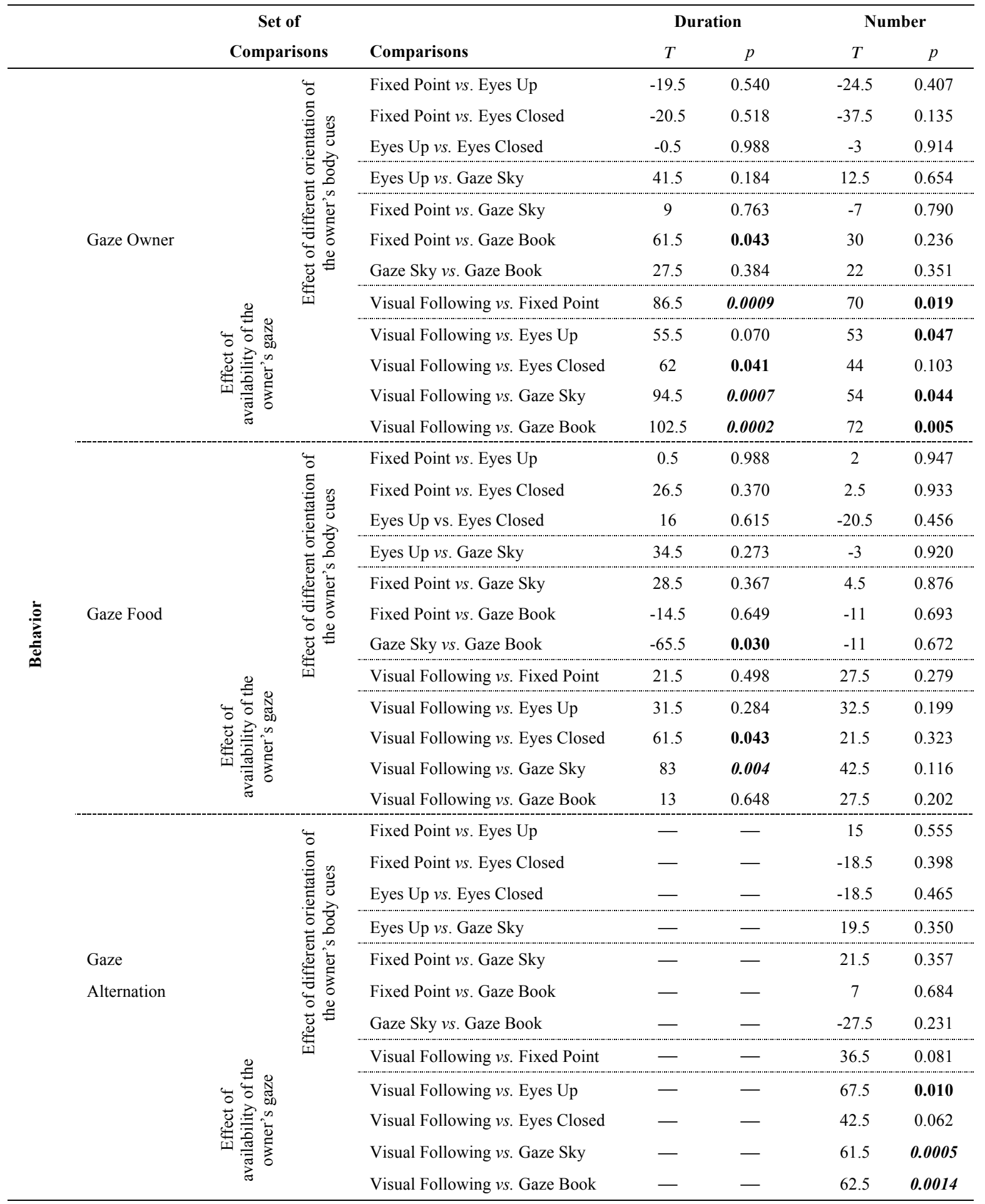


Table 3b - Multiple comparisons for the relative duration and number of the behaviors and the two-samples Wilcoxon rank signed tests $(\mathrm{n}=22$ dogs $)$. Significant differences are in bold. After the FDR BL adjustment, only the p-values shown in italics remain statistically significant (continuation).

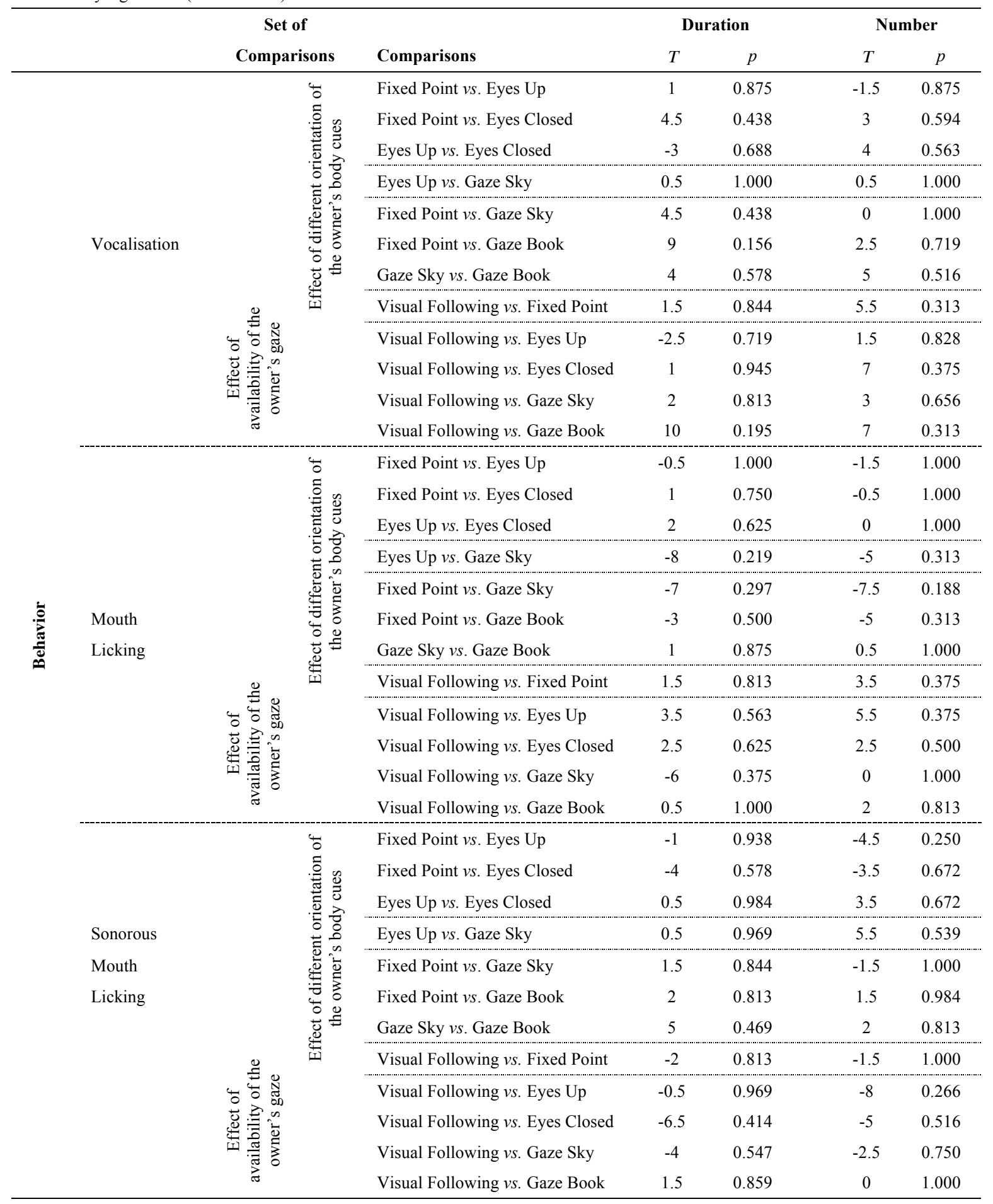


Table 3c - Multiple comparisons for the relative duration and number of behaviors and the relative duration of location and the twosamples Wilcoxon rank signed tests $(n=22$ dogs $)$. Significant differences are in bold. After the FDR BL adjustment, only the p-values shown in italics remain statistically significant (continuation).

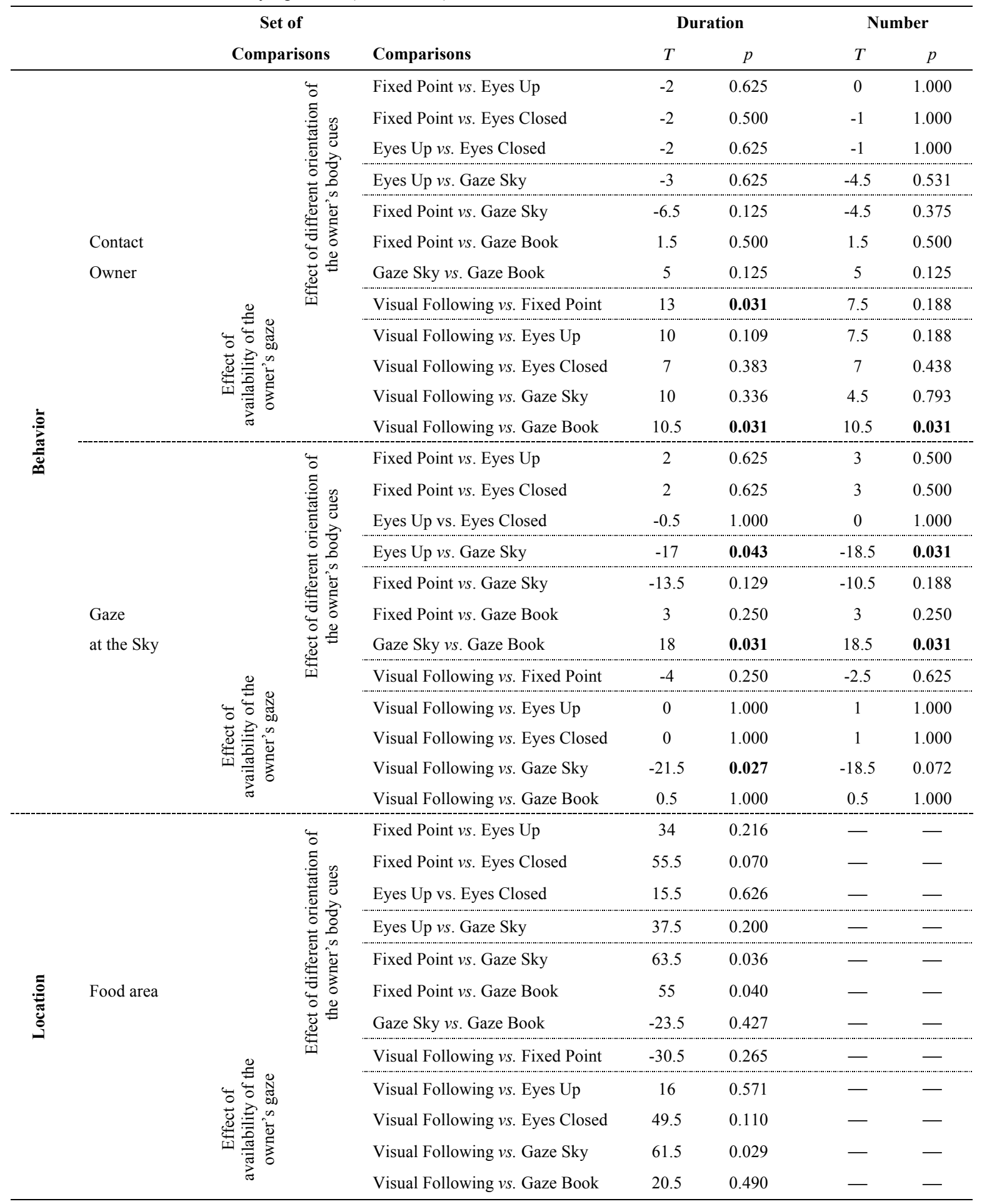


Table 4a - Multiple comparisons for the relative duration of the combination of Food area with the behaviors and the two-samples Wilcoxon rank signed tests $(n=22$ dogs). Significant differences are in bold. After the FDR BL adjustment, only the p-values shown in italics remain statistically significant.

\begin{tabular}{|c|c|c|c|c|c|c|}
\hline \multicolumn{5}{|c|}{ Set of } & \multicolumn{2}{|c|}{ Duration } \\
\hline & & \multicolumn{2}{|c|}{ Comparisons } & Comparisons & $T$ & $p$ \\
\hline \multirow{36}{*}{ 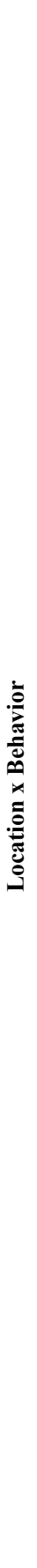 } & \multirow{12}{*}{$\begin{array}{l}\text { Food area x } \\
\text { Gaze Owner }\end{array}$} & \multirow{12}{*}{ 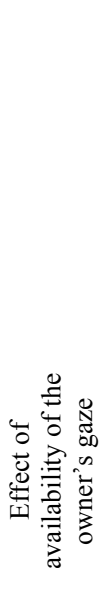 } & \multirow{12}{*}{ 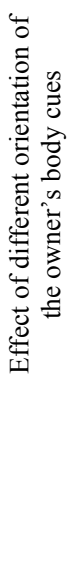 } & Fixed Point $v s$. Eyes Up & 24.5 & 0.304 \\
\hline & & & & Fixed Point vs. Eyes Closed & 38.5 & 0.156 \\
\hline & & & & Eyes Up vs. Eyes Closed & 14 & 0.588 \\
\hline & & & & Eyes Up vs. Gaze Sky & 28 & 0.159 \\
\hline & & & & Fixed Point vs. Gaze Sky & 40.5 & 0.057 \\
\hline & & & & Fixed Point vs. Gaze Book & 68 & 0.005 \\
\hline & & & & Gaze Sky vs. Gaze Book & 6.5 & 0.753 \\
\hline & & & & Visual Following vs. Fixed Point & -20 & 0.399 \\
\hline & & & & Visual Following vs. Eyes Up & 0.5 & 1.000 \\
\hline & & & & Visual Following vs. Eyes Closed & 26.5 & 0.298 \\
\hline & & & & Visual Following vs. Gaze Sky & 50 & 0.028 \\
\hline & & & & Visual Following vs. Gaze Book & 53.5 & 0.018 \\
\hline & \multirow{12}{*}{$\begin{array}{l}\text { Food area x } \\
\text { Gaze Food }\end{array}$} & \multirow{12}{*}{ 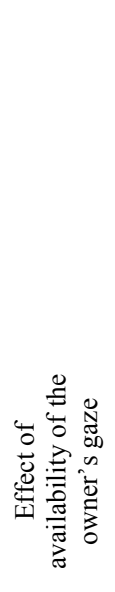 } & \multirow{12}{*}{ 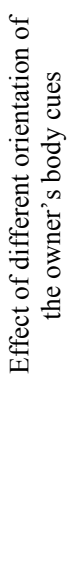 } & Fixed Point vs. Eyes Up & 6.5 & 0.806 \\
\hline & & & & Fixed Point vs. Eyes Closed & 20 & 0.475 \\
\hline & & & & Eyes Up vs. Eyes Closed & 20.5 & 0.458 \\
\hline & & & & Eyes Up vs. Gaze Sky & 41.5 & 0.050 \\
\hline & & & & Fixed Point $v s$. Gaze Sky & 36 & 0.189 \\
\hline & & & & Fixed Point $v s$. Gaze Book & -10 & 0.729 \\
\hline & & & & Gaze Sky vs. Gaze Book & -48 & 0.055 \\
\hline & & & & Visual Following vs. Fixed Point & 0 & 1.000 \\
\hline & & & & Visual Following vs. Eyes Up & 36.5 & 0.119 \\
\hline & & & & Visual Following vs. Eyes Closed & 41 & 0.135 \\
\hline & & & & Visual Following vs. Gaze Sky & 63.5 & 0.009 \\
\hline & & & & Visual Following vs. Gaze Book & -4 & 0.898 \\
\hline & \multirow{12}{*}{$\begin{array}{l}\text { Food area } \mathrm{x} \\
\text { Gaze Alternation }\end{array}$} & \multirow{12}{*}{ 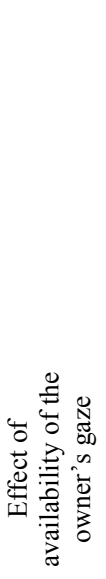 } & \multirow{12}{*}{ 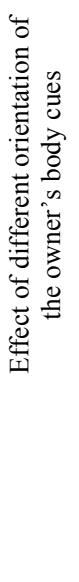 } & Fixed Point $v s$. Eyes Up & 5 & 0.795 \\
\hline & & & & Fixed Point vs. Eyes Closed & 6 & 0.753 \\
\hline & & & & Eyes Up vs. Eyes Closed & 0 & 1.000 \\
\hline & & & & Eyes Up vs. Gaze Sky & 17.5 & 0.136 \\
\hline & & & & Fixed Point vs. Gaze Sky & 19 & 0.195 \\
\hline & & & & Fixed Point vs. Gaze Book & 6.5 & 0.639 \\
\hline & & & & Gaze Sky vs. Gaze Book & -9.5 & 0.407 \\
\hline & & & & Visual Following vs. Fixed Point & 1.5 & 0.957 \\
\hline & & & & Visual Following vs. Eyes Up & 3 & 0.861 \\
\hline & & & & Visual Following vs. Eyes Closed & 17 & 0.353 \\
\hline & & & & Visual Following vs. Gaze Sky & 21 & $\mathbf{0 . 0 3 5}$ \\
\hline & & & & Visual Following vs. Gaze Book & 13 & 0.315 \\
\hline
\end{tabular}


Table $4 \mathrm{~b}$ - Multiple comparisons for the relative duration of the combination of Food area with the behaviors and the two-samples Wilcoxon rank signed tests $(\mathrm{n}=22$ dogs). Significant differences are in bold. After the FDR BL adjustment, only the p-values shown in italics remain statistically significant (continuation).

\begin{tabular}{|c|c|c|c|c|c|c|}
\hline & & \multicolumn{2}{|c|}{ Set of } & \multirow[b]{2}{*}{ Comparisons } & \multicolumn{2}{|c|}{ Duration } \\
\hline & & \multicolumn{2}{|c|}{ Comparisons } & & $T$ & $p$ \\
\hline \multirow{36}{*}{ 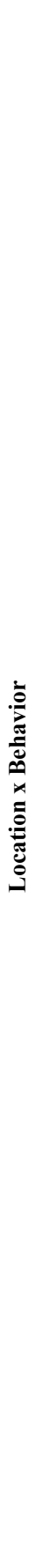 } & \multirow{12}{*}{$\begin{array}{l}\text { Food area } \mathrm{x} \\
\text { Vocalisation }\end{array}$} & \multirow{12}{*}{ 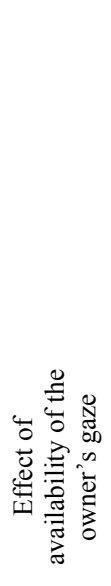 } & \multirow{12}{*}{ 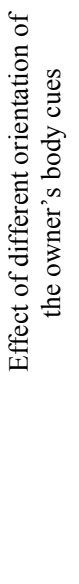 } & Fixed Point $v s$. Eyes Up & 7.5 & 0.156 \\
\hline & & & & Fixed Point vs. Eyes Closed & 5 & 0.125 \\
\hline & & & & Eyes Up vs. Eyes Closed & 1 & 0.875 \\
\hline & & & & Eyes Up vs. Gaze Sky & -1 & 0.875 \\
\hline & & & & Fixed Point $v s$. Gaze Sky & 6.5 & 0.125 \\
\hline & & & & Fixed Point $v s$. Gaze Book & 5 & 0.125 \\
\hline & & & & Gaze Sky vs. Gaze Book & 2 & 0.500 \\
\hline & & & & Visual Following vs. Fixed Point & -6.5 & 0.125 \\
\hline & & & & Visual Following vs. Eyes Up & -1.5 & 0.813 \\
\hline & & & & Visual Following vs. Eyes Closed & 2.5 & 0.625 \\
\hline & & & & Visual Following vs. Gaze Sky & -1.5 & 0.813 \\
\hline & & & & Visual Following vs. Gaze Book & 3 & 0.375 \\
\hline & \multirow{12}{*}{$\begin{array}{l}\text { Food area } \mathrm{x} \\
\text { Sonorous } \\
\text { Mouth Licking }\end{array}$} & \multirow{12}{*}{ 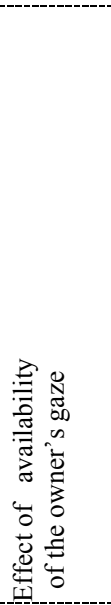 } & \multirow{12}{*}{ 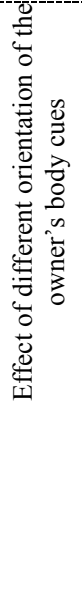 } & Fixed Point $v s$. Eyes Up & -3.5 & 0.438 \\
\hline & & & & Fixed Point vs. Eyes Closed & -3 & 0.375 \\
\hline & & & & Eyes Up vs. Eyes Closed & 0.5 & 0.938 \\
\hline & & & & Eyes Up vs. Gaze Sky & 4 & 0.469 \\
\hline & & & & Fixed Point $v s$. Gaze Sky & 0.5 & 1.000 \\
\hline & & & & Fixed Point vs. Gaze Book & 0.5 & 1.000 \\
\hline & & & & Gaze Sky vs. Gaze Book & 0 & 1.000 \\
\hline & & & & Visual Following vs. Fixed Point & 0 & 1.000 \\
\hline & & & & Visual Following vs. Eyes Up & -3.5 & 0.563 \\
\hline & & & & Visual Following vs. Eyes Closed & -5.5 & 0.313 \\
\hline & & & & Visual Following vs. Gaze Sky & 0 & 1.000 \\
\hline & & & & Visual Following vs. Gaze Book & 1.5 & 0.750 \\
\hline & \multirow{12}{*}{$\begin{array}{l}\text { Food area } \mathrm{x} \\
\text { Gaze at the Sky }\end{array}$} & \multirow{12}{*}{\multicolumn{2}{|c|}{ 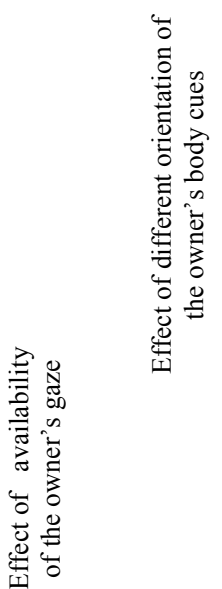 }} & Fixed Point vs. Eyes Up & 1 & 0.750 \\
\hline & & & & Fixed Point vs. Eyes Closed & 1.5 & 0.500 \\
\hline & & & & Eyes Up vs. Eyes Closed & 0.5 & 1.000 \\
\hline & & & & Eyes Up vs. Gaze Sky & 0.5 & 1.000 \\
\hline & & & & Fixed Point $v s$. Gaze Sky & 1.5 & 0.750 \\
\hline & & & & Fixed Point vs. Gaze Book & 1.5 & 0.500 \\
\hline & & & & Gaze Sky vs. Gaze Book & -0.5 & 1.000 \\
\hline & & & & Visual Following vs. Fixed Point & -1.5 & 0.500 \\
\hline & & & & Visual Following vs. Eyes Up & -0.5 & 1.000 \\
\hline & & & & Visual Following vs. Eyes Closed & 0.5 & 1.000 \\
\hline & & & & Visual Following vs. Gaze Sky & 0.5 & 1.000 \\
\hline & & & & Visual Following vs. Gaze Book & -0.5 & 1.000 \\
\hline
\end{tabular}


Suplementary 3 - Correction by the relative size of areas (Experiment 1)

In experiment 1 we defined some areas that had different sizes, then in order to make the surfaces comparable (e.g. Food area with Door2 area), a correction that represented an index of proportionality of surfaces was applied.

For example, in order to compare a behavior that happened in the Food area $\left(2.16 \mathrm{~cm}^{2}\right)$ during Food+Owner condition, for example Gaze at the food, with a behavior that happened in the Door2 area $\left(0,88 \mathrm{~cm}^{2}\right)$ during Absence of Food, for example Gaze at the Door2, we applied the correction:

In the Food+Owner condition:

Gaze at the food corrected $=($ Gaze at the food $) \times[$ Door2 area $/($ Door2 area + Food area $)]$;

And in the Absence of Food condition:

Gaze at the Door 2 corrected $=($ Gaze at the Door 2$) \times[$ Food area $/($ Door2 area + Food area $)]$ 